\title{
Chemodynamic nanomaterials for cancer theranostics
}

\author{
Jingqi Xin ${ }^{1}$, Caiting Deng ${ }^{1}$, Omer Aras $^{2}$, Mengjiao Zhou ${ }^{3 *}$, Chunsheng Wu ${ }^{1 *}$ and Feifei $\mathrm{An}^{1 *}$
}

\begin{abstract}
It is of utmost urgency to achieve effective and safe anticancer treatment with the increasing mortality rate of cancer. Novel anticancer drugs and strategies need to be designed for enhanced therapeutic efficacy. Fenton- and Fenton-like reaction-based chemodynamic therapy (CDT) are new strategies to enhance anticancer efficacy due to their capacity to generate reactive oxygen species (ROS) and oxygen $\left(\mathrm{O}_{2}\right)$. On the one hand, the generated ROS can damage the cancer cells directly. On the other hand, the generated $\mathrm{O}_{2}$ can relieve the hypoxic condition in the tumor microenvironment (TME) which hinders efficient photodynamic therapy, radiotherapy, etc. Therefore, CDT can be used together with many other therapeutic strategies for synergistically enhanced combination therapy. The antitumor applications of Fenton- and Fenton-like reaction-based nanomaterials will be discussed in this review, including: (ib) producing abundant ROS in-situ to kill cancer cells directly, (ii) enhancing therapeutic efficiency indirectly by Fenton reaction-mediated combination therapy, (iii) diagnosis and monitoring of cancer therapy. These strategies exhibit the potential of CDT-based nanomaterials for efficient cancer therapy.
\end{abstract}

Keywords: Fenton reaction, Chemodynamic therapy, Theranostics, Hypoxia, Combination therapy

\section{Background}

Cancer poses a serious threat to human health and has attracted considerable attention in biomedical research over the past few decades [1]. The mortality rate of cancer increases year by year, making it of utmost urgency to develop even more efficient cancer therapeutic strategies. There are many cancer therapeutic strategies, ranging from traditional strategies such as surgery, chemotherapy, radiotherapy, photodynamic therapy (PDT), to newer strategies such as photothermal therapy (PTT) and immunotherapy [2-6]. Often, the anticancer efficiency of these strategies is limited by low tumor selectivity, systemic toxicity, and adverse reactions, etc. [7].

\footnotetext{
*Correspondence: mjzhou0207@163.com; wuchunsheng@xjtu.edu.cn; anfeifei@xjtu.edu.cn

${ }^{1}$ Institute of Medical Engineering, Department of Biophysics, School of Basic Medical Science, Health Science Center, Xi'an Jiaotong University, No. 76 Yanta West Road, Xi'an, Shaanxi 710061, People's Republic of China ${ }^{3}$ Department of Pharmacology, School of Pharmacy, Nantong University, 226000 Nantong, Jiangsu, People's Republic of China

Full list of author information is available at the end of the article
}

Besides, many types of cancer gradually develop resistance to traditional therapies [8]. In order to improve the therapeutic effect, novel anticancer drugs and strategies are still desired $[9,10]$. Chemodynamic therapy (CDT), which is defined as in-situ treatment via Fenton and Fenton-like reactions, has attracted more and more attention in recent years [11-13]. As a novel modality for cancer treatment, CDT exhibits preferable therapeutic performance and satisfying biosafety [14]. In comparison with traditional therapies, CDT can generate spatiotemporal controllable and tissue depth-unlimited reactive oxygen species (ROS) and oxygen $\left(\mathrm{O}_{2}\right)$ in response to the high level of hydrogen peroxide $\left(\mathrm{H}_{2} \mathrm{O}_{2}\right)$ in the tumor microenvironment (TME) [14-17].

Fenton and Fenton-like reactions, which generate abundant oxidative $\bullet \mathrm{OH}$ or $\mathrm{O}_{2}$, can be triggered by the endogenous $\mathrm{H}_{2} \mathrm{O}_{2}$ of cancer cells and catalyzed by transition metal ions or their complexes [18]. While Fenton and Fenton-like reactions are commonly suppressed by the insufficient $\mathrm{H}_{2} \mathrm{O}_{2}$ and slightly alkaline conditions of a normal microenvironment, in the acidic TME, metal

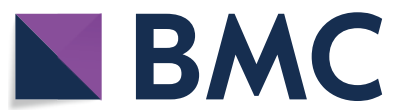

(c) The Author(s) 2021. This article is licensed under a Creative Commons Attribution 4.0 International License, which permits use, sharing, adaptation, distribution and reproduction in any medium or format, as long as you give appropriate credit to the original author(s) and the source, provide a link to the Creative Commons licence, and indicate if changes were made. The images or other third party material in this article are included in the article's Creative Commons licence, unless indicated otherwise in a credit line to the material. If material is not included in the article's Creative Commons licence and your intended use is not permitted by statutory regulation or exceeds the permitted use, you will need to obtain permission directly from the copyright holder. To view a copy of this licence, visit http://creativecommons.org/licenses/by/4.0/. The Creative Commons Public Domain Dedication waiver (http://creativecommons.org/publicdomain/zero/1.0/) applies to the data made available in this article, unless otherwise stated in a credit line to the data. 
ions can be dissolved from iron or other transition metal ions-based nanomaterials to activate Fenton and Fentonlike reactions [19]. On the one hand, the production of - $\mathrm{OH}$ can result in oxidant damage to cellular constituents (proteins, lipids, DNA, et al.), apoptosis or necrosis, and likely cell death $[20,21]$. The generated $\bullet \mathrm{OH}$ can inhibit tumor growth directly without damaging normal tissue [22]. On the other hand, Fenton and Fenton-like reactions can generate $\mathrm{O}_{2}$ to relieve tumor hypoxia, which can lead to path-breaking enhanced cancer therapeutic combination strategies [23]. It is well known that tumor hypoxia is a result of an insufficient supply but quick oxygen consumption in the fast-growing neoplastic cell population in solid tumors [24, 25]; tumor hypoxia has been implicated as one of the major factors that limits treatment efficacy and that promotes development of resistance in many cancer therapeutic methods [26-28]. Fenton and Fenton-like reactions are important strategies to overcome hypoxia via in-situ production of $\mathrm{O}_{2}$ in the TME [29]. When used with other anticancer strategies, Fenton and Fenton-like reactions can enhance the tumor sensitivity to other anticancer strategies by supplying $\mathrm{O}_{2}$ to the hypoxic TME, resulting in enhanced anticancer efficacy.

Recently, nanotechnology has played a significant role in the development of new targeted tumor diagnosis and therapeutic strategies [30-32]. Emerging Fenton and Fenton-like reaction-based nanomaterials are mainly iron-based, followed by other metal-based nanoparticles (NPs) (including $\mathrm{Mn}^{2+}, \mathrm{Cu}^{2+}$, and $\mathrm{Ti}^{3+}$ ions, etc.), and several organic NPs [33-35]. Due to the characteristics of these nanomaterials, including tumor targeting ability, large specific surface area, and high reactivity, they are potent tools for the production of $\cdot \mathrm{OH}$ and $\mathrm{O}_{2}$ via Fenton and Fenton-like reactions [36]. With the tumor targeting ability of these nanomaterials, Fenton- and Fentonlike reactions-based NPs can lead to gains in therapeutic efficiency while causing only a low level of side effects [11]. Herein, we present an overview of recent findings related to Fenton- and Fenton-like reaction-based nanomaterials, which can be categorized into three groups for different applications in cancer theranostics: (i) producing abundant ROS in situ to kill cancer cells directly, (ii) enhancing the therapeutic efficiency indirectly by Fenton- and Fenton-like reaction-mediated combination therapy, (iii) diagnosis and monitoring of cancer therapy (Scheme 1).

\section{Fenton and Fenton-like reactions for in-situ ROS generation}

Cancer cells typically already have more ROS compared with normal cells due to their increased metabolism, increased receptor signaling, and malfunction of

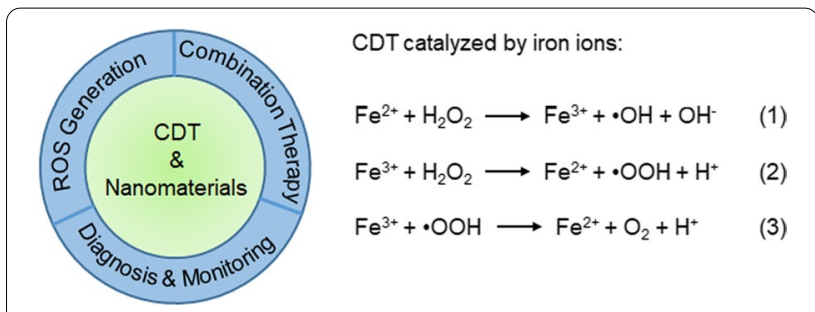

Scheme 1. The medical applications of CDT-based nanomaterials and the representative reactions for CDT

oncogene activity and mitochondria. ROS at low levels play an important role in supporting cellular life cycles [37]. By contrast, high concentrations of ROS damage cellular constituents [38]. In particular, $\bullet \mathrm{OH}$ radicals cause more serious damage to cancer cells than other ROS, which is ascribed to their relatively stronger reactivity with cellular constituents [39]. Fenton and Fenton-like reactions triggered by iron or other metal ions exhibit the ability to generate abundant $\cdot \mathrm{OH}$ by decomposing the endogenous $\mathrm{H}_{2} \mathrm{O}_{2}$ in cancer cells [40, 41]. Therefore, Fenton and Fenton-like reactions can be used to treat cancer by in-situ production of abundant ROS to kill cancer cells directly [42], but first, the selection of the catalyst is pivotal [43]. Several nanomaterials can efficiently trigger Fenton and Fenton-like reactions, due to their high catalytic efficiency and excellent biocompatibility; these include iron-based nanomaterials, other metal-based nanomaterials (including $\mathrm{Mn}^{2+}, \mathrm{Cu}^{2+}$, and $\mathrm{Mo}^{3+}$, etc.), and several organic nanomaterials (Fig. 1) [44-47]. These nanomaterials can serve as efficient catalysts for various theranostic applications (Table 1).

\section{Iron-based nanomaterials}

According to the Fenton reaction (Eq. 1 and 2), overproduction of $\mathrm{H}_{2} \mathrm{O}_{2}$ in the TME can be converted to $\cdot \mathrm{OH}$, . $\mathrm{OOH}$ and $\mathrm{O}_{2}$ in the presence of iron ions $\left(\mathrm{Fe}^{2+}\right.$ and $\left.\mathrm{Fe}^{3+}\right)[73,74]$.

$$
\begin{aligned}
& \mathrm{Fe}^{2+}+\mathrm{H}_{2} \mathrm{O}_{2} \rightarrow \mathrm{Fe}^{3+}+\bullet \mathrm{OH}+\mathrm{OH}^{-} \\
& \mathrm{Fe}^{3+}+\mathrm{H}_{2} \mathrm{O}_{2} \rightarrow \mathrm{Fe}^{2+}+\bullet \mathrm{OOH}+\mathrm{H}^{+} \\
& \mathrm{Fe}^{3+}+\bullet \mathrm{OOH} \rightarrow \mathrm{Fe}^{2+}+\mathrm{O}_{2}+\mathrm{H}^{+}
\end{aligned}
$$

The Fenton reaction can be directly catalyzed by iron ions to generate $\bullet \mathrm{OH}, \cdot \mathrm{OOH}$, and $\mathrm{O}_{2}$ [75].

Meanwhile, iron ions also play a key role in ferroptosis, in which lipid-based ROS is produced due to the inhibition of system $\mathrm{x}_{\mathrm{c}^{-}}$and the biosynthesis of glutathione (GSH) [76]. In ferroptosis, the activity of system $\mathrm{x}_{\mathrm{c}^{-}}$(SLC7A11) is inhibited, resulting in decreased 


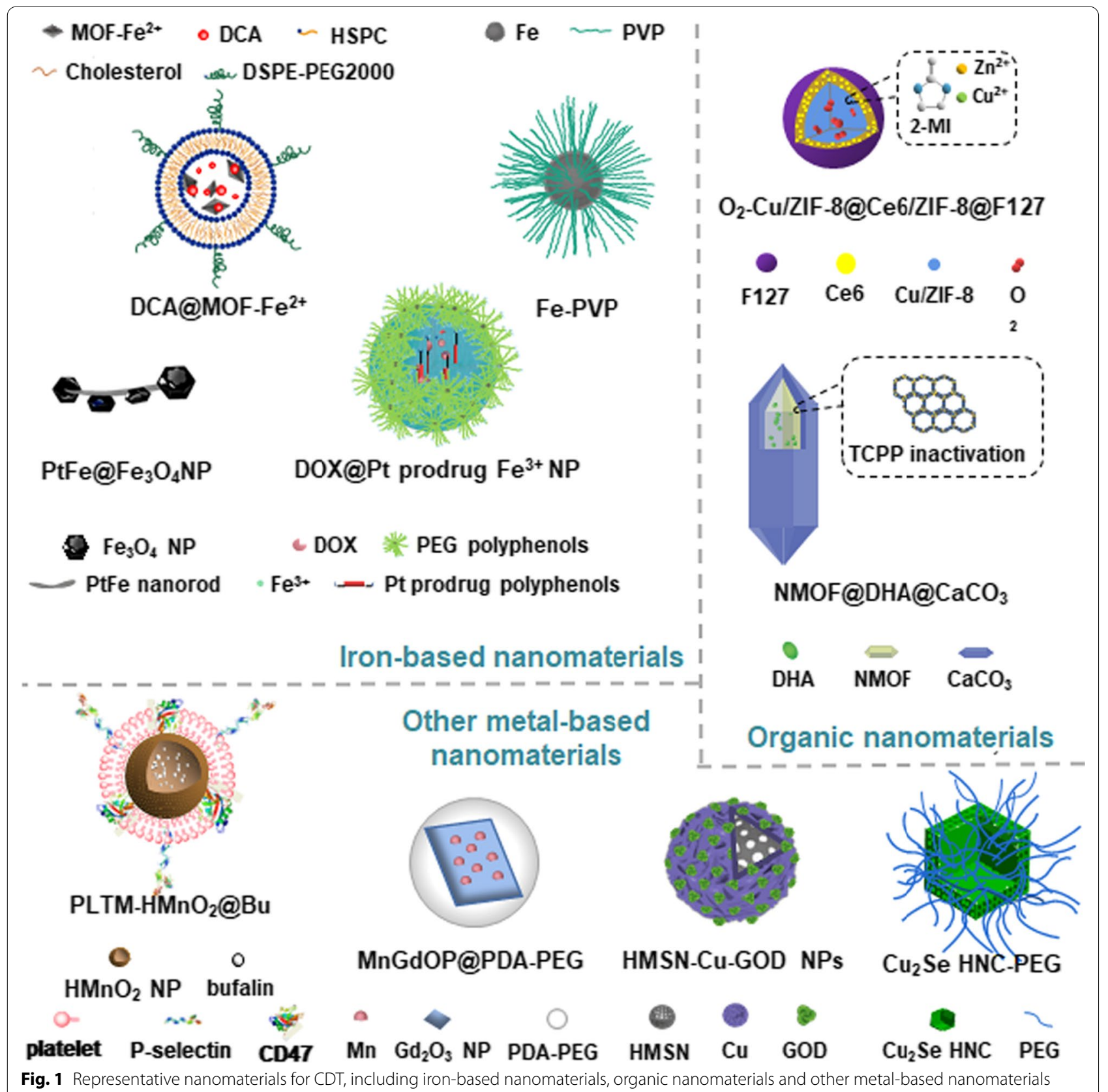

import of cysteine, GSH depletion, inactivation of the glutathione peroxidase 4 (GPX4), and finally ferroptosis $[77,78]$. In addition, the tumor suppresser p53 can negatively regulate histone $\mathrm{H} 2 \mathrm{~B}$ monoubiquitination levels by promoting the nuclear translocation of the deubiquitinase to inhibit the expression of SLC7A11, leading to ferroptosis $[79,80]$. Therefore, in addition to contributing to Fenton reaction-assisted therapy, iron ions can also produce an enhanced treatment effect via ferroptosis $[81,82]$.
In recent years, diverse efforts based on GSH depletion or $\mathrm{H}_{2} \mathrm{O}_{2}$ concentration elevation have been made to improve the anticancer efficiency triggered by Fenton and Fenton-like reactions $[11,83,84]$. GSH is overexpressed in many types of cancer cells and can reduce the ROS that are generated by Fenton- and Fenton-like reactions, thereby decreasing the therapeutic effect of CDT [85-87]. Therefore, in one study, the GSH depletion agent, sabutoclax, was loaded into $\mathrm{Fe}^{3+}$-containing nanoparticles (NPs) in order to produce the synergistic 
Table 1 Representative Fenton- and Fenton-like reaction-based nanomaterials and their typical applications in cancer theranostics

\begin{tabular}{|c|c|c|c|}
\hline Nanomaterials & Fenton nanoagents & Applications & Refs. \\
\hline \multirow[t]{9}{*}{ Iron-based nanomaterials } & Dichloroacetic acid@MOF-Fe $e^{2+}$ & CDT & {$[48]$} \\
\hline & DOX-ferrocene-inhibitor@ $\beta$-CD NPs & CDT-chemotherapy & [49] \\
\hline & DOX@Pt prodrug-Fe ${ }^{3+} \mathrm{NPs}$ & CDT-chemotherapy & {$[50]$} \\
\hline & $\mathrm{Fe}_{3} \mathrm{O}_{4} /$ triphenylphosphine/PpIX NPs & CDT-PDT & [51] \\
\hline & PtFe@Fe $\mathrm{O}_{4} \mathrm{NPS}$ & CDT-PTT & {$[52]$} \\
\hline & Fe-porphyrin@Bis(DPA-Zn)-RGD/(SOD2)-siRNA NPs & CDT-SDT & [19] \\
\hline & Hollow $\mathrm{Fe}_{3} \mathrm{O}_{4}$ mesocrystals NPS & CDT-MHT & [53] \\
\hline & Zero-valence iron-polyvinyl pyrrolidone NPs & CDT-MHT-PTT & {$[54]$} \\
\hline & Fe-MIL-100/GOD@HA-PDA NPs & All-in-one agent & {$[55]$} \\
\hline \multirow[t]{6}{*}{ Mn-based nanomaterials } & Thiol-functionalized MSN NPs@MnO ${ }_{2}$ NPs & CDT & {$[56]$} \\
\hline & Bufalin@hollow $\mathrm{MnO}_{2} \mathrm{NPs}$ & CDT-chemotherapy & {$[57]$} \\
\hline & Mn-carbon dots NPs & CDT-PDT & [58] \\
\hline & $\mathrm{Mn}-\mathrm{Gd}_{2} \mathrm{O}_{3} @ P D A N P s$ & CDT-PTT & [59] \\
\hline & PpIX@hollow mesoporous organosilica-MnO $-\mathrm{RGD}$ NPs & CDT-SDT & {$[60]$} \\
\hline & Hollow $\mathrm{MnO}_{2}$-DOX-GOD-HA NPS & All-in-one agent & {$[61]$} \\
\hline \multirow[t]{6}{*}{ Cu-based nanomaterials } & CU-TCPP MOF & CDT & [62] \\
\hline & Hollow mesoporous silica-Cu-GOD NPs & CDT-chemotherapy & [63] \\
\hline & $\mathrm{Cu}_{2} \mathrm{Se}$ hollow nanocubes-PEG & CDT-PTT & {$[64]$} \\
\hline & Cu-5,10,15,20-tetrabenzoatoporphyrin nMOF and anti-PDL-1 & CDT-PDT-immunotherapy & {$[65]$} \\
\hline & Ce6@Cu-MOF NPs & CDT-SDT & {$[66]$} \\
\hline & GOD@hollow mesoporous $\mathrm{Cu}_{2} \mathrm{MoS}_{4} \mathrm{NPs}$ & All-in-one agent & [46] \\
\hline \multirow[t]{6}{*}{ Other metal-based nanomaterials } & $\mathrm{TiO}_{2}$-ruthenium(II) complexe NPs & CDT & {$[67]$} \\
\hline & $\mathrm{MoS}_{2} @ G O D$-tirapazamine-chitosan NPs & CDT-chemotherapy & {$[68]$} \\
\hline & ZIF-67-DOX@PpIX@ZIF-8@PDANPs & CDT-PDT-chemotherapy & [69] \\
\hline & 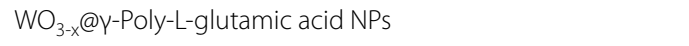 & CDT-PTT & [70] \\
\hline & $\mathrm{TiO}_{1+x}-\mathrm{PEG}$ NPs & CDT-SDT & [71] \\
\hline & $\mathrm{Au}_{2} \mathrm{Pt}$-Ce6-PEG NPs & All-in-one agent & {$[72]$} \\
\hline
\end{tabular}

effect of $\mathrm{Fe}^{3+}$-mediated Fenton reactions and sabutoclax-induced GSH depletion [51]. In another study, the ROS inducer, $\beta$-lapachone, was loaded into the $\mathrm{Fe}_{3} \mathrm{O}_{4}$ $\mathrm{NPs}$ to produce the synergistic effect of $\mathrm{Fe}_{3} \mathrm{O}_{4}$-mediated Fenton reactions and $\beta$-lapachone-induced ROS generation [88]. In addition, several studies have made use of glucose oxidase (GOD), an endogenous enzyme that not only consumes GSH in cancer cells, leading to starvation therapy, but also simultaneously generates plenty of $\mathrm{H}_{2} \mathrm{O}_{2}$ to facilitate Fenton and Fenton-like reactions $[89,90]$. For example, GOD has been loaded into an adenosine triphosphate (ATP)-responsive Fenton system (GOD@ZIF@MPN) to enhance cancer therapy [91]. The outer shell metal polyphenol network (MPN) of GOD@ZIF@MPN was degraded into $\mathrm{Fe}^{3+}$ and tannic acid (TA) and the internal GOD was exposed when internalized into the ATP-overexpressed tumor cells. TA reduced $\mathrm{Fe}^{3+}$ to $\mathrm{Fe}^{2+}$, and GOD reacted with endogenous glucose to generate tremendous $\mathrm{H}_{2} \mathrm{O}_{2}$ for $\mathrm{Fe}^{2+}$-catalyzed Fenton reaction. The combination of this $\mathrm{Fe}^{2+}$-induced Fenton reaction with ferroptosis synergistically resulted in an improved antitumor effect [92].

In order to further improve Fenton reaction-assisted cancer therapy, one study delivered exogenous $\mathrm{H}_{2} \mathrm{O}_{2}$ to the tumor to increase the level of $\mathrm{H}_{2} \mathrm{O}_{2}$ in the TME [93]. The liquid $\mathrm{H}_{2} \mathrm{O}_{2}$ was loaded in the form of $\mathrm{H}_{2} \mathrm{O}_{2} / \mathrm{Fe}_{3} \mathrm{O}_{4}$ PLGA polymersome, in which $\mathrm{H}_{2} \mathrm{O}_{2}$ located in the hydrophilic core and $\mathrm{Fe}_{3} \mathrm{O}_{4}$ NPs inside the polymersome membrane. Upon exposure to ultrasound, the encapsulated $\mathrm{H}_{2} \mathrm{O}_{2}$ was released to react with the packed $\mathrm{Fe}_{3} \mathrm{O}_{4}$ NPs to yield $\cdot \mathrm{OH}$ via the Fenton reaction, and finally improve the therapeutic efficacy. Another study used the in situ generation of $\mathrm{H}_{2} \mathrm{O}_{2}$ to improve Fenton reactionassisted cancer therapy, whereby $\mathrm{H}_{2} \mathrm{O}_{2}$ was supplied from the reaction of $\mathrm{CaO}_{2}$ and $\mathrm{H}^{+}$[94]. In this study, $\mathrm{CaO}_{2}$ was integrated into theFe $\mathrm{O}_{4} @ \mathrm{HA}-\mathrm{Cy} 7$ NPs by preparing hybrid $\mathrm{CaO}_{2}$ and $\mathrm{Fe}_{3} \mathrm{O}_{4} \mathrm{NPs}$ with hyaluronate acid as the stabilizer and $\mathrm{Cy} 7$ as a fluorescence tracer. $\mathrm{Fe}_{3} \mathrm{O}_{4}$-mediated Fenton reaction was enhanced by $\mathrm{H}_{2} \mathrm{O}_{2}$ supply from the reaction of $\mathrm{CaO}_{2}$ and $\mathrm{H}^{+}$. In yet another study, E coli MG1655 was engineered with NDH-2 
enzyme over-expression (Ec-pE) to generate $\mathrm{H}_{2} \mathrm{O}_{2}$ at the tumor site [95]. The chemically decorated magnetic $\mathrm{Fe}_{3} \mathrm{O}_{4}$ NPs (MNP) on the surface of the engineered bacteria performed as a Fenton-like reaction catalyst to convert $\mathrm{H}_{2} \mathrm{O}_{2}$ to cytotoxic $\cdot \mathrm{OH}$. NDH-2 transferred accepted electrons to oxygen to produce $\mathrm{H}_{2} \mathrm{O}_{2}$. With the accumulation of $\mathrm{H}_{2} \mathrm{O}_{2}$, cancer cell death was induced by plenty of generated $\bullet \mathrm{OH}$ (Fig. 2). This study shows that self-supplied therapeutics can be achieved without direct $\mathrm{H}_{2} \mathrm{O}_{2}$ provision.

\section{Other metal-based nanomaterials}

Manganese-based nanomaterials can release manganese ions to catalyze Fenton-like reactions, making them widely used in cancer diagnostics and therapeutics [96-98]. Owing to the enhanced spin-spin relaxation of manganese, manganese-based nanomaterials also exhibit low toxicity, tumor targeting ability, and potential magnetic resonance (MR) imaging contrast [99]. In one study, $\mathrm{MnO}_{2}$-containing nanoparticles were used to deplete GSH via the reaction between $\mathrm{MnO}_{2}$ and the thiol groups [56]. The $\mathrm{Mn}^{2+}$ was released due to the reaction, which consequently triggered the Fenton-like reaction. The $\mathrm{MnO}_{2}$-containing NPs were able to both deliver Fentonlike $\mathrm{Mn}^{2+}$ and deplete intracellular GSH. $\mathrm{Mn}^{2+}$ induced the generation of $\cdot \mathrm{OH}$ from $\mathrm{H}_{2} \mathrm{O}_{2}$ via the Fenton-like reaction. Upon uptake of the NPs by cancer cells, the shell of $\mathrm{MnO}_{2}$ underwent the reduction by intracellular GSH to form glutathione disulfide and $\mathrm{Mn}^{2+}$, which enhanced CDT by GSH depletion. In another study to enhance $\mathrm{CDT}$, a hybrid $\mathrm{Fe}_{5} \mathrm{C}_{2} @ \mathrm{MnO}_{2} \mathrm{NP}, \mathrm{GOD}$ was loaded to generate extra $\mathrm{H}_{2} \mathrm{O}_{2}$ [100]. Acidic TME not only induced the decomposition of $\mathrm{MnO}_{2}$ nanoshell into $\mathrm{Mn}^{2+}$ and $\mathrm{O}_{2}$, but also triggered the release of GOD. Then, the released GOD not only effectively exhaust glucose in cancer cells, leading to starvation therapy, but also simultaneously generated plenty of $\mathrm{H}_{2} \mathrm{O}_{2}$ to accelerate the subsequent Fenton reaction to produce $\cdot \mathrm{OH}$ for enhanced anticancer efficacy. As metal ions not only in the NPs but also in the metallic complex could trigger the Fenton-like reaction, in yet another study, using a $\mathrm{Mn}$-Cu bimetallic complex, the $\mathrm{Mn}(\mathrm{II})$ catalyzed Fenton-like reaction to produce ROS to induce tumor cell death [101]. In addition, the copper depleted GSH to prevent ROS depletion, which further enhanced the CDT effect.

Besides manganese, copper-based nanomaterials have attracted broad attention in recent years because of their low cost, high natural abundance, and easy synthesis [102]. Particularly, copper-based nanomaterials can induce the Fenton-like reaction in wide $\mathrm{pH}$ range, with comparable and even better performance compared to iron-based nanomaterials [103]. It has been reported that $\mathrm{Cu}_{2-\mathrm{x}} \mathrm{S}$-PEG nanodots $(\leq 5 \mathrm{~nm})$ can produce high amounts of $\cdot \mathrm{OH}$ by decomposing tumor-overexpressed $\mathrm{H}_{2} \mathrm{O}_{2}$ [104]. The generated $\bullet \mathrm{OH}$ exhibited an augmented synergistic cancer therapeutic effect to the nanodots' PDT at NIR-II wavelength range $(1000-1350 \mathrm{~nm})$. In another study, $\mathrm{Gd}^{3+}$ doped $\mathrm{CuS}$ NPs were shown to enable MRI guidance for CDT [105]. The $\mathrm{Cu}^{2+}$ of NPs reacted with GSH to generate $\mathrm{Cu}^{+}$, which further catalyzed the Fenton-like reaction to induce tumor death. In yet another study, self-assembled copper-amino acid mercaptide NPs

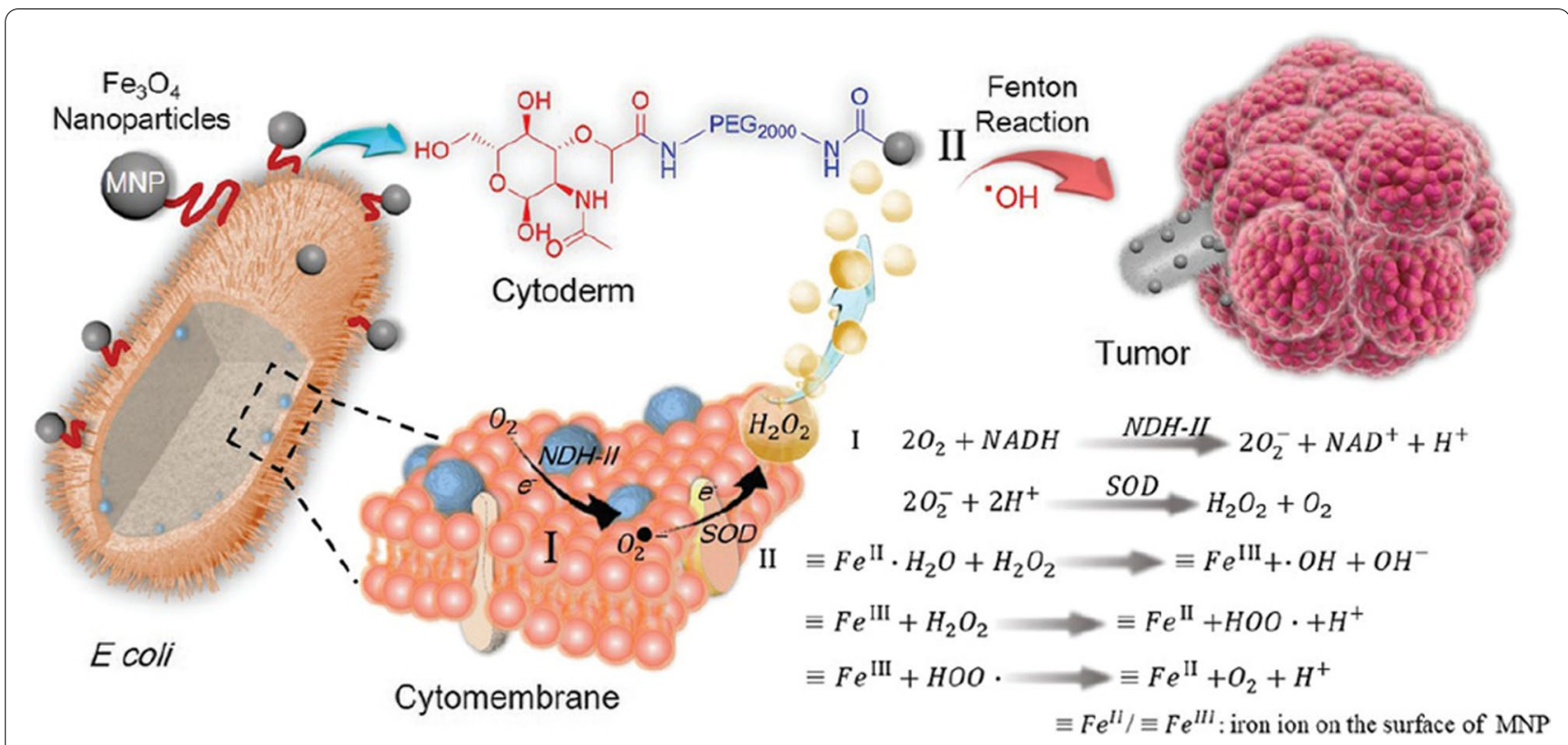

Fig. 2 a The scheme of engineered bacteria as a Fenton-like reactor for tumor CDT. Reproduced with permission from Ref. [95] 
(Cu-Cys NPs) were intracellularly activated by both GSH and $\mathrm{H}_{2} \mathrm{O}_{2}$ which were overexpressed in cancer cells [106]. The $\mathrm{Cu}$-Cys NPs exhibited efficient CDT for drug-resistant breast cancer. The $\mathrm{Cu}$-Cys NPs reacted with intracellular GSH to deplete GSH and reduce $\mathrm{Cu}^{2+}$ to $\mathrm{Cu}^{+}$. Subsequently, $\mathrm{Cu}^{+}$triggered the Fenton-like reaction to produce cytotoxic $\cdot \mathrm{OH}$. The high concentrations of GSH and $\mathrm{H}_{2} \mathrm{O}_{2}$ inside cancer cells were key factors to trigger the intracellular redox reactions; therefore, the $\mathrm{Cu}$-Cys NPs exhibited significantly higher toxicity to cancer cells than normal cells. Apart from these studies, in one study, as GOD can be used to produce starvation therapy, it was loaded into copper-embedded hollow mesoporous silica (HMSN-Cu) NPs [63]. Once internalized in cancer cells, GOD-catalyzed starvation therapy produced gluconic acid to accelerate the $\mathrm{Cu}^{2+}$ release from the collapsed HMSN-Cu framework. $\mathrm{Cu}^{+}$-mediated Fenton-like reaction and $\mathrm{Cu}^{2+}$-induced GSH depletion was promising to synergistically strengthen starvation therapy. In a very recent study, a single-atom copper species (Cu-HNCS) was prepared and exhibited direct catalysis ability to decompose both $\mathrm{O}_{2}$ and $\mathrm{H}_{2} \mathrm{O}_{2}$ to ROS [107]. The generated ROS oxidized intracellular biomolecules automatically, which resulted in an enhanced inhibition of tumor growth. Notably, the Fenton-like reaction showed $\sim 5000$ times turnover frequency of $\mathrm{Cu}$ species than that of $\mathrm{Fe}$ in $\mathrm{Fe}_{3} \mathrm{O}_{4}$ NPs.

Besides iron, manganese and copper, Fenton-like reactions can be catalyzed by other metal cations, such as $\mathrm{Ti}^{3+}, \mathrm{Ir}^{3+}, \mathrm{Cr}^{4+}, \mathrm{Ce}^{3+}, \mathrm{Co}^{3+}$, and $\mathrm{Mo}^{3+}$ [108-111]. For example, a ruthenium complex (abbreviated as N3) was conjugated to a $\mathrm{TiO}_{2} \mathrm{NP}$ to produce $\mathrm{TiO}_{2}-\mathrm{N} 3$ [67]. When exposing $\mathrm{TiO}_{2}-\mathrm{N} 3$ to light, it produced three- and four- fold more cytotoxic $\cdot \mathrm{OH}$ than $\mathrm{TiO}_{2}$ intrinsically. In another example, using prepared $\mathrm{MoSe}_{2} / \mathrm{CoSe}_{2} @ \mathrm{PEG}$ NPs, near infrared (NIR) light not only triggered PTT but also induced the efficient electron-hole separation to result in efficient $\mathrm{H}_{2} \mathrm{O}_{2}$ generation [111]. The generated $\mathrm{H}_{2} \mathrm{O}_{2}$ was further decomposed into $\bullet \mathrm{OH}$ via the Fentonlike reaction. The system not only supplied $\mathrm{O}_{2}$ to relieve the tumor hypoxia but also extra $\mathrm{H}_{2} \mathrm{O}_{2}$ for Fenton-like reaction. These advances demonstrate that inorganic nanomaterials can be rationally designed to manipulate therapeutic platforms based on Fenton or Fenton-like reactions for efficient antitumor therapy.

\section{Organic nanomaterials}

Besides inorganic nanomaterials, several organic agents, such as metal-organic framework (MOF) and ferrocene, can also be used as catalysts for Fenton-like reactions $[112,113]$.

With their strong catalytic ability, MOF materials have been widely studied as catalysts for Fenton-like reaction. Ultrathin two-dimensional MOF of $\mathrm{Cu}$-TCPP nanosheets have been reported to be promising for Fenton-like reaction-assisted cancer therapy [62]. The NPs consisted of $\mathrm{Cu}^{2+}$ and tetrakis(4-carboxyphenyl) porphyrin (TCPP) ligand. The TCPP ligands are peroxidized by $\mathrm{H}_{2} \mathrm{O}_{2}$ under acidic TME, and further reduced to $\mathrm{ROO}$ - in the presence of peroxidase-like $\mathrm{Cu}$-TCPP nanosheets and copper ions. GSH depletion by the incorporated $\mathrm{Cu}^{2+}$ in the nanosheets also enhanced the therapeutic efficiency.

Ferrocene is promising as a catalyst for the Fenton reaction [114]. One study explored the feasibility of using ROS-sensitive NPs (P@P/H NPs) containing ferrocene and $\beta$-cyclodextrin inclusion complex $(\beta-C D @$ $\mathrm{Fc}$ ) to prevent tumor metastasis by intracellular ROS amplification and subsequent cascade biological reaction activation [115]. PLGA- $\beta-C D$ and polyethyleneimine-Fc (PEI-Fc) were conjugated with $\beta$-CD@Fc to form an ROS-responsive amphiphilic polymer (PLGA$\beta-C D @ P E I-F c)$, which was then self-assembled into NPs (P@P NPs). Finally, heparin absorbed onto P@P NPs via charge interaction and then DOX was loaded by absorption. After the P@P/H NPs were internalized by the cancer cells, they rapidly disassembled and released DOX and $\mathrm{Fe}^{2+}$ in the presence of $\mathrm{H}_{2} \mathrm{O}_{2}$, leading to rising $\cdot \mathrm{OH}$ levels, which then destroyed the mitochondrial membrane and released cytochrome $\mathrm{c}$ to activate the caspase apoptosis pathway, which consequently resulted in a synergistic effect of chemotherapy and CDT.

\section{Fenton and Fenton-like reactions-mediated combination therapy}

Combination therapy, which integrates multiple therapeutic agents into one nanoplatform, is generally more effective than monotherapy [116, 117]. For example, Vyxeos, a FDA-approved liposomal anticancer nanomedicine that is comprised of daunorubicin and cytarabine in fixed ratio, has been shown to increase the survival time of patients [118]. Nanomedicines combining Fenton/Fenton-like reactions with other therapeutic modalities may further improve anticancer efficiency. Fenton and Fenton-like reactions-mediated combination therapy can enhance therapeutic efficiency by relieving tumor hypoxia through $\mathrm{O}_{2}$ production or by damaging tumor cells by highly toxic ROS in situ. Therefore, multifunctional NPs for Fenton reaction-based combination therapy have increasingly been recognized as a promising strategy for tumor therapy and have been explored in combination with chemotherapy, PDT, PTT, gas therapy, sonodynamic therapy, radiotherapy, immunotherapy, and magnetic hyperthermia therapy (MHT) (Fig. 3). 


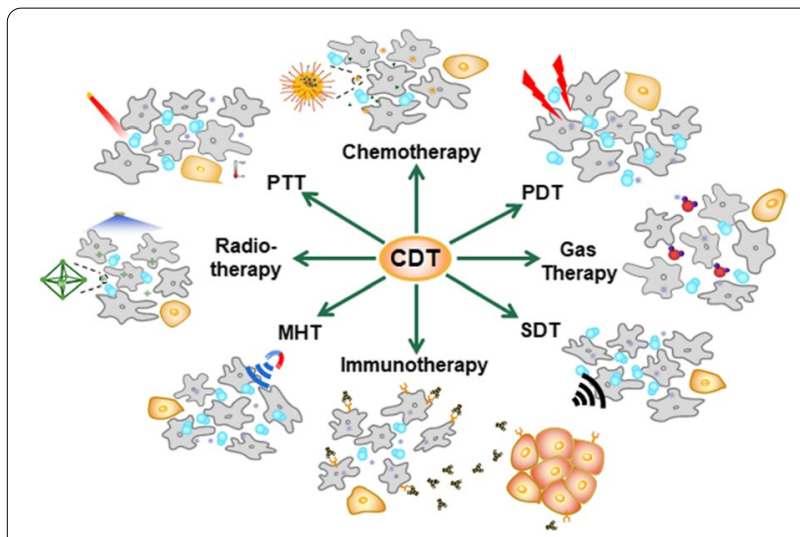

Fig. 3 Applications of CDT in combination therapy

\section{Combination of Fenton and Fenton-like reactions with chemotherapy}

Chemotherapy is one of the main strategies to treat cancer. Various chemotherapy drugs, such as doxorubicin (DOX), cisplatin (CDDP), camptothecin (CPT), and tirapazamine (TPZ), have clear therapeutic mechanisms and can have remarkable therapeutic effects. However, drug resistance may develop and toxicity remains a limiting factor for chemotherapy. Recently, Fenton reaction/ chemotherapy combination therapy have been demonstrated to strengthen the therapeutic efficiency of chemotherapeutic drugs with reduced side effects, even against drug-resistant cancer cells [119-121].

To enhance the therapeutic effect of loaded DOX, $\mathrm{Fe}^{3+}$ and $\mathrm{Mn}^{2+}$ have been incorporated into NPs to enable Fenton and Fenton-like reactions to generate ROS [122124]. DOX and platinum prodrugs have also been encapsulated in $\mathrm{Fe}^{3+}$-polyphenol networks NPs [50], whereby the $\mathrm{Fe}^{3+}$-mediated Fenton reaction induced the generation of highly toxic $\cdot \mathrm{OH}$ to synergize with chemotherapy. In one study, as a $\mathrm{H}_{2} \mathrm{O}_{2}$ inducer, $\beta$-lapachone was loaded into a $\mathrm{pH} / \mathrm{ROS}$ dual-responsive NP, which consisted of $\mathrm{pH}$-responsive polymer and ROS-responsive polyprodrug [125]. The NPs disassembled when triggered by low $\mathrm{pH}$, and then released $\beta$-lapachone and polyprodrug. The $\beta$-lapachone supplied endogenous $\mathrm{H}_{2} \mathrm{O}_{2}$ for the Fenton reaction, which produced ROS to trigger DOX release, allowing combination therapy consisting of CDT and chemotherapy to take place. In another study, a ferroptosis-inducing agent was fabricated based on arginine-rich manganese silicate nanobubbles (AMSNs), which can deplete GSH efficiently and induce ferroptosis by GPX4 inactivation [126]. In addition, DOX was loaded to the surface of AMSNs to perform chemotherapy, achieving a synergistic effect of CDT and chemotherapy.

It was found that platinum (Pt) can act as ROS inducer [127]. Thus, several studies have used platinum to enhance combination therapy consisting of Fenton and Fenton-like reactions with cisplatin chemodrugs. For example, $\mathrm{Fe}_{3} \mathrm{O}_{4} @$ PEI-Pt(IV)-PEG NPs were fabricated to enhance cisplatin-based chemotherapy by ironmediated Fenton reaction [128]. Cisplatin activated the formation of superoxide radical $\left(\mathrm{O}_{2}{ }^{\cdot-}\right)$ and $\mathrm{H}_{2} \mathrm{O}_{2}$ from $\mathrm{O}_{2}$, while iron-catalyzed Fenton chemistry converted $\mathrm{H}_{2} \mathrm{O}_{2}$ into $\cdot \mathrm{OH}$, leading to lipid and protein oxidation and DNA damage. In another study, organic theranostic nanomedicine (PTCG NPs) were incorporated with the platinum(IV) prodrug (Pt-OH) $\mathrm{Fe}^{3+}$ [129]. The activated cisplatin elevated the $\mathrm{H}_{2} \mathrm{O}_{2}$ level, which was catalyzed by $\mathrm{Fe}^{3+}$ to produce cytotoxic ROS, thus enhancing the therapeutic efficacy. Apart from platinum, ferrocene has been used, whereby a ferrocene-containing nanovesicle (FcNV) was loaded with GOD and cisplatin (Pt) to combat multidrug-resistant tumors [130]. In the system, $\mathrm{H}_{2} \mathrm{O}_{2}$ generation was activated by $\mathrm{Pt}$ to enhance chemotherapy; glucose was consumed by GOD to generate $\mathrm{H}_{2} \mathrm{O}_{2}$ and gluconic acid for starvation therapy; and all $\mathrm{H}_{2} \mathrm{O}_{2}$ were catalyzed by Fenton reaction to generate cytotoxic $\cdot \mathrm{OH}$ for CDT. Lastly, $\mathrm{Mn}^{2+}$ is also promising for combination therapy, as shown in a study where the cisplatin prodrug was anchored onto the surface of $\mathrm{MnO}_{2}$-coated upconversion hybrid nanocomposite, the $\mathrm{MnO}_{2}$ shell was degraded by intracellular GSH, and then, the released $\mathrm{Mn}^{2+}$ performed Fenton-like reaction for CDT to synergize with Pt-based chemotherapy [131].

$\mathrm{H}_{2} \mathrm{O}_{2}$ performs an important role in the Fenton and Fenton-like reactions-mediated CDT; thus, extra $\mathrm{H}_{2} \mathrm{O}_{2}$ induced by nanomaterials is promising to enhance the cancer therapeutic effect of CPT chemodrugs. Therefore, in one study, the $\mathrm{H}_{2} \mathrm{O}_{2}$ inducer, $\beta$-lapachone, and camptothecin prodrug were co-loaded into iron oxide NPs [132]. The $\mathrm{H}_{2} \mathrm{O}_{2}$ that was induced by $\beta$-lapachone reacted with iron ions via the Fenton reaction to produce cytotoxic $\bullet \mathrm{OH}$ for $\mathrm{CDT}$ as well as activate the release of CPT for chemotherapy. In the hybrid FeMOF NPs with $\mathrm{Au}$ NPs anchored on the surface and CPT loaded inside, the NPs converted glucose into $\mathrm{H}_{2} \mathrm{O}_{2}$ for TCPP $(\mathrm{Fe})$-mediated Fenton reaction, enhancing CDT-catalyzed chemotherapy [133]. In another study, the hybrid NPs, Fe/G@RNRs, were prepared by loading responsive polyprodrug polymersomes with ultrasmall iron oxide NPs and GOD (Fig. 4) [134]. Triggered by the acidic TME, Fe/G@R-NRs released GOD to catalyze starvation therapy, and Fe to catalyze the Fenton reaction, which generated $\cdot \mathrm{OH}$ to react with polyprodrug polymersomes to release $\mathrm{CPT}$ for chemotherapy.

Many other common chemotherapeutic drugs have also been explored for synergistic treatment with Fenton and Fenton-like reactions. Tirapazamine (TPZ) exhibits selective cytotoxicity for hypoxic solid tumors. Thus, in 


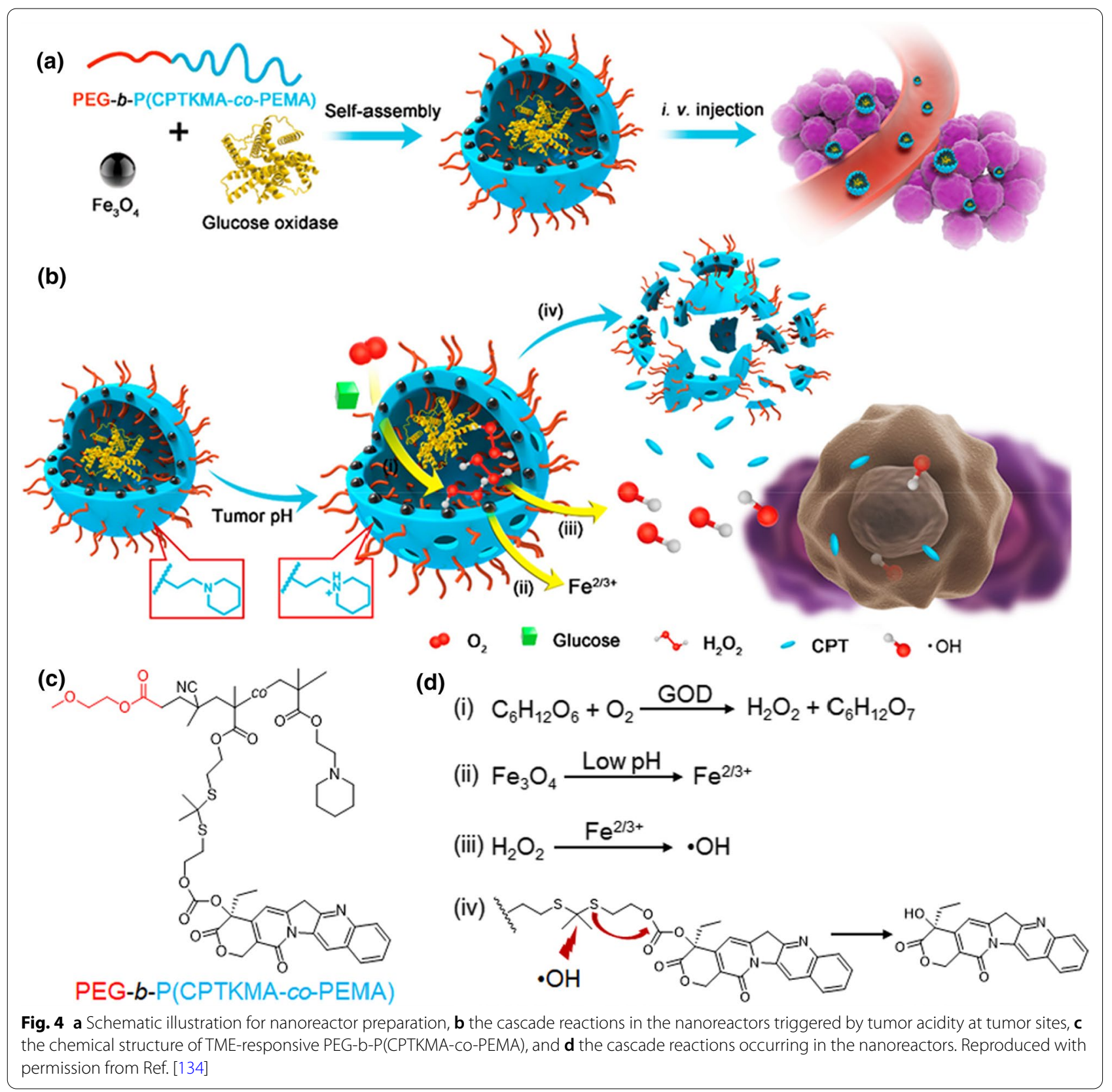

several studies, TPZ has been explored for its potential use in the Fenton reaction system, whereby oxygen was depleted and TPZ was activated [135, 136]. Furthermore, the GSH synthesis inhibitor, l-buthionine sulfoximine (BSO), has been explored to synergize with the Fenton reaction to deplete intracellular GSH, showing that this enhanced the chemotherapy and radiotherapy [137]. Mitomycin c has also been explored to synergize with the Fenton reaction by being encapsulated into superparamagnetic iron oxide NPs@PEG (SPIONs@PEG) [138]. The surface-anchored GOD catalyzed and converted glucose into gluconic acid and $\mathrm{H}_{2} \mathrm{O}_{2}$ for the Fenton reaction to strengthen chemotherapy. In addition, parthenolide, chloroquine, cinnamaldehyde, and bufalin have been explored as chemotherapeutic drugs to synergize with Fenton reaction-mediated CDT for an enhanced therapeutic effect $[57,139,140]$.

\section{Combination of Fenton and Fenton-like reactions with PDT} PDT has been used for the management of neoplastic and nonmalignant diseases and is attracting more and more attention in recent years [141]. PDT is composed 
of three components: photosensitizers (PSs), light source, and oxygen. PSs can generate ROS under light irradiation, leading to the selective killing of tumors and cancer cells. According to the skeleton structure of their molecules, PSs are mainly divided into porphyrins, chlorins, and phthalocyanines. However, PDT has been limited by several unresolved challenges, such as inefficient therapeutic efficiency as a result of the hypoxic TME [142]. Recently, the combination of Fenton and Fenton-like reactions with PDT has been demonstrated to enhance the therapeutic antitumor effect [143, 144].

With their high ROS generation efficiency, good light stability, and low dark toxicity, porphyrins are often used as molecular probes and PSs, showing high cytotoxicity towards cancer cells under light irradiation [145]. To achieve targeted delivery to the tumor, the photosensitizer Zinc(II) protoporphyrin IX ( $\mathrm{ZnP})$ was inserted into the iron storage protein bacterioferritin (Bfr) in one study [146]. The inner cavity was loaded with a ferric oxyhydroxide polymer and then conjugated with polyethylene glycol on the outer surface. Under light irradiation, $3 \mathrm{ZnP}$ in the Bfr protein shell reduced $\mathrm{Fe}^{3+}$ in the enclosed $[\mathrm{FeO}(\mathrm{OH})]_{\mathrm{n}}$ core to $\mathrm{Fe}^{2+}$, which subsequently triggered the Fenton reaction to generate ROS for PDT enhancement. In another study, in order to enhance the tumor accumulation of the nanomaterial, the targeted molecule AS1411 aptamer was modified onto porphyrin photosensitizer-loaded $\mathrm{Fe}_{2} \mathrm{O}_{3}$ NPs [147]. In yet another study, as GSH depletion plays an important role in CDT-related therapy, the hydrophobic photosensitizer 5,10,15,20-tetrakis(4-methacryloyloxyphenyl)porphyrin (TMPP) that contains multiple carbon-carbon double bonds was loaded into a nanosystem (TPFcNP) that was composed of a ferrocene-containing amphiphilic block copolymer (PEG-b-PMAEFc) [148]. The ferrocene of PEG-b-PMAEFc can catalyze $\mathrm{H}_{2} \mathrm{O}_{2}$ to generate $\cdot \mathrm{OH}$ in the acidic TME via the Fenton reaction. The generated $\cdot \mathrm{OH}$ was promising to damage cancer cells and to catalyze the addition reaction between the carbon-carbon double bonds of TMPP and the overexpressed GSH in cancer cells. The addition reaction between TMPP and GSH improved the photosensitizer hydrophilicity effectively to reduce their aggregation, leading to enhanced PDT. Increasing $\mathrm{TME} \mathrm{O}_{2}$ concentration is another contribution by Fenton reaction to enhance PDT using porphyrin as a photosensitizer. In one study, a multifunctional Fenton reaction nanoplatform was fabricated [149]. The nanoplatform was prepared by co-precipitation in the presence of triphenylphosphine (TPP)-grafted dextran (Dex-TPP) and $\mathrm{Fe}^{2+} / \mathrm{Fe}^{3+}$ to form $\mathrm{Fe}_{3} \mathrm{O}_{4} @ D$ Dex-TPP NPs. Then, the photosensitizers of protoporphyrin IX (PpIX) and glutathione-responsive mPEG-ss-COOH were modified on the surface to form $\mathrm{Fe}_{3} \mathrm{O}_{4} @ \mathrm{Dex} / \mathrm{TPP} / \mathrm{PpIX} /$
ss-mPEG NPs. After internalization, $\mathrm{Fe}^{2+} / \mathrm{Fe}^{3+}$ were released in the acidic lysosome and then diffused into the cytoplasm, which subsequently reacted with the intracellular $\mathrm{H}_{2} \mathrm{O}_{2}$ to produce $\mathrm{O}_{2}$ and $\bullet \mathrm{OH}$ for cancer therapy.

Chlorins exhibit good biological activity in antitumor, anti-pathogenic microorganisms, and anti-rheumatoid arthritis applications, which make them important candidates in the development of photosensitizers for PDT. Chlorin e6 (Ce6) is a suitable chlorin derivative for the development of PDT due to its high efficiency in producing ROS. Thus, Ce6 is a representative photosensitizer that has been explored together with Fenton and Fentonlike reactions [150]. Fenton and Fenton-like reactions decompose $\mathrm{H}_{2} \mathrm{O}_{2}$ into $\mathrm{O}_{2}$ to relieve the tumor hypoxia for enhanced PDT [151-153]. Ferrous ions not only take part in the Fenton reaction but also induce ferroptosis. Thus, in one study, the ferroptosis inducer sorafenib (SRF) was loaded into the Hb-Ce6 NPs by connecting hemoglobin (Hb) with Ce6 [154]. SRF-induced ferroptosis was shown to enhance Ce6-mediated PDT efficiently. In another study, as increased $\mathrm{H}_{2} \mathrm{O}_{2}$ concentration at the tumor will supply more raw material for Fenton and Fenton-like reactions to enhance PDT, the photosensitizer $\mathrm{Cu}^{2+}, \mathrm{Au}$ NPs, and collagenase $(\mathrm{Col})$ were integrated into the framework of HMON [155]. Au NPs converted glucose into $\mathrm{H}_{2} \mathrm{O}_{2}$, and then $\mathrm{Cu}^{2+}$ catalyzed Fenton-like reaction to enhance photosensitizer mediated-PDT. In addition, Col degraded the collagen I fiber in the extracellular matrix, enhancing the NPs penetration for therapy. In another recent study, a nanoassembly was made from $\mathrm{Ce} 6$, carbon dots, and $\mathrm{Cu}^{2+}[156] . \mathrm{Cu}^{2+}$ allowed both CDT function through Fenton-like reaction with $\mathrm{H}_{2} \mathrm{O}_{2}$ and GSH depletion by a redox reaction. In addition, the reduction of $\mathrm{Cu}^{2+}$ into $\mathrm{Cu}^{+}$induced the disassembling of the NP to release $\mathrm{Ce} 6$, which recovered its fluorescence and ROS generation capacity. The prepared NPs acted as not only an activatable fluorescence probe but also a synergistic cancer therapeutic agent of PTT, PDT, and CDT. In yet another application of Ce6, a Ce6-loaded lanthanide-doped upconversion nanoconjugate, $\mathrm{MnO}_{2}$ nanosheets, and hyaluronic acid biopolymer were integrated [157]. The Fenton-like reaction produced more $\mathrm{H}_{2} \mathrm{O}_{2}$ in the acidic TME, and the $\mathrm{MnO}_{2}$ nanosheets were degraded to produce massive $\mathrm{O}_{2}$, enhancing the PDT effect. In addition, hyaluronic acid can reprogram the pro-tumor M2-type TAMs to anti-tumor M1-type macrophages to prevent tumor recurrence (Fig. 5).

Phthalocyanines are easy to metabolize and exhibit low phototoxicity to the skin, making them a promising alternative to porphyrins. In one study, the photosensitizer zinc phthalocyanine $(\mathrm{ZnPc})$ was incorporated into the ferric pyrophosphate coordination polymer (FeP) NPs [158]. The prepared NPs released the $\mathrm{Fe}^{3+}$ to react with 


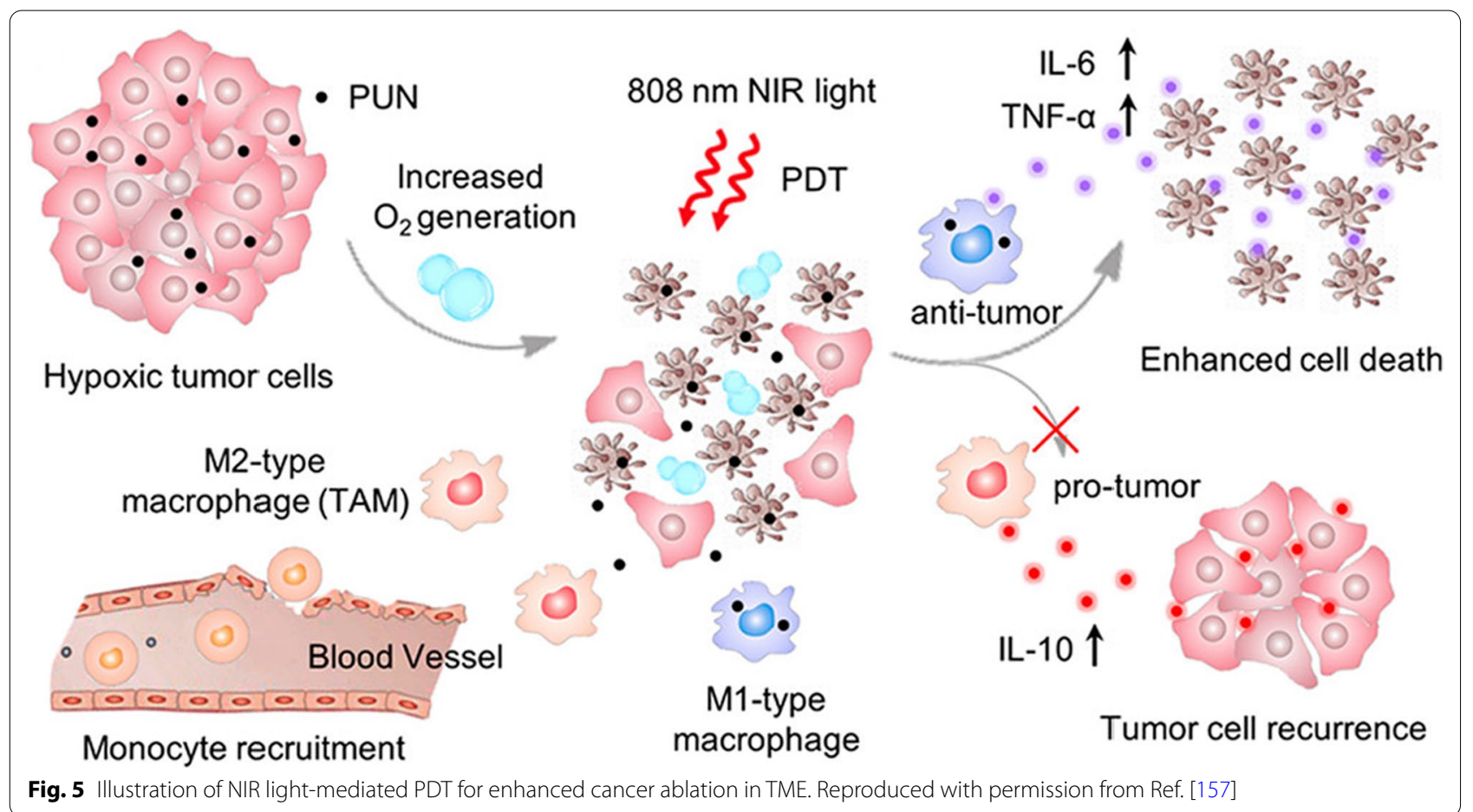

GSH, which yielded $\mathrm{Fe}^{2+}$ for the Fenton reaction to take place, enhancing PDT.

\section{Combination of Fenton and Fenton-like reactions with PTT}

PTT is a type of therapy that relies on light irradiation to generate a local temperature elevation for cancer ablation [159]. The combination of Fenton and Fenton-like reactions with PTT has exhibited improved therapeutic efficiency over monotherapy [160]. Both inorganic materials and organic materials can be used as photothermal materials. Inorganic materials mainly include the noble metals (e.g., $\mathrm{Au}, \mathrm{Ag}$, and Pt), metal chalcogenides (e.g., $\mathrm{CuS}$ ), and carbon-based nanomaterials [161, 162]. Organic photothermal materials mainly include small molecule dyes (e.g., indocyanine green, prussian blue) and conjugated polymers (e.g., polyaniline, polypyrrole, polythiophene, polydopamine) [163-165]. One main issue for PTT is that insufficient light penetration depth may lead to incomplete elimination of tumor cells, and residual tumor cells may lead to tumor recurrence and distant metastasis. The combination of PTT and Fenton/Fentonlike reactions has demonstrated great potential to achieve synergistic effects and improve therapeutic performance [166]. On the one hand, ROS production can be promoted under a higher temperature by light-enhanced Fenton reaction. On the other hand, ROS production can enhance PTT effect by sensitizing tumor cells [167].
Noble metals exhibit a strong resistance to oxidation and are regarded the most classical photothermal materials [72, 168]. Noble metals absorb light energy and then release energy in the form of heat via non-radiative decay. In addition, many metal ions released from the noble metal nanomaterials are efficient catalysts for Fenton/ Fenton-like reactions [169]. In one study, $\mathrm{Cu}_{2} \mathrm{MoS}_{4} / \mathrm{Au}$ NPs were prepared by depositing plasmonic Au NPs into $\mathrm{Cu}_{2} \mathrm{MoS}_{4}$ nanosheets [170]. The prepared $\mathrm{Cu}_{2} \mathrm{MoS}_{4} / \mathrm{Au}$ NPs exhibited excellent photothermal conversion property and ROS generation capability, enabling synergistic therapy of PTT and PDT. Moreover, the $\mathrm{Cu}_{2} \mathrm{MoS}_{4} / \mathrm{Au}$ NPs converted $\mathrm{H}_{2} \mathrm{O}_{2}$ into $\mathrm{O}_{2}$ via the Fenton-like reaction to relieve tumor hypoxia and to enhance the therapeutic effect. In another study, hybrid NPs were prepared by coating upconverting NPs with iron-porphyrin MOFs on the surface and integrating Au NPs [171]. The NPs tuned the visible light harvesting ability of MOFs to excite MOFs for PDT. Moreover, the Au NPs depleted glucose and produced large amount of $\mathrm{H}_{2} \mathrm{O}_{2}$, resulting in enhanced Fenton reaction catalyzed by $\mathrm{Fe}^{2+}$ of MOFs. In yet another study, the nanozyme made of PtFe@ $\mathrm{Fe}_{3} \mathrm{O}_{4}$ exhibited dual enzyme-like activities of both intrinsic peroxidase-like and catalase-like activities in the acidic TME [52]. On the one hand, the prepared nanozyme promoted ROS production by direct electron transfer and $\mathrm{Fe}^{3+}$-mediated Fenton reaction. On the other hand, ROS generation was significantly improved by the 
photothermal effect of nanozymes, achieving the synergistic catalytic therapy and PTT. In one last study, DOX@ Fe(III)@WS - PVP NPs were designed by loading Fe(III)@ $\mathrm{WS}_{2}$-PVP fabricated via one-pot synthesis process with DOX [172]. On the one hand, the redox reaction between $\mathrm{Fe}^{3+}$ and $\mathrm{WS}_{2}$ generated $\mathrm{Fe}^{2+}$ and $\mathrm{WO}_{4}{ }^{2-}$. On the other hand, $\mathrm{Fe}^{2+}$ catalyzed the Fenton reaction which generated $\mathrm{Fe}^{3+}$ for the redox reaction. This repetitive endogenous redox reaction resulted in biodegradation and DOX release from DOX@Fe(III)@WS ${ }_{2}$-PVP, leading to chemotherapy and CDT for PTT enhancement.

With their wide range of optical absorption and reasonable photothermal properties, metal chalcogenides have received great attention in recent years [173-175]. Their use has been explored to achieve synergistic combination therapy of Fenton-like activity and PTT $[176,177]$. For example, in one study, $\left(\mathrm{Cu}_{2-\mathrm{x}} \mathrm{Se}\right)$-Au Janus NPs were prepared for tri-combination antitumor therapy [178]. In the designed NPs, both the $\mathrm{Cu}_{2-\mathrm{x}} \mathrm{Se}$ and the Au promoted - $\mathrm{OH}$ generation. In addition, the Janus structure promoted photo-induced electron-hole separation to produce additional $\bullet \mathrm{OH}$. Both $\mathrm{Cu}_{2-\mathrm{x}} \mathrm{Se}$ and $\mathrm{Au}$ contributed to PTT and promoted the reactions. As a result, synergistic tri-combination antitumor therapy was achieved. In another study, ultrasmall chalcopyrite $\mathrm{CuFeS}_{2}$ NPs were prepared by using bovine serum albumin (BSA) as a template [179]. The prepared NPs possessed $\mathrm{pH}$-independent $\mathrm{Cu}$-catalyzed Fenton-like reaction property to produce $\cdot \mathrm{OH}$ for enhanced PTT. BSA was used to anchor $\mathrm{Cu}$ and $\mathrm{Fe}$ ions based on the excellent affinity of carboxyl groups and the surfactant. In yet another study, CuS NPs, another kind of NIR absorbing material for PTT was used, whereby the $\mathrm{Cu}^{2+}$ released from the NP was found capable to trigger the Fenton-like reaction [180]. When $\mathrm{CuS}$ NPs were integrated with iron-containing prodrug, the hybrid NPs not only acted as a PTT agent for photothermal ablation of tumor cells but also acted a catalyst to catalyze the regeneration of high-active $\mathrm{Fe}^{2+}$ from low-active $\mathrm{Fe}^{3+}$, enhancing $\mathrm{Fe}^{2+}$-mediated Fenton reaction. In another application of CuS NPs, they were integrated with $\mathrm{MnO}_{2}$ to generate the hybrid HMCMD NPs [181]. The HMCMD NPs possessed excellent photothermal conversion efficiency and the release of the loaded DOX was promoted under laser irradiation to enhance DOX-mediated chemotherapy. Meanwhile, $\mathrm{Mn}^{2+}$ released from the HMCMD NPs through a redox reaction between $\mathrm{MnO}_{2}$ and intracellular GSH promoted the decomposition of intracellular $\mathrm{H}_{2} \mathrm{O}_{2}$ by the Fentonlike reaction to generate highly toxic $\cdot \mathrm{OH}$ for synergistic chemotherapy/CDT/PDT. Lastly, one study prepared $\mathrm{CoS}_{2}$ NPs via the self-assembly of $\mathrm{CoS}_{2}$ nanosclusters [182]. $\mathrm{Co}^{2+}$-mediated Fenton-like reaction enhanced the $\mathrm{CoS}_{2}$ mediated-PTT.
Carbon-based materials, such as carbon nanotubes, graphene, graphene oxide, and carbon dots, can also convert light energy to heat energy for cancer treatment [183]. Therefore, in one study, the hollow carbon matrix core, which contained ultrasmall $\mathrm{Fe}_{3} \mathrm{O}_{4} \mathrm{NPs}$, was coated with a nanoflower-like $\mathrm{MnO}_{2}$ shell to form a redox and light-responsive nanoplatform [184]. $\mathrm{Fe}^{2+}$ and $\mathrm{Fe}^{3+}$ released in the acidic TME catalyzed the Fenton reaction for enhanced PTT. In another study, hollow porous carbon was used to coat $\mathrm{FeS}_{2}\left(\mathrm{HPFeS}_{2} @ \mathrm{C}\right) \mathrm{NPs}$ which were further loaded with tannic acid (TA) and GOD [185]. After endocytosis by cancer cells, GOD effectively catalyzed glucose to generate $\mathrm{H}_{2} \mathrm{O}_{2}$, which led to the generation of highly toxic $\cdot \mathrm{OH}$ via $\mathrm{Fe}^{2+}$-mediated Fenton reaction. Meanwhile, TA reduced the generated $\mathrm{Fe}^{3+}$ back to $\mathrm{Fe}^{2+}$ to recycle the Fenton reaction for enhanced therapeutic effect.

Prussian blue is an inorganic material that contains a ferrous element and that possesses good absorption at the NIR wavelength region. Prussian blue-based nanomaterials have shown promise for both PTT and Fentonreaction mediated CDT [186]. In one study, MIL-100 (Fe) coated $\mathrm{K}_{2} \mathrm{Mn}\left[\mathrm{Fe}(\mathrm{CN})_{6}\right]$ NPs (PBAM) were prepared for CDT and PTT combination therapy [187]. In the mildly acidic TME, the MIL-100 shell was degraded to release $\mathrm{Fe}^{3+}$, which further exchanged with $\mathrm{Mn}^{2+}$ to synthesize Prussian blue for PTT. Additionally, $\mathrm{Mn}^{2+}$ catalyzed the Fenton-like reaction, enhancing PTT. The in vitro data conformed that the T1-weighted MRI with $\mathrm{Mn}^{2+}$ contrast and photoacoustic imaging with Prussian blue contrast obtained more detailed and precise tumor information for cancer therapy. The in vivo data further exhibited that the combination of $\mathrm{Mn}^{2+}$-mediated CDT and Prussian blue-mediated PDT achieved synergistic anticancer performance under the guidance of PA/MRI. And with their high tumor specificity, PBAM showed promise to monitor invisible lymph node metastases and to have an accurate theranostic effect.

Ferrous-sulfur NPs are a class of nanomaterials possessing strong absorption in the NIR wavelength region, making them a good PTT agent to combine with ferrous ion-mediated Fenton reaction [188]. In one study, defectrich $\mathrm{Fe}_{3} \mathrm{~S}_{4}$ tetragonal nanosheets (TNSs) were fabricated by a hot-injection thermal decomposition reaction and then modified with a PVP coating [189]. PVP-coated $\mathrm{Fe}_{3} \mathrm{~S}_{4}$ TNSs produced localized heat by PTT from the defect-rich structure, which enhanced the Fenton process by utilizing the excess $\mathrm{H}_{2} \mathrm{O}_{2}$ in the TME. In return, the produced $\cdot \mathrm{OH}$ inhibited tumor growth and recurrence after PPT, achieving synergetic therapy of Fenton reaction and PTT. In another study, $\mathrm{FeS}_{2} @ \mathrm{C}-\mathrm{ICG}-\mathrm{PEG}$ NPs were prepared by loading indocyanine green (ICG) into the $\mathrm{FeS}_{2} @ \mathrm{C}$ yolk-shell and modifying PEG on the 
C yolk-shell surface [190]. FeS $2 @ C-I C G-P E G$ possessed high photothermal conversion efficiency, enabling enhanced PTT. Besides, FeS ${ }_{2} @$ C-ICG-PEG generated NIR-triggered $\operatorname{ROS}\left(\cdot \mathrm{OH}\right.$ and $\left.\mathrm{O}^{2-}\right)$ and oxidized water to form $\mathrm{O}_{2}$ under NIR irradiation to relieved tumor hypoxia. Moreover, $\mathrm{FeS}_{2}$-mediated Fenton reaction and ICG-mediated PTT enhanced the therapeutic effect. In yet another study, thermally oxidized pyrite nanosheets (TOPY-PEG NSs) were modified on the surface [191]. The TOPY-PEG NSs catalyzed PDT via electron transfer between their $\mathrm{FeS}_{2}$ core and $\mathrm{Fe}_{2} \mathrm{O}_{3}$ shell. In addition, the $\mathrm{Fe}_{2} \mathrm{O}_{3}$ shell and $\mathrm{Fe}^{3+}$ depleted GSH and generated $\mathrm{Fe}^{2+}$ for the Fenton reaction, enhancing not only PDT but TOPY-PEG NSs-mediated PTT. And the fluorescent, photothermal imaging and photoacoustic capabilities of the TOPY-PEG NSs were shown to allow multimodal imaging-guided cancer treatment. In one last study, except for Ferrous-sulfur NPs, ferrous phosphide nanorods $\left(\mathrm{Fe}_{2} \mathrm{P}\right.$ NRs) were shown to be a superior PTT agent as well as CDT agent by $\mathrm{Fe}^{3+}$-mediated Fenton reaction [192].

Among organic nanoplatforms, conjugated polymers with excellent optical properties have gained tremendous popularity recently. The large $\pi$-conjugated backbone and high electron delocalization structure of conjugated polymers have excellent light amplification and light harvesting properties, thus providing new opportunities in the fields of bioimaging and phototherapy [193, 194]. Polydopamine (PDA) is a kind of conjugated polymer with excellent absorption in the NIR wavelength region, which facilitates its application for PTT [195]. Thus, metal ions could be incorporated into the PDA-based NPs to enhance PDA-mediated PTT via Fenton or Fentonlike reaction-mediated CDT [196]. In order to further improve the synergistic effect of PDA-based PTT/CDT, GOD has been incorporated into the NPs to deplete glucose and supplied $\mathrm{H}_{2} \mathrm{O}_{2}$ for the Fenton reaction [197]. DOX has also been further loaded into such system to explore the synergistic effect of PTT/CDT/chemotherapy [198].

\section{Combination of Fenton reaction and sonodynamic therapy (SDT)}

SDT is a cancer therapy modality triggered by low-intensity ultrasound and has emerged as a promising cancer treatment modality due to its deep penetration and noninvasive therapeutic features [199]. SDT has many advantages, including deep tissue penetration, controllability, and good patient compliance; however, its therapeutic effect is limited in the hypoxic TME and where there is low ROS release and low sensitivity [200-202]. Therefore, combining Fenton reaction with SDT can strengthen the therapeutic efficiency of either Fenton reaction or SDT [203].

Sonosensitizers like porphyrin derivatives are generally used to enhance the SDT [204]. In one study, the Fe(III)porphyrin-based nano-sonosensitizer was fabricated by coordinating meso-tetrakis (4-sulfonatophenyl) porphyrin (TPPS) and $\mathrm{Fe}^{3+}$ as a core, and then anchoring with Bis(DPA-Zn)-RGD and manganese superoxide dismutase (SOD2) siRNA [205]. $\mathrm{Fe}^{3+}$ in the nano-sonosensitizer reduced into $\mathrm{Fe}^{2+}$ to deplete $\mathrm{GSH}$ and catalyze CDT for TPPS-SDT enhancement. In another study, another multifunctional nanosonosensitizer (PpIX@HMONsMnOx-RGD, designated as PMR) was prepared by integrating a $\mathrm{MnO}_{\mathrm{x}}$ component with hollow mesoporous organosilica NPs (HMONs), protoporphyrin (PpIX) and cyclic arginine-glycine-aspartic pentapeptide [60]. These multifunctional nanosonosensitizers enhanced ultrasound-triggered SDT by improving the tumor oxygen level. The $\mathrm{MnO}_{\mathrm{x}}$ in the nanosonosensitizer acted as a nanoenzyme to convert TME overexpressed $\mathrm{H}_{2} \mathrm{O}_{2}$ into oxygen to facilitate SDT-triggered ROS generation and to enhance SDT efficacy. There are also some reports about the use of inorganic NPs as sonosensitizers to combine with Fenton reaction. For example, Janus Au-MnO NPs were prepared by the self-assembly of Janus $\mathrm{Au}-\mathrm{MnO}$ NPs with hydrophilic thiolated PEG (PEG-SH) and hydrophobic ROS-sensitive poly-(1,4-phenyleneacetone dimethylene thioketal) (PPADT-SH) [206]. Upon ultrasound stimulation, the prepared NPs firstly disassembled into small Janus $\mathrm{Au}-\mathrm{MnO} \mathrm{NPs}$, and then divided into $\mathrm{Au}$ NPs and $\mathrm{Mn}^{2+}$ ions. $\mathrm{Mn}^{2+}$-mediated Fenton-like reaction enhanced $\mathrm{Au}$-mediated SDT. In another study, $\mathrm{PtCu}_{3}$ nanocages were synthesized via one-pot solvothermal method, and then coated with PEG [207]. $\mathrm{PtCu}_{3}$-PEG nanocages acted not only a sonosensitizer under ultrasound irradiation but also a catalyst for Fenton-like reaction. Besides, the copper ion of the $\mathrm{PtCu}_{3}-\mathrm{PEG}$ nanocages depleted GSH, strengthening the combination therapy. In yet another study using titanium oxide NPs, the introduction of the iron element enhanced both SDT and CDT and resulted in synergistic combination therapy [208].

\section{Combination of Fenton reaction and immunotherapy}

Cancer immunotherapy has recently gained considerable attention as a novel therapeutic option; moreover, the rational combination of immunotherapy with other therapeutic modalities presents an appealing approach to improve cancer therapy [209-212]. In recent studies, Fenton reaction-based CDT-immunotherapy not only achieved the shrinkage of in situ tumor but effectively eradicated distant tumors [213]. 
The Fenton reaction can be used to modulate cellular metabolic processes for antitumor activities, e.g., hijacking the estrogen metabolic pathway [214]. High serum levels of estrogens, especially estradiol (E2), are associated with increased cancer risks. Estrogens were found to form stable adducts with DNA by generating ROS in the downstream metabolic processes in the presence of $\mathrm{Cu}^{2+}$ mediated Fenton-like reaction (Fig. 6). The intratumoral administration of free $\mathrm{Cu}^{2+}$ can potentially hijack the estrogen metabolic pathway and trigger cytotoxic ROS generation to reduce cell-proliferation-induced tumorigenesis and enhance effective radical therapy.

It is well known that radiotherapy (RT) can trigger the immune response but its anticancer efficacy has been limited by inadequate $\mathrm{T}$ cell infiltration. Thus, porous Hf-based nMOFs have been explored as effective radioenhancer [65]. The combination of nMOF-mediated low-dose RT with the anti-programmed death-ligand
1 (anti-PD-L1) antibody exhibited effective therapeutic effects to distant tumors via abscopal effects. When copper was doped into hybrid NPs, the resultant product exhibited synergistic PTT, PDT, CDT as well as activated immune responses effectively [215]. Further combination with anti-PD-L1 checkpoint blockade therapy resulted in successful suppression of distant tumor growth and cancer metastasis.

It is also well known that the TGF- $\beta$ inhibitor can regulate the TME to induce macrophage polarization from $M 2$ to $\mathrm{M} 1$, which can regenerate $\mathrm{H}_{2} \mathrm{O}_{2}$. Thus, the TGF- $\beta$ inhibitor has been loaded into the PEGylated iron manganese silicate NPs (IMSN) to trigger the synergistic cancer therapy [216]. The IMSN exhibited both peroxidase-like and catalase-like activities in the acidic TME, thus generating $\bullet \mathrm{OH}$ and $\mathrm{O}_{2}$, respectively. The generated $\mathrm{H}_{2} \mathrm{O}_{2}$ induced by TGF- $\beta$ inhibitor was an efficient supplement to the TME for IMSN-based combination therapy.

(a)

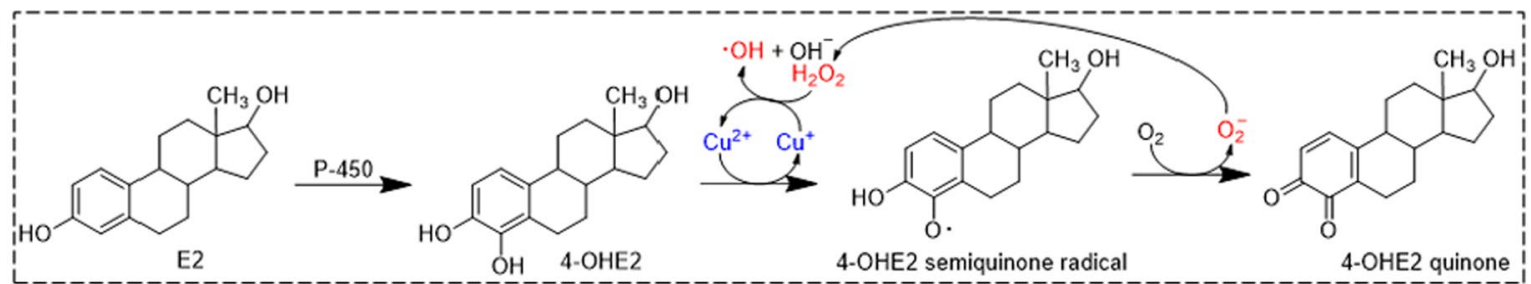

(b)

1) $\mathrm{pH}$ triggered decomposition

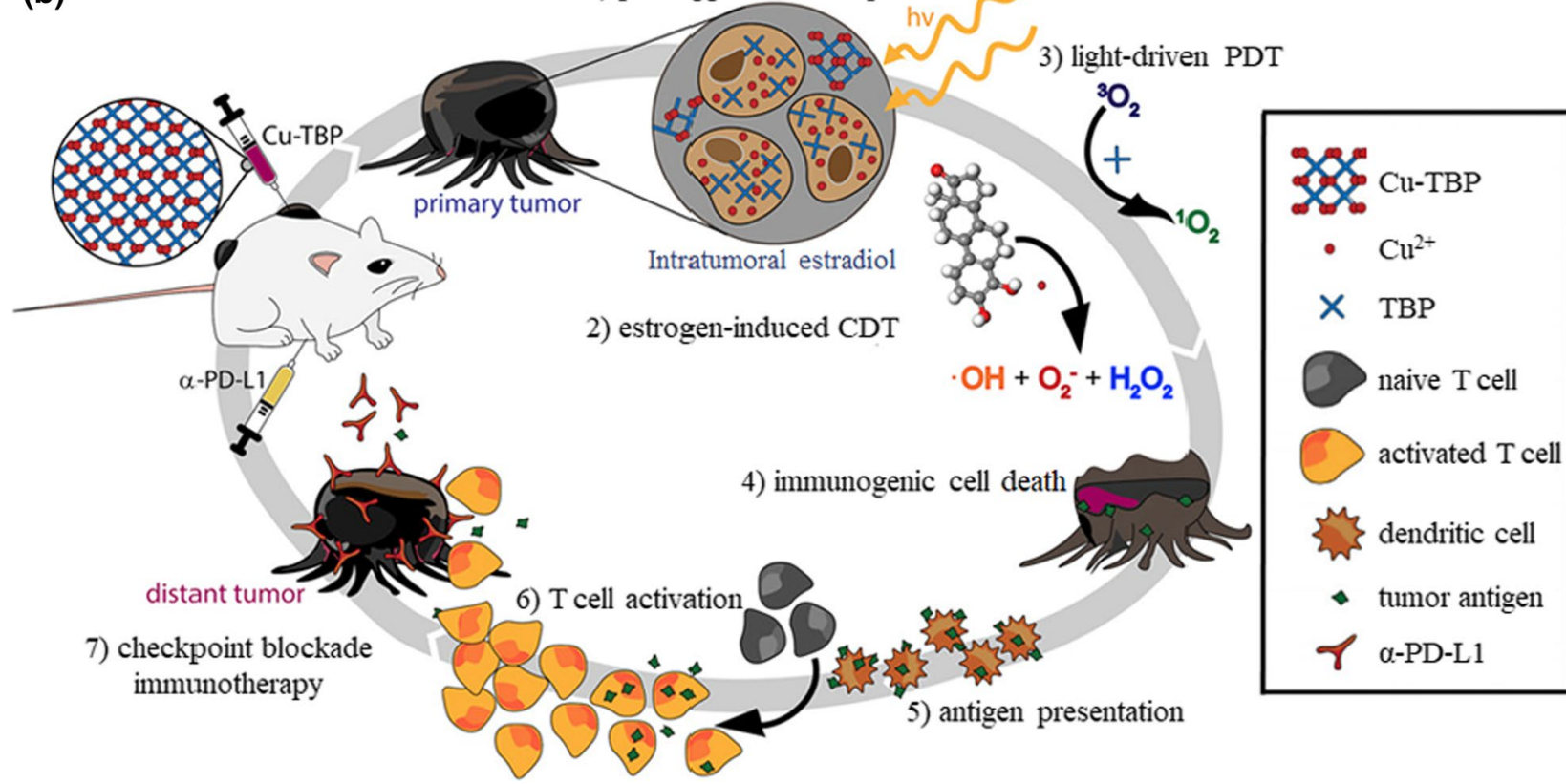

Fig. 6 a Hormone-induced Cu-mediated ROS generation process. b Synergy of checkpoint blockade immunotherapy and nMOF-mediated radical therapy triggered by both hormone and light stimulation. Reproduced with permission from Ref. [214] 


\section{Combination of Fenton reaction and magnetic hyperthermia therapy (MHT)}

MHT is a strategy using an external alternating magnetic field to induce the relaxation and hysteresis loss of magnetic NPs, resulting in magnetic-heat conversion for cancer therapy [98]. MHT can treat tumors by producing localized heat with minimum adverse effects and without depth limitations [217]. The combination of the Fenton reaction and $\mathrm{MHT}$ is promising to produce more effective treatment with less side effects [54].

Hollow $\mathrm{Fe}_{3} \mathrm{O}_{4}$ mesocrystals have been shown to enhance $\mathrm{Fe}_{3} \mathrm{O}_{4}$-mediated MHT by the Fenton reaction [53]. On the one hand, the Fenton reaction produced - $\mathrm{OH}$ which induced cell apoptosis and reduced the expression of heat shock proteins, enabling low-temperature-mediated magnetic hyperthermia. On the other hand, in situ hyperthermia in turn facilitated the Fenton reaction to achieve synergistic combination therapy. In another study, the lipophilic iridium(III) cation in the $\mathrm{Ir}$ (III) complexes modified $\mathrm{MnFe}_{2} \mathrm{O}_{4}$ NPs acted as a target ligand to the tumor [218]. On exposure to an alternating magnetic field, the $\mathrm{MnFe}_{2} \mathrm{O}_{4} @ \mathrm{Ir}$ NPs caused localized hyperthermia, leading to mitochondrial damage and even cell death. Moreover, $\mathrm{Fe}^{3+}$ on the surface of NPs converted into $\mathrm{Fe}^{2+}$ by reacting with GSH, catalyzing the Fenton reaction to enhance magnetic hyperthermia. In yet another study, the further loading of GOD not only resulted in starvation therapy but also generated more $\mathrm{H}_{2} \mathrm{O}_{2}$ at the tumor, resulting in synergistic starvation-chemodynamic-hyperthermia tumor therapy [219]. Lastly, one study showed that in graphene oxide-grafted magnetic manorings, the elaboration of ferrimagnetic vortex-domain iron oxide nanoring and graphene oxide exhibited efficient thermal conversion and amplified the Fenton reaction-induced ROS level significantly under an alternating magnetic field [220]. The magnetothermal effect and ROS generation activated the in vivo immunologic effect to carry out efficient MHT in vivo.

\section{Combination of Fenton reaction and RT}

RT is a widely used cancer therapeutic modality in clinic. Tumor hypoxia is a major reason for RT resistance. As Fenton and Fenton-like reactions can produce $\mathrm{O}_{2}$ to relieve tumor hypoxia, they are promising to enhance RT [221]. Traditionally, the therapeutic efficacy of RT is a result of direct radiation damage and indirect damage caused by $\cdot \mathrm{OH}$. In one study, Janus-like $\mathrm{Au}-\mathrm{Fe}_{2} \mathrm{C} \mathrm{NPs}$ that performed as Fenton reaction catalysts were synthesized to sensitize RT by generating more hydroxyl radicals $(\cdot \mathrm{OH})$ than that by pure Au NPs under radiation [222]. The catalysis-based radiosensitization strategy exhibited improved anticancer performances both in vitro and in vivo.
To further improve the sensitization effect by the Fenton reaction, in another study, Hafnium-based nanoscale metal - organic frameworks (Hf-nMOFs) with uniformly dispersed $\mathrm{Fe}^{3+}$ were constructed [223]. The NPs generated tremendous ROS, resulting in persistent ROS stress and reassorted cell cycle distribution. In addition, highenergy electrons resulting from $\mathrm{Hf}^{4+}$ partially converted $\mathrm{H}_{2} \mathrm{O}$ to $\cdot \mathrm{OH}$ and relaxed to a low-energy state to facilitate the reduction of $\mathrm{Fe}^{3+}$ to $\mathrm{Fe}^{2+}$ that promoted the production of $\cdot \mathrm{OH}$ via the Fenton reaction. The NPs exhibited improved radiotherapeutic effects on tumors by both the $\mathrm{Fe}^{2+}$-based Fenton reaction and $\mathrm{Hf}^{4+}$-induced $\mathrm{X}$-ray energy conversion. In yet another study, the incorporation of anti-PD-L1 improved the local therapeutic effect of RT to distant tumors [65].

To improve the selectivity and controllability of the combination therapy of Fenton-like reaction and RT, a TME-responsive $\mathrm{Cu}_{2}(\mathrm{OH}) \mathrm{PO}_{4} \mathrm{NP}$ was synthesized [224]. The $\mathrm{Cu}_{2}(\mathrm{OH}) \mathrm{PO}_{4}$ NP was responsive to both $\mathrm{H}_{2} \mathrm{O}_{2}$ and $\mathrm{X}$-ray. Under X-ray irradiation, the NP generated $\mathrm{CuI}$ sites to serve as a Fenton-like catalyst to decompose overexpressed TME $\mathrm{H}_{2} \mathrm{O}_{2}$ into cytotoxic $\bullet \mathrm{OH}$. Meanwhile, the Fenton-like reaction was limited within normal tissues and organs due to lower $\mathrm{H}_{2} \mathrm{O}_{2}$ level compared to that at the tumor. This TME responsive Fenton-like catalyst ensured the radiosentization in hypoxic tumors but not in normal cells.

\section{Combination of Fenton reaction and gas therapy}

It is well known that some gases perform as signal molecules in vivo that influence many pathophysiological processes such as cancer. Therefore, controllable gas release and tumor-targeted gas delivery is highly desired to avoid the risk of poisoning normal tissues and organs, and to amplify their cancer therapeutic effect [225].

In a study using $\mathrm{Fe}_{1-\mathrm{x}} \mathrm{S}$ NPs, the increased temperature induced by NIR light irradiation prompted Fenton reaction-mediated $\bullet \mathrm{OH}$ generation [226]. In addition, these NPs produced $\mathrm{H}_{2} \mathrm{~S}$ gas in the acidic $(\mathrm{pH}=6.5) \mathrm{TME}$, which suppressed the enzyme activity of cytochrome $\mathrm{c}$ oxidase to inhibit the tumor growth. Both in vitro and in vivo results demonstrated that the $\mathrm{H}_{2} \mathrm{~S}$-mediated gas therapy and Fenton reaction-mediated CDT produced a synergistically enhanced antitumor performance, thereby opening up a new method for gas-mediated cancer treatment. In another study, the released $\mathrm{H}_{2} \mathrm{~S}$ gas produced extra suppression on the intracellular catalase activity of cancer cells to induce the accumulation of $\mathrm{H}_{2} \mathrm{O}_{2}$ that facilitated Fenton reaction-mediated ROS generation [227].

Nitric oxide (NO) is another signal molecule exhibiting multiple antitumor activities [228]. Therefore, one study incorporated a GSH-sensitive NO donor into the 
iron-based nanoscale coordination polymer (NCP) [229]. The high level of GSH in tumor cells triggered the specific release of $\mathrm{NO}$ in situ. Meanwhile, $\mathrm{Fe}^{2+}$-mediated Fenton reaction at the tumor generate cytotoxic $\bullet \mathrm{OH}$ for $\mathrm{CDT}$. In addition, the Haber-Weiss reaction between $\mathrm{Fe}^{2+}$ with $\mathrm{H}_{2} \mathrm{O}_{2}$ produced plenty of $\bullet \mathrm{O}_{2}$, which further reacted with $\mathrm{NO}$ to generate $\mathrm{ONOO}^{-}$, which was more cytotoxic than - $\mathrm{O}_{2}{ }^{-}$or NO.

Though carbon monoxide (CO) poisoning is harmful to human life, the controllable release and tumor targeted delivery are allow its use as an antitumor agent. In one study, in order to apply metal carbonyl complexes in an antitumor agent, the iron pentacarbonyl $\left(\mathrm{Fe}(\mathrm{CO})_{5}\right)$ was incorporated inside an $\mathrm{Au}$ nanocage under an oxygenfree atmosphere [230]. The $\mathrm{Fe}(\mathrm{CO})_{5}$ formed an iron oxide shell on the nanocage surface under aerobic conditions to avoid the leakage and oxidation of the caged $\mathrm{Fe}(\mathrm{CO})_{5}$. The resulting NPs could be activated under NIR light irradiation to generate $\mathrm{CO}$ and iron ions, triggering $\mathrm{CO}-$ mediated gas therapy and iron ion-mediated CDT. The generated $\mathrm{CO}$ and iron ions exhibited excellent synergistically enhanced antitumor effects.

\section{Diagnosis and monitoring of cancer therapy}

Cancer theranostics, an approach that integrates diagnosis and treatment, has been a hot research topic of late [231]. Various imaging modalities can be combined with various therapies to form tumor-targeted multifunctional nanoprobes that aim at improving the identification of malignant tumors while also having a significant treatment effect [232].

In addition to inducing the death of tumor cells, Fenton and Fenton-like reactions be applied for diagnosing cancer and monitoring treatment response to guide therapies. Towards this end, various Fenton and
Fenton-like-based nanosensors have been adapted for use with different imaging modalities including magnetic resonance imaging (MRI), computed tomography (CT), and photoacoustic imaging (PAI) (Fig. 7) [233, 234].

\section{MRI-guided cancer theranostics}

Owing to its superior sensitivity, high spatial resolution, and non-invasive and radiation-free characteristics, MRI has been widely used in clinical diagnosis [235]. In MRI, the atomic nuclear magnetization signal is reconstructed and converted into two-/three-dimensional images which are used for monitoring in vivo therapeutic performance [236]. To improve signal enhancement at the tumor site, TME-responsive NPs are beneficial [237].

The combination of MRI and cancer therapy has been demonstrated as an effective theranostic strategy. Recently, tumor-responsive PEGylated antiferromagnetic pyrite $\left(\mathrm{FeS}_{2}\right)$ NPs were developed to generate an enhanced MRI signal [238]. The $\mathrm{FeS}_{2}$-PEG NPs promoted the Fenton reaction after entering the tumor cells, which not only led to the production of toxic ROS but also allowed $\mathrm{H}_{2} \mathrm{O}_{2}$ content in the tumor area to be monitored via $\mathrm{T} 1$ and $\mathrm{T} 2$ signal enhancement, thus enabling MRI monitoring of therapeutic performance. In addition, the localized heat generated by $\mathrm{FeS}_{2}$-PEG NPs accelerated the intratumoral Fenton reactivity and achieved a synergetic PTT/CDT effect. This MRI-guided synergetic nanoplatform opens up a new direction for anticancer theranostics.

In another study, to enhance the sensitivity of MRI, switchable MRI-guided core-shell-structured $\mathrm{Fe}_{5} \mathrm{C}_{2} @$ $\mathrm{Fe}_{3} \mathrm{O}_{4}$ NPs with a $\mathrm{Fe}_{5} \mathrm{C}_{2}$ core and a $\mathrm{Fe}_{3} \mathrm{O}_{4}$ shell were fabricated [239]. Compared with $\mathrm{Fe}_{3} \mathrm{O}_{4} \mathrm{NPs}$, the $\mathrm{Fe}_{5} \mathrm{C}_{2} @ \mathrm{Fe}_{3} \mathrm{O}_{4}$ NPs exhibited high magnetization and discharged ferrous ions more effectively in acidic TME. The high magnetic

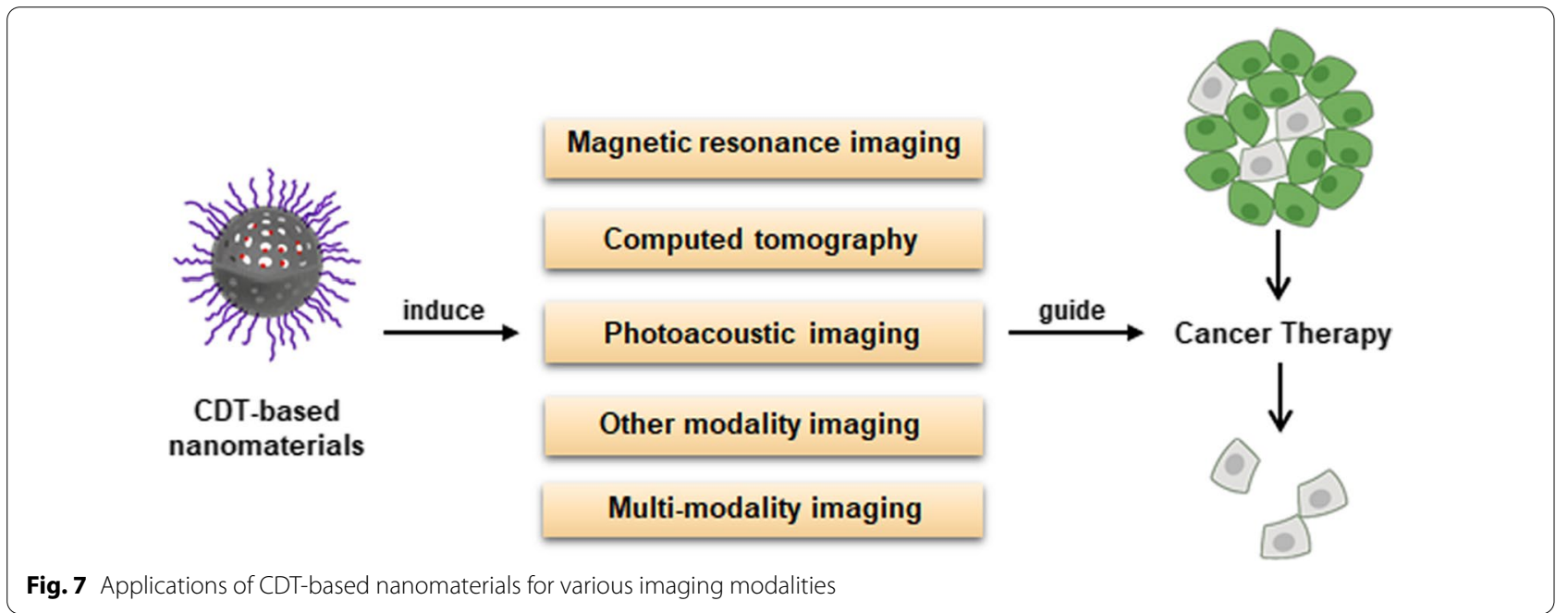


property of $\mathrm{Fe}_{5} \mathrm{C}_{2} @ \mathrm{Fe}_{3} \mathrm{O}_{4} \mathrm{NPs}$ benefited the visualization of tumor aggregation via T2-weighted MRI and magnetic targeting. Both in vitro and in vivo studies demonstrated effective ROS generation and tumor orientation, exhibiting enhanced therapeutic efficacy and low toxicity. Besides, the ionization of $\mathrm{Fe}_{5} \mathrm{C}_{2} @ \mathrm{Fe}_{3} \mathrm{O}_{4}$ NPs in the acidic TME reduced the T2 signal, while the ferrous ions release increased the T1 signal in MRI, which provided enhanced MRI-guided cancer therapy for tumor treatment. The $\mathrm{Fe}_{5} \mathrm{C}_{2} @ \mathrm{Fe}_{3} \mathrm{O}_{4}$ NPs provided an effective strategy for specific cancer therapy guided further by MRI.

To overcome the biological barriers of drug delivery, in one study, a precise tumor-targeting nanozyme $\left(\mathrm{Ag}_{2} \mathrm{~S} @\right.$ $\mathrm{Fe}_{2} \mathrm{C}$-DSPE-PEG-iRGD) was rationally prepared for enhanced cancer therapy [240]. This nanozyme displayed efficient intracellular uptake, intense fluorescence, and high level of ROS production in cancer cells. Moreover, this nanozyme realized high-resolution tumor monitoring in tumor-bearing mice, including superior fluorescence imaging in NIR-II and high-sensitivity MRI, which was beneficial for tumor vascular normalization. Besides, the antitumor effect of $\mathrm{Ag}_{2} \mathrm{~S} @ \mathrm{Fe}_{2} \mathrm{C}-\mathrm{DSPE}-\mathrm{PEG}$-iRGD was enhanced in vivo when combined with bevacizumabinduced tumor vascular normalization. In addition, a high-degree of $\mathrm{Ag}_{2} \mathrm{~S} @ \mathrm{Fe}_{2} \mathrm{C}$-DSPE-PEG-iRGD ( 90\%) could be rapidly excreted from the mice within 14 days, promoting the clinical application of the nanozyme. Hence, the combination of tumor vascular normalization and imaging-guided nanozymes may accelerate the development and clinical applications of nanomedicines.

\section{CT-guided cancer theranostics}

Owing to its high efficiency and high resolution as well as its low cost, CT has been a widely used non-invasive clinical imaging technique [241]. Although CT exhibits a much higher resolution than several other imaging strategies, it remains difficult to distinguish small changes in tissue over time. In order to enhance the accuracy of disease diagnosis, various CT contrast agents have been designed and developed. The commonly used CT contrast agents in clinic are small molecule iodides; however, the toxicity and short circulation time limit their further application [242]. The development of nanosized contrast agents can effectively improve the diagnostic efficacy and reduce the side effects of contrast agents. Besides iodinecontaining NPs, some heavy metal-based NPs (gold, bismuth, tantalum and lanthanide, etc.) are promising as $\mathrm{CT}$ contrast agents, exhibiting obvious advantages for the visualization imaging of blood vessels and tumors [243].

Because of their high- $Z$ atoms, Au NPs with good biocompatibility and simple synthesis strategy are widely used as a contract agent to enhance CT imaging [244]. To develop a versatile nanoplatform for tumor theranostics, in one study, a novel Au@Prussian blue (Au@PB) nanocubes (NCs) was constructed via the templates method, and then DOX was subsequently encapsulated into the $\mathrm{Au} @ \mathrm{~PB}$ NCs [245]. The in vitro and in vivo experiments demonstrated that the DOX-Au@PB NCs exhibited synergistic effects on tumor growth inhibition. Besides, owing to the excellent X-ray attenuation coefficient of $\mathrm{Au}$, the Au@PB NCs displayed higher CT imaging efficiency $\left(\sim 27.13 \mathrm{HU} \cdot \mathrm{mL} \cdot \mathrm{mg}^{-1}\right)$ than the reported CT agents. This study provides a potential strategy for CT-guided tumor therapy.

In another study, a nanocomposite $\left(\mathrm{Fe}_{3} \mathrm{O}_{4} @ \mathrm{PDA} @\right.$ BSA- $\mathrm{Bi}_{2} \mathrm{~S}_{3}$ ) that was composed of $\mathrm{Fe}_{3} \mathrm{O}_{4}$, polydopamine, bovine serum albumin and $\mathrm{Bi}_{2} \mathrm{~S}_{3}$ was designed for MRI/ CT monitored CDT/PTT combination therapy [173]. In this formulation, the stability and biocompatibility of the NPs were rendered by BSA coating. Meanwhile, the $\mathrm{Fe}_{3} \mathrm{O}_{4}$ NPs not only triggered Fenton reactions and produced highly cytotoxic $\bullet \mathrm{OH}$ for tumor therapy, but also acted as the MRI contrast agent for precise cancer diagnosis. Besides, the $\mathrm{Bi}_{2} \mathrm{~S}_{3}$ component exhibited outstanding photothermal transducing ability and $\mathrm{CT}$ imaging capacity. Besides, the high T2-relaxation time of $\mathrm{Fe}_{3} \mathrm{O}_{4}$ improved the MRI contrast, while the high X-ray attenuation coefficient of $\mathrm{Bi}$ enhanced the CT contrast, thereby facilitating the precise monitoring and synergistic tumor therapy. This work displays a feasible strategy to construct a composite nanoplatform for tumor theranostics.

\section{PAI-guided cancer theranostics}

Owing to its outstanding fine spatial resolution and deep tissue penetration, PAI is a promising imaging modality in clinical cancer diagnosis [246]. In PAI, the pulsed laser radiation energy is absorbed by the contrast agent and converted into an acoustic signal, and then the signal is measured and images are constructed by a scanning transducer [247]. The development of nanomaterials as PAI contrast agents with high sensitivities and optimal NIR absorption is crucial to PAI applications.

By decorating the 2,2'-azino-bis (3-ethylbenzothiazoline-6-sulfonic acid) (ABTS) on the surface of graphene quantum dot nanozyme (GQDzyme) and then camouflaging with FA conjugated natural erythrocyte membranes, a novel exosome-like GQDzyme/ABTS vesicle was developed as an in vivo $\mathrm{H}_{2} \mathrm{O}_{2}$-sensitive PAI agent in the treatment of nasopharyngeal carcinoma in one study [248]. In the presence of $\mathrm{H}_{2} \mathrm{O}_{2}$, ABTS was effectively oxidized by the peroxidase-like activity of GQDzyme. The achieved oxidized ABTS displayed strong NIR absorbance, and the GQDzyme/ABTS NP showed to be a promising catalytic PAI contrast agent with high sensitivity to $\mathrm{H}_{2} \mathrm{O}_{2}$ in the cancer cells. Attractively, the lysosomal escape of the nanozyme vesicles promoted their 
interactions with $\mathrm{H}_{2} \mathrm{O}_{2}$ in cancer cells. Due to the photothermal properties and optical absorption of ABTS, PA signal was selectively triggered in the cancer cells with overexpressed $\mathrm{H}_{2} \mathrm{O}_{2}$ based on the peroxidase-like activity of GQDzyme. In addition, GQDzyme acted as nanocarriers for delivery and tracking drugs, exhibiting optimal stealth ability and biocompatibility for long blood circulation time. Overall, the GQDzyme/ABTS-based nanozyme vesicle was shown to be a promising PAI contrast agent for non-invasive tumor imaging.

In another study, to effectively exterminate tumors, biocompatible ferrous phosphide nanorods (FP NRs) was constructed under the NIR-II laser illumination, exhibiting high photothermal conversion efficiency [249]. Owing to their excellent photothermal conversion efficiency $(56.6 \%)$ and traverse relaxivity $\left(277.79 \mathrm{~mm}^{-1} \mathrm{~s}^{-1}\right)$, the FP NRs acted as optimal PAI and MRI agents, achieving dual-mode imaging guided enhanced combination therapeutic efficacy of CDT and PTT. The in vitro and in vivo experiments exhibited that the FR NRs could efficiently induce the death of cancer cells and completely exterminate tumor. The metallic phosphide-based NRs could realize deep tissue penetration under NIR-II laser irradiation and ultrasound stimuli for enhancing the antitumor effect via PAI/MRI monitoring, which provides an ideal strategy for developing multifunctional Fenton nanoplatform in future clinical applications.

\section{Other imaging modality-guided cancer theranostics}

Surface-enhanced Raman scattering (SERS) can provide molecular fingerprint information in various cells and tissues [250]. SERS possesses remarkable advantages, including being non-invasive and having ultrahigh specificity and resolution, and resistance to autofluorescence and photobleaching [251]. In an interesting study, paraaminothiophenol (PATP) and hemin were decorated on gold NP (Au@PATP/Hemin) to detect.OH, $\mathrm{O}^{2 \cdot-}$, ROO., and ${ }^{1} \mathrm{O}_{2}$ directly, and $\mathrm{H}_{2} \mathrm{O}_{2}$ indirectly [252]. $\mathrm{H}_{2} \mathrm{O}_{2}$ was converted into $\cdot \mathrm{OH}$ via hemin-catalyzed Fenton reaction, and PATP reacted with $\bullet \mathrm{OH}, \mathrm{O}^{2 \cdot-}$, ROO $\cdot$ or ${ }^{1} \mathrm{O}_{2}$ by a radical oxidant coupling reaction to form 4,4'-dimercaptoazobenzene (DMAB), eliciting new Raman peaks for quantitative detection. The nanoprobes were sensitive and quantitative, showing promise to monitor tumor development and inflammation progression, and guide therapies.

The capture and inactivation of circulating tumor cells (CTCs) in blood vessels have been regarded as a promising strategy to inhibit tumor metastasis [253]. Thus, in one study, an all-in-one nanoplatform was prepared as a signal probe and CDT agent by integrating magnetic MOF (magMOF) NPs with $\mathrm{TiO}_{2}$ nanotube arrays (TiNTs) [254]. The magMOF NPs were constructed by encapsulating $\mathrm{Fe}_{3} \mathrm{O}_{4}$ with a MIL-100(Fe) shell, and then the GOD was loaded into the magMOF NPs. The gluconic acid generated by GOD enhanced TME acidity, therefore prompting the dissolution of MIL-100(Fe) to produce $\mathrm{Fe}^{3+}$, and then effectively improved the cell killing efficiency via the Fenton-like reaction. Attractively, the CTCs were magnetically captured and collected onto TiNTs. TiNT photocatalysis activated the release of $\mathrm{Fe}^{3+}$ and produced exogenous $\cdot \mathrm{OH}$ radicals, which could be measured by pulse voltammetry and TiNTs as the electrode. The intensities of differential pulse voltammetry were correlated with CTC numbers ranging from 2 to 5000 cell $\mathrm{mL}^{-1}$. This material provides a novel method for constructing multifunctional chips for CTC capture and early tumor diagnosis.

\section{Multi-modality imaging-guided cancer theranostics}

Precisely locating the tumor site and achieving wholebody visualization based on multimodal imaging have garnered extensive research attention for accurate and efficient antitumor therapy [255]. In one investigation, pure phase bismuth ferrite nanocatalysts (BFO NCs) were prepared for multimodal imaging-guided Fenton effect against malignant tumors [256]. The prepared BFO NCs showed excellent physiological stability and biocompatibility in the blood circulation. Interestingly, the external ultrasound assistance enhanced the ROS generation of BFO NCs, owing to the partial grievous turbulence of cavitation bubbles triggered by ultrasound, thereby promoting the transfer efficacy of the Fenton reagents. Meanwhile, the BFO NCs exhibited superior fluorescence intensity within the NIR-II laser. Besides, the high $\mathrm{X}$-ray attenuation coefficient $\left(5.74 \mathrm{~cm}^{2} / \mathrm{kg}\right.$ at $\left.100 \mathrm{kV}\right)$ and intrinsic magnetic performance of $\mathrm{Bi}$ rendered $\mathrm{BFO}$ $\mathrm{NCs}$ an excellent contrast agent for $\mathrm{CT}$ imaging and MRI. According to the in vitro and in vivo results, the $\mathrm{BFO}$ NCs effectively inhibited tumor growth under the external ultrasound assistance, which was precisely monitored by fluorescence imaging, CT, and MRI. Overall, the BFO NCs presented multimodality imaging capacity and enhanced Fenton therapeutic effect, offering a promising prospect for precise and non-invasive antitumor therapy.

In the recent years, lanthanide-based downconversion NPs (DCNPs) have attracted attention because of their unique characteristics, including high stability, long luminescence lifetimes, low photobleaching, and precisely controlled size [257]. To achieve high-resolution realtime tumor observation and whole-body visualization, biodegradable copper/manganese silicate nanospherecoated lanthanide-doped NPs (LDNPs@CMCNs) were developed for trimodal imaging (NIR-II, MRI, and CT) guided CDT/PDT combination therapy in one study [258]. The $\mathrm{Yb}^{3+} / \mathrm{Er}^{3+} / \mathrm{Tm}^{3+}$ were doped in the core and 
$\mathrm{Yb}^{3+} / \mathrm{Ce}^{3+}$ in the shell, enabling the ultraefficient upconversion and downconversion emissions of LDNPs upon NIR light excitation. In the hypoxic tumor, the GSHresponsive CMSNs were degraded and released $\mathrm{Mn}^{2+}$ and $\mathrm{Cu}^{+}$ions for Fenton-like $\cdot \mathrm{OH}$ generation. The $\mathrm{Ce}^{3+}$ and $\mathrm{Er}^{3+}$ were doped in the shell and core of LDNPs, respectively, allowing NIR-II imaging. In addition, lanthanide-doped DCNPs allowed T1 MRI and CT imaging. The TME-responsive release of $\mathrm{Mn}^{2+}$, together with self-amplified trimodal bioimaging (NIR-II luminescence imaging, MRI, and CT) makes this approach greatly promising for highly efficient tumor theranostics.

Lastly, in one study, using biodegradable manganese carbonate NPs, the release of $\mathrm{Mn}^{2+}$ and $\mathrm{CO}_{2}$ gas can be triggered by acidic TME and the released $\mathrm{Mn}^{2+}$ and $\mathrm{CO}_{2}$ can allow for MR and ultrasound imaging of tumors, respectively [259].

\section{Conclusions and outlook}

In recent years, many studies have described innovative strategies to treat cancer on the basis of Fenton and Fenton-like reactions. This review summarizes the latest developments in Fenton and Fenton-like reactions by analyzing the purpose and mechanism of Fenton and Fenton-like reaction-based nanomaterials. Fenton and Fenton-like reactions can adequately exert their potential when combined with other therapeutic strategies, providing specific, efficient, and safe protocols for cancer treatment. Fenton and Fenton-like reaction-based nanomaterials can also be used for accurate tumor diagnosis and for monitoring tumor growth and guiding the therapy of cancers in the clinic using different imaging modalities such as MRI, CT, and PAI.

There has been significant progress in the development of Fenton and Fenton-like reaction-based nanomaterials; however, there are some problems which need to be solved in order for them to be used clinically. (i) The stability, biocompatibility, and biosafety of Fenton and Fenton-like agents need to be improved. Ultrasmall or biodegradable CDT-based nanomaterials which can be removed from the body and which exhibit a rapid metabolism can achieve better clinical safety. And relative to inorganic nanomaterials, organic molecules are more degradable and some of them also exhibit the potential of triggering Fenton and Fenton-like reactions. Therefore, the exploration of organic molecules with properties of Fenton and Fenton-like reactions may provide extra opportunities to discover biocompatible Fenton and Fenton-like agents. (ii) The traditionally understood mechanism of the Fenton and Fenton-like reactions may not adequately explain their reactions in a complicated physiological system. More attention should be paid to monitor in situ Fenton reactions and Fenton-like reactions process via on-line characterization techniques, thereby optimizing their antitumor efficacy and enhancing their clinical applications. (iii) Fenton and Fenton-like reactions can generate $\mathrm{O}_{2}$ to alleviate the tumor hypoxia, which is a main restriction in clinical radiotherapy. However, the exploration of their combination with other therapeutic strategies is still lacking. In addition, in improve therapeutic efficacy, CDT-based combination therapy with genetic or molecular methodologies should also be explored. (iv) The TME responsive agents of Fenton and Fenton-like reactions have exhibited improved specificity, efficacy, and safety for tumor therapy. However, there remains an urgent need to design personalized TME responsive agents for different tumors microenvironments, which will benefit their clinical translation.

Although Fenton and Fenton-like reactions-mediated synergistic strategies for cancer therapy face several challenges, the clinical translation of Fenton and Fenton-like reactions-based nanomedicines are still promising, especially after their current drawbacks have been addressed in the future.

\section{Acknowledgements}

Not applicable.

\section{Authors' contributions}

$J X, C D$ and OA wrote and revised the manuscript, FA, CW and $M Z$ conceived the idea, revised and corrected the manuscript, JX prepared graphical section. All the authors have read and approved the final manuscript.

\section{Funding}

This work was supported by the National Natural Science Foundation of China (51903201), China Postdoctoral Science Foundation Grant (2019M653660), and Fundamental Research Funds for the Central Universities (xzy012019077). OA was partially supported through the NIH/NCI Cancer Center Support Grant P30 CA008748.

\section{Declarations}

Consent for publication

All authors agree to be published.

Competing interests

The authors declare no conflict of interest, financial or otherwise.

\section{Author details}

${ }^{1}$ Institute of Medical Engineering, Department of Biophysics, School of Basic Medical Science, Health Science Center, Xi'an Jiaotong University, No. 76 Yanta West Road, Xi'an, Shaanxi 710061, People's Republic of China. ${ }^{2}$ Department of Radiology, Memorial Sloan Kettering Cancer Center, New York, NY 10065, USA. ${ }^{3}$ Department of Pharmacology, School of Pharmacy, Nantong University, 226000 Nantong, Jiangsu, People's Republic of China.

Received: 25 March 2021 Accepted: 13 June 2021

Published online: 28 June 2021

\section{References \\ 1. Miller KD, Nogueira L, Mariotto AB, Rowland JH, Yabroff KR, Alfano CM, Jemal A, Kramer JL, Siegel RL. Cancer treatment and survivorship}


statistics, 2019. CA Cancer J Clin. 2019;69(5):363-85. https://doi.org/10. 3322/caac.21565.

2. Sang W, Zhang Z, Dai Y, Chen X. Recent advances in nanomaterialbased synergistic combination cancer immunotherapy. Chem Soc Rev. 2019:48(14):3771-810. https://doi.org/10.1039/C8CS00896E.

3. Chen Q, Chen J, Yang Z, Xu J, Xu L, Liang C, Han X, Liu Z. Nanoparticleenhanced radiotherapy to trigger robust cancer immunotherapy. Adv Mater. 2019;31(10):1802228. https://doi.org/10.1002/adma.201802228.

4. Lo P-C, Rodríguez-Morgade MS, Pandey RK, Ng DKP, Torres T, Dumoulin F. The unique features and promises of phthalocyanines as advanced photosensitisers for photodynamic therapy of cancer. Chem Soc Rev. 2020:49(4):1041-56. https://doi.org/10.1039/C9CS00129H.

5. Du C, Zhou M, Jia F, Ruan L, Lu H, Zhang J, Zhu B, Liu X, Chen J, Chai Z, Hu Y. D-arginine-loaded metal-organic frameworks nanoparticles sensitize osteosarcoma to radiotherapy. Biomaterials. 2021. https://doi. org/10.1016/j.biomaterials.2020.120642.

6. Zhu Y, Yu X, Thamphiwatana SD, Zheng Y, Pang Z. Nanomedicines modulating tumor immunosuppressive cells to enhance cancer immunotherapy. Acta Pharm Sin B. 2020;10(11):2054-74. https://doi.org/10. 1016/..apsb.2020.08.010.

7. Blanco E, Shen H, Ferrari M. Principles of nanoparticle design for overcoming biological barriers to drug delivery. Nat Biotechnol. 2015;33(9):941-51. https://doi.org/10.1038/nbt.3330.

8. Vasan N, Baselga J, Hyman DM. A view on drug resistance in cancer. Nature. 2019;575(7782):299-309. https://doi.org/10.1038/ s41586-019-1730-1.

9. Yao Z, Zhang B, Liang T, Ding J, Min Q, Zhu JJ. Promoting oxidative stress in cancer starvation therapy by site-specific startup of hyaluronic acid-enveloped dual-catalytic nanoreactors. ACS Appl Mater Interfaces. 2019;11(21):18995-9005. https://doi.org/10.1021/acsami.9b06034.

10. Wang D, Zhou J, Chen R, Shi R, Xia G, Zhou S, Liu Z, Zhang N, Wang $\mathrm{H}$, Guo Z, Chen Q. Magnetically guided delivery of DHA and Fe ions for enhanced cancer therapy based on $\mathrm{pH}$-responsive degradation of DHA-loaded Fe $\mathrm{O}_{4} @ \mathrm{C} @ \mathrm{MIL}-100(\mathrm{Fe})$ nanoparticles. Biomaterials. 2016;107:88-101. https://doi.org/10.1016/..biomaterials.2016.08.039.

11. Li Y, Zhao P, Gong T, Wang H, Jiang X, Cheng H, Liu Y, Wu Y, Bu W. Redox dyshomeostasis strategy for hypoxic tumor therapy based on dnazyme-loaded electrophilic zifs. Angew Chem Int Ed. 2020;59(50):2253743. https://doi.org/10.1002/anie.202003653.

12. Min H, Qi Y, Zhang Y, Han X, Cheng K, Liu Y, Liu H, Hu J, Nie G, Li Y. A graphdiyne oxide-based iron sponge with photothermally enhanced tumor-specific fenton chemistry. Adv Mater. 2020;32(31):2000038. https://doi.org/10.1002/adma.202000038.

13. Lin J, He T, Yuan Y, Jiang C, Blum NT, He J, Huang P. Light-triggered transformable ferrous ion delivery system for photothermal primed chemodynamic therapy. Angew Chem Int Ed. 2021;60(11):6047-54. https://doi.org/10.1002/anie.202015379.

14. Liu Y, Jiang Y, Zhang M, Tang Z, He M, Bu W. Modulating hypoxia via nanomaterials chemistry for efficient treatment of solid tumors. Acc Chem Res. 2018;51(10):2502-11. https://doi.org/10.1021/acs.accounts. 8 b00214.

15. Liu M-D, Guo D-K, Zeng R-Y, Ye J-J, Wang S-B, Li C-X, Sun Y-X, Cheng S-X, Zhang $X$-Z. Yolk-shell structured nanoflowers induced intracellular oxidative/thermal stress damage for cancer treatment. Adv Funct Mater. 2020;30(51):2006098. https://doi.org/10.1002/adfm.202006098.

16. Chen Q, Liu X, Chen J, Zeng J, Cheng Z, Liu Z. A self-assembled albumin-based nanoprobe for in vivo ratiometric photoacoustic ph imaging. Adv Mater. 2015;27(43):6820-7. https://doi.org/10.1002/adma. 201503194.

17. Lin H, Chen Y, Shi J. Nanoparticle-triggered in situ catalytic chemical reactions for tumour-specific therapy. Chem Soc Rev. 2018;47(6):193858. https://doi.org/10.1039/c7cs00471k.

18. Niu X, Liu Y, Li X, Wang W, Yuan Z. Nir light-driven $\mathrm{Bi}_{2} \mathrm{Se}_{3}$-based nanoreactor with "three in one" hemin-assisted cascade catalysis for synergetic cancer therapy. Adv Funct Mater. 2020;30(52):2006883. https://doi.org/ 10.1002/adfm.202006883.

19. Chen Q, Shan X, Shi S, Jiang C, Li T, Wei S, Zhang X, Sun G, Liu J. Tumor microenvironment-responsive polydopamine-based core/shell nanoplatform for synergetic theranostics. J Mater Chem B. 2020;8(18):405666. https://doi.org/10.1039/D0TB00248H.
20. Goldstein S, Meyerstein D, Czapski G. The fenton reagents. Free Radic Biol Med. 1993;15(4):435-45. https://doi.org/10.1016/0891-5849(93) 90043-t.

21. Walling C. Intermediates in the reactions of fenton type reagents. Acc Chem Res. 1998;31(4):155-7. https://doi.org/10.1021/ar9700567.

22. Ni K, Lan G, Lin W. Nanoscale metal-organic frameworks generate reactive oxygen species for cancer therapy. ACS Cent Sci. 2020;6(6):861-8. https://doi.org/10.1021/acscentsci.0c00397.

23. Ma Z, Zhang M, Jia X, Bai J, Ruan Y, Wang C, Sun X, Jiang X. Fe'll -doped two-dimensional $\mathrm{C}_{3} \mathrm{~N}_{4}$ nanofusiform: a new $\mathrm{O}_{2}$-evolving and mitochondria-targeting photodynamic agent for MRI and enhanced antitumor therapy. Small. 2016;12(39):5477-87. https://doi.org/10.1002/smll.20160 1681.

24. Span PN, Bussink J. Biology of hypoxia. Semin Nucl Med. 2015;45(2):101-9. https://doi.org/10.1053/j.semnuclmed.2014.10.002.

25. Zhou M, Xie Y, Xu S, Xin J, Wang J, Han T, Ting R, Zhang J, An F. Hypoxiaactivated nanomedicines for effective cancer therapy. Eur J Med Chem. 2020;195:112274. https://doi.org/10.1016/i.ejmech.2020.112274.

26. Shi B, Yan QL, Tang J, Cin K, Zhang JC, Zhu Y, Xu G, Wang RC, Chen J, Gao W, Zhu TL, Shi JY, Fan CH, Zhao CC, Tian H. Hydrogen sulfide-activatable second near-infrared fluorescent nanoassemblies for targeted photothermal cancer therapy. Nano Lett. 2018;18(10):6411-6. https://doi.org/ 10.1021/acs.nanolett.8b02767.

27. Piao W, Hanaoka K, Fujisawa T, Takeuchi S, Komatsu T, Ueno T, Terai T, Tahara T, Nagano T, Urano Y. Development of an azo-based photosensitizer activated under mild hypoxia for photodynamic therapy. J Am Chem Soc. 2017;139(39):13713-9. https://doi.org/10.1021/jacs.7b05019.

28. Alsaab HO, Sau S, Alzhrani RM, Cheriyan VT, Polin LA, Vaishampayan U, Rishi AK, Iyer AK. Tumor hypoxia directed multimodal nanotherapy for overcoming drug resistance in renal cell carcinoma and reprogramming macrophages. Biomaterials. 2018;183:280-94. https://doi.org/10. 1016/j.biomaterials.2018.08.053.

29. Jiao Y, Li W-L, Xu J-F, Wang G, Li J, Wang Z, Zhang X. A supramolecularly activated radical cation for accelerated catalytic oxidation. Angew Chem Int Ed. 2016;55(31):8933-7. https://doi.org/10.1002/anie.20160 3182.

30. Li Y, Mei T, Han S, Han T, Sun Y, Zhang H, An F. Cathepsin B-responsive nanodrug delivery systems for precise diagnosis and targeted therapy of malignant tumors. Chin Chem Lett. 2020;31(12):3027-40. https://doi. org/10.1016/j.cclet.2020.05.027.

31. Zheng P, Liu Y, Chen J, Xu W, Li G, Ding J. Targeted pH-responsive polyion complex micelle for controlled intracellular drug delivery. Chin Chem Lett. 2020;31(5):1178-82. https://doi.org/10.1016/j.cclet.2019.12. 001.

32. Yu W, Shevtsov M, Chen X, Gao H. Advances in aggregatable nanoparticles for tumor-targeted drug delivery. Chin Chem Lett. 2020;31(6):136674. https://doi.org/10.1016/j.cclet.2020.02.036.

33. Duan L-Y, Wang Y-J, Liu J-W, Wang Y-M, Li N, Jiang J-H. Tumor-selective catalytic nanosystem for activatable theranostics. Chem Commun. 2018;54(59):8214-7. https://doi.org/10.1039/C8CC03922D.

34. Sun X, Zhang G, Du R, Xu R, Zhu D, Qian J, Bai G, Yang C, Zhang Z, Zhang X, Zou D, Wu Z. A biodegradable $\mathrm{MnSiO}_{3} @ \mathrm{Fe}_{3} \mathrm{O}_{4}$ nanoplatform for dual-mode magnetic resonance imaging guided combinatorial cancer therapy. Biomaterials. 2019;194:151-60. https://doi.org/10.1016/j. biomaterials.2018.12.004.

35. Xiao J, Zhang G, Xu R, Chen H, Wang H, Tian G, Wang B, Yang C, Bai G, Zhang Z, Yang H, Zhong K, Zou D, Wu Z. A pH-responsive platform combining chemodynamic therapy with limotherapy for simultaneous bioimaging and synergistic cancer therapy. Biomaterials. 2019;216: 119254. https://doi.org/10.1016/.biomaterials.2019.119254.

36. Fan J-X, Peng M-Y, Wang H, Zheng H-R, Liu Z-L, Li C-X, Wang X-N, Liu $X-H$, Cheng S-X, Zhang X-Z. Biomedical materials: engineered bacterial bioreactor for tumor therapy via fenton-like reaction with localized $\mathrm{H}_{2} \mathrm{O}_{2}$ generation. Adv Mater. 2019;31(16):1970119. https://doi.org/10. 1002/adma.201970119.

37. Finkel T. Signal transduction by reactive oxygen species in non-phagocytic cells. J Leukoc Biol. 1999;65(3):337-40. https://doi.org/10.1002/jlb. 65.3.337.

38. Gupta SC, Hevia D, Patchva S, Park B, Koh W, Aggarwal BB. Upsides and downsides of reactive oxygen species for cancer: the roles of reactive oxygen species in tumorigenesis, prevention, and therapy. Antioxid 
Redox Signal. 2012;16(11):1295-322. https://doi.org/10.1089/ars.2011. 4414.

39. Valko M, Rhodes CJ, Moncol J, Izakovic M, Mazur M. Free radicals, metals and antioxidants in oxidative stress-induced cancer. Chem Biol Interact. 2006;160(1):1-40. https://doi.org/10.1016/j.cbi.2005.12.009.

40. Fu S, Yang R, Zhang L, Liu W, Du G, Cao Y, Xu Z, Cui H, Kang Y, Xue P. Biomimetic CoO@AuPt nanozyme responsive to multiple tumor microenvironmental clues for augmenting chemodynamic therapy. Biomaterials. 2020;257: 120279. https://doi.org/10.1016/j.biomaterials. 2020.120279 .

41. Duan H, Guo H, Zhang R, Wang F, Liu Z, Ge M, Yu L, Lin H, Chen Y. Two-dimensional silicene composite nanosheets enable exogenous/ endogenous-responsive and synergistic hyperthermia-augmented catalytic tumor theranostics. Biomaterials. 2020;256: 120206. https://doi. org/10.1016/j.biomaterials.2020.120206.

42. Meng Y, Chen Y, Zhu J, Qi Y, Ding J, Zhou W. Polarity control of DNA adsorption enabling the surface functionalization of $\mathrm{CuO}$ nanozymes for targeted tumor therapy. Mater Horiz. 2021. https://doi.org/10.1039/ DOMH01372B.

43. Han Y, Gao S, Zhang Y, Ni Q, Li Z, Liang XJ, Zhang J. Metal-based nanocatalyst for combined cancer therapeutics. Bioconjug Chem. 2020;31(5):1247-58. https://doi.org/10.1021/acs.bioconjchem.0c00194.

44. Liu Y, Zhen W, Jin L, Zhang S, Sun G, Zhang T, Xu X, Song S, Wang Y, Liu J, Zhang H. All-in-one theranostic nanoagent with enhanced reactive oxygen species generation and modulating tumor microenvironment ability for effective tumor eradication. ACS Nano. 2018;12(5):4886-93. https://doi.org/10.1021/acsnano.8b01893.

45. Liu C, Cao Y, Cheng Y, Wang D, XU T, Su L, Zhang X, Dong H. An open source and reduce expenditure ROS generation strategy for chemodynamic/photodynamic synergistic therapy. Nat Commun. 2020;11(1):1735. https://doi.org/10.1038/s41467-020-15591-4.

46. Chang M, Wang M, Wang M, Shu M, Ding B, Li C, Pang M, Cui S, Hou Z, Lin J. A multifunctional cascade bioreactor based on hollow-structured $\mathrm{Cu}_{2} \mathrm{MoS}_{4}$ for synergetic cancer chemo-dynamic therapy/starvation therapy/phototherapy/immunotherapy with remarkably enhanced efficacy. Adv Mater. 2019;31(51):1905271. https://doi.org/10.1002/ adma.201905271.

47. Xiao S, Lu Y, Feng M, Dong M, Cao Z, Zhang X, Chen Y, Liu J. Multifunctional $\mathrm{FeS}_{2}$ theranostic nanoparticles for photothermal-enhanced chemodynamic/photodynamic cancer therapy and photoacoustic imaging. Chem Eng J. 2020;396: 125294. https://doi.org/10.1016/j.cej. 2020.125294.

48. Sun L, Xu Y, Gao Y, Huang X, Feng S, Chen J, Wang X, Guo L, Li M, Meng X, Zhang J, Ge J, An X, Ding D, Luo Y, Zhang Y, Jiang Q, Ning $X$. Synergistic amplification of oxidative stress-mediated antitumor activity via liposomal dichloroacetic acid and MOF-Fe ${ }^{2+}$. Small. 2019;15(24):1901156. https://doi.org/10.1002/smll.201901156.

49. Zhang J, Yang J, Zuo T, Ma S, Xokrat N, Hu Z, Wang Z, Xu R, Wei Y, Shen Q. Heparanase-driven sequential released nanoparticles for ferroptosis and tumor microenvironment modulations synergism in breast cancer therapy. Biomaterials. 2021;266: 120429. https://doi.org/10.1016/j. biomaterials.2020.120429.

50. Dai Y, Yang Z, Cheng S, Wang Z, Zhang R, Zhu G, Wang Z, Yung BC, Tian R, Jacobson O, Xu C, Ni Q, Song J, Sun X, Niu G, Chen X. Toxic reactive oxygen species enhanced synergistic combination therapy by self-assembled metal-phenolic network nanoparticles. Adv Mater. 2018;30(8):1704877. https://doi.org/10.1002/adma.201704877.

51. Shi L, Hu F, Duan Y, Wu W, Dong J, Meng X, Zhu X, Liu B. Hybrid nanospheres to overcome hypoxia and intrinsic oxidative resistance for enhanced photodynamic therapy. ACS Nano. 2020;14(2):2183-90.

52. Li S, Shang L, Xu B, Wang S, Gu K, Wu Q, Sun Y, Zhang Q, Yang H, Zhang F, Gu L, Zhang T, Liu H. A nanozyme with photo-enhanced dual enzyme-like activities for deep pancreatic cancer therapy. Angew Chem Int Ed. 2019:58(36):12624-31. https://doi.org/10.1002/anie.20190 4751.

53. Du W, Liu T, Xue F, Cai X, Chen $\mathrm{Q}$, Zheng $\mathrm{Y}$, Chen $\mathrm{H}_{\text {. }} \mathrm{Fe}_{3} \mathrm{O}_{4}$ mesocrystals with distinctive magnetothermal and nanoenzyme activity enabling self-reinforcing synergistic cancer therapy. ACS Appl Mater Interfaces. 2020;12(17):19285-94. https://doi.org/10.1021/acsami.0c02465.

54. Dai C, Wang C, Hu R, Lin H, Liu Z, Yu L, Chen Y, Zhang B. Photonic/magnetic hyperthermia-synergistic nanocatalytic cancer therapy enabled by zero-valence iron nanocatalysts. Biomaterials. 2019;219: 119374. https://doi.org/10.1016/j.biomaterials.2019.119374.

55. Zhang Y, Lin L, Liu L, Liu F, Sheng S, Tian H, Chen X. Positive feedback nanoamplifier responded to tumor microenvironments for selfenhanced tumor imaging and therapy. Biomaterials. 2019;216: 119255. https://doi.org/10.1016/j.biomaterials.2019.119255.

56. Lin L-S, Song J, Song L, Ke K, Liu Y, Zhou Z, Shen Z, Li J, Yang Z, Tang W, $\mathrm{Niu} \mathrm{G}$, Yang $\mathrm{H}-\mathrm{H}$, Chen $X$. Simultaneous fenton-like ion delivery and glutathione depletion by $\mathrm{MnO}_{2}$-based nanoagent to enhance chemodynamic therapy. Angew Chem Int Ed. 2018;57(18):4902-6. https://doi. org/10.1002/anie.201712027.

57. Wang H, Bremner DH, Wu K, Gong X, Fan Q, Xie X, Zhang H, Wu J, Zhu L-M. Platelet membrane biomimetic bufalin-loaded hollow $\mathrm{MnO}_{2}$ nanoparticles for MRl-guided chemo-chemodynamic combined therapy of cancer. Chem Eng J. 2020;382: 122848. https://doi.org/10.1016/j.cej. 2019.122848.

58. Jia Q, Ge J, Liu W, Zheng X, Chen S, Wen Y, Zhang H, Wang P. A magnetofluorescent carbon dot assembly as an acidic $\mathrm{H}_{2} \mathrm{O}_{2}$-driven oxygenerator to regulate tumor hypoxia for simultaneous bimodal imaging and enhanced photodynamic therapy. Adv Mater. 2018;30(13):1706090. https://doi.org/10.1002/adma.201706090.

59. Zhao Z, Xu K, Fu C, Liu H, Lei M, Bao J, Fu A, Yu Y, Zhang W. Interfacial engineered gadolinium oxide nanoparticles for magnetic resonance imaging guided microenvironment-mediated synergetic chemodynamic/photothermal therapy. Biomaterials. 2019;219: 119379. https:// doi.org/10.1016/j.biomaterials.2019.119379.

60. Zhu P, Chen Y, Shi J. Nanoenzyme-augmented cancer sonodynamic therapy by catalytic tumor oxygenation. ACS Nano. 2018;12(4):3780-95. https://doi.org/10.1021/acsnano.8b00999.

61. Zhang Y, Cao Y, Gao T, Kuang Y, An Z, Mao Z, He Y, Yan J, Lu Z, Pei R. Tumor microenvironment-responsive and catalytic cascade-enhanced nanocomposite for tumor thermal ablation synergizing with chemodynamic and chemotherapy. ACS Appl Bio Mater. 2020;3(6):3880-93. https://doi.org/10.1021/acsabm.0c00042.

62. Wang C, Cao F, Ruan Y, Jia X, Zhen W, Jiang X. Specific generation of singlet oxygen through the russell mechanism in hypoxic tumors and gsh depletion by Cu-TCPP nanosheets for cancer therapy. Angew Chem Int Ed. 2019;58(29):9846-50. https://doi.org/10.1002/anie.201903981.

63. Wang Y, Song M. Ph-responsive cascaded nanocatalyst for synergistic like-starvation and chemodynamic therapy. Colloids and Surf B Biointerfaces. 2020;192: 111029. https://doi.org/10.1016/j.colsurfb.2020. 111029.

64. Wang X, Zhong X, Lei H, Geng Y, Zhao Q, Gong F, Yang Z, Dong Z, Liu Z, Cheng $\mathrm{L}$. Hollow $\mathrm{Cu}_{2} \mathrm{Se}$ nanozymes for tumor photothermal-catalytic therapy. Chem Mater. 2019;31(16):6174-86. https://doi.org/10.1021/acs. chemmater.9b01958.

65. Ni K, Lan G, Chan C, Quigley B, Lu K, Aung T, Guo N, La Riviere P, Weichselbaum RR, Lin W. Nanoscale metal-organic frameworks enhance radiotherapy to potentiate checkpoint blockade immunotherapy. Nat Commun. 2018;9(1):2351. https://doi.org/10.1038/s41467-018-04703-w.

66. Zhang K, Meng X, Yang Z, Dong H, Zhang X. Enhanced cancer therapy by hypoxia-responsive copper metal-organic frameworks nanosystem. Biomaterials. 2020;258: 120278. https://doi.org/10.1016/j.biomaterials. 2020.120278 .

67. Gilson RC, Black KCL, Lane DD, Achilefu S. Hybrid TiO ${ }_{2}$-ruthenium nano-photosensitizer synergistically produces reactive oxygen species in both hypoxic and normoxic conditions. Angew Chem Int Ed. 2017;56(36):10717-20. https://doi.org/10.1002/anie.201704458.

68. Mei L, Ma D, Gao Q, Zhang X, Fu W, Dong X, Xing G, Yin W, Gu Z, Zhao Y. Glucose-responsive cascaded nanocatalytic reactor with self-modulation of the tumor microenvironment for enhanced chemo-catalytic therapy. Mater Horiz. 2020;7(7):1834-44. https://doi.org/10.1039/ DOMH00105H.

69. Ren S-Z, Wang B, Zhu X-H, Zhu D, Liu M, Li S-K, Yang Y-S, Wang Z-C, Zhu $H$-L. An oxygen self-sufficient core-shell metal-organic frameworkbased smart nanoplatform for enhanced synergistic chemotherapy and photodynamic therapy. ACS Appl Mater Interfaces. 2020;12(22):2466274. https://doi.org/10.1021/acsami.0c08534.

70. Liu P, Wang Y, An L, Tian Q, Lin J, Yang S. Ultrasmall $W_{3-x} @ y$-poly-L-glutamic acid nanoparticles as a photoacoustic imaging and effective photothermal-enhanced chemodynamic therapy 
agent for cancer. ACS Appl Mater Interfaces. 2018;10(45):38833-44. https://doi.org/10.1021/acsami.8b15678.

71. Wang X, Zhong X, Bai L, Xu J, Gong F, Dong Z, Yang Z, Zeng Z, Liu Z, Cheng $\mathrm{L}$. Ultrafine titanium monoxide $\left(\mathrm{TiO}_{1+x}\right)$ nanorods for enhanced sonodynamic therapy. J Am Chem Soc. 2020;142(14):6527-37. https:// doi.org/10.1021/jacs.9b10228.

72. Wang M, Chang M, Chen Q, Wang D, Li C, Hou Z, Lin J, Jin D, Xing B. $\mathrm{Au}_{2} \mathrm{Pt}-\mathrm{PEG}-\mathrm{Ce} 6$ nanoformulation with dual nanozyme activities for synergistic chemodynamic therapy/phototherapy. Biomaterials. 2020;252: 120093. https://doi.org/10.1016/j.biomaterials.2020.120093.

73. Bokare $A D, C$ Choi W. Review of iron-free fenton-like systems for activating $\mathrm{H}_{2} \mathrm{O}_{2}$ in advanced oxidation processes. J Hazard Mater. 2014;275:121-35. https://doi.org/10.1016/j.jhazmat.2014.04.054.

74. Li M, Zhang H, Hou Y, Wang X, Xue C, Li W, Cai K, Zhao Y, Luo Z. Stateof-the-art iron-based nanozymes for biocatalytic tumor therapy. Nanoscale Horiz. 2020;5(2):202-17. https://doi.org/10.1039/C9NHO 0577C.

75. Zhang C, Bu W, Ni D, Zhang S, Li Q, Yao Z, Zhang J, Yao H, Wang Z, Shi J. Synthesis of iron nanometallic glasses and their application in cancer therapy by a localized fenton reaction. Angew Chem Int Ed. 2016;55(6):2101-6. https://doi.org/10.1002/anie.201510031.

76. Liu T, Liu W, Zhang M, Yu W, Gao F, Li C, Wang S-B, Feng J, Zhang X-Z. Ferrous-supply-regeneration nanoengineering for cancer-cell-specific ferroptosis in combination with imaging-guided photodynamic therapy. ACS Nano. 2018;12(12):12181-92. https://doi.org/10.1021/ acsnano.8b05860.

77. Yang WS, SriRamaratnam R, Welsch ME, Shimada K, Skouta R, Viswanathan VS, Cheah JH, Clemons PA, Shamji AF, Clish CB, Brown LM, Girotti AW, Cornish VW, Schreiber SL, Stockwell BR. Regulation of ferroptotic cancer cell death by gpx4. Cell. 2014;156(1-2):317-31. https://doi.org/ 10.1016/j.cell.2013.12.010.

78. Conrad M, Sato H. The oxidative stress-inducible cystine/glutamate antiporter, system $\mathrm{x}_{c}^{-}:$cystine supplier and beyond. Amino Acids. 2012;42(1):231-46. https://doi.org/10.1007/s00726-011-0867-5.

79. Jiang L, Kon N, LiT, Wang SJ, Su T, Hibshoosh H, Baer R, Gu W. Ferroptosis as a p53-mediated activity during tumour suppression. Nature. 2015;520(7545):57-62. https://doi.org/10.1038/nature14344.

80. Wang Y, Yang L, Zhang X, Cui W, Liu Y, Sun Q-R, He Q, Zhao S, Zhang G-A, Wang Y, Chen S. Epigenetic regulation of ferroptosis by $\mathrm{H} 2 \mathrm{~B}$ monoubiquitination and p53. EMBO Rep. 2019;20(7): e47563. https://doi. org/10.15252/embr.201847563.

81. Yang B, Liu Q, Yao X, Zhang D, Dai Z, Cui P, Zhang G, Zheng X, Yu D. FePt@MnO-based nanotheranostic platform with acidity-triggered dual-ions release for enhanced MR imaging-guided ferroptosis chemodynamic therapy. ACS Appl Mater Interfaces. 2019;11(42):38395-404. https://doi.org/10.1021/acsami.9b11353.

82. Zhu J, Dai P, Liu F, Li Y, Qin Y, Yang Q, Tian R, Fan A, Medeiros SDF, Wang $Z$, Zhao Y. Upconverting nanocarriers enable triggered microtubule inhibition and concurrent ferroptosis induction for selective treatment of triple-negative breast cancer. Nano Lett. 2020;20(9):6235-45. https:// doi.org/10.1021/acs.nanolett.0c00502.

83. Sun P, Deng Q, Kang L, Sun Y, Ren J, Qu X. A smart nanoparticleladen and remote-controlled self-destructive macrophage for enhanced chemo/chemodynamic synergistic therapy. ACS Nano. 2020;14(10):13894-904. https://doi.org/10.1021/acsnano.0c06290.

84. Feng L, Liu B, Xie R, Wang D, Qian C, Zhou W, Liu J, Jana D, Yang P, Zhao $Y$. An ultrasmall $\mathrm{SnFe}_{2} \mathrm{O}_{4}$ nanozyme with endogenous oxygen generation and glutathione depletion for synergistic cancer therapy. Adv Funct Mater. 2021;31(5):2006216. https://doi.org/10.1002/adfm.20200 6216.

85. Chen G, Yang Y, Xu Q, Ling M, Lin H, Ma W, Sun R, Xu Y, Liu X, Li N, Yu $Z$, Yu M. Self-amplification of tumor oxidative stress with degradable metallic complexes for synergistic cascade tumor therapy. Nano Lett. 2020;20(11):8141-50. https://doi.org/10.1021/acs.nanolett.0c03127.

86. Chen Y, Huang Y, Zhou S, Sun M, Chen L, Wang J, Xu M, Liu S, Liang K, Zhang Q, Jiang T, Song Q, Jiang G, Tang X, Gao X, Chen J. Tailored chemodynamic nanomedicine improves pancreatic cancer treatment via controllable damaging neoplastic cells and reprogramming tumor microenvironment. Nano Lett. 2020;20(9):6780-90. https://doi.org/10. 1021/acs.nanolett.0c02622.
87. He Y-J, Liu X-Y, Xing L, Wan X, Chang X, Jiang H-L. Fenton reactionindependent ferroptosis therapy via glutathione and iron redox couple sequentially triggered lipid peroxide generator. Biomaterials. 2020;241: 119911. https://doi.org/10.1016/j.biomaterials.2020.119911.

88. Chen Q, Zhou J, Chen Z, Luo Q, XU J, Song G. Tumor-specific expansion of oxidative stress by glutathione depletion and use of a fenton nanoagent for enhanced chemodynamic therapy. ACS Appl Mater Interfaces. 2019;1 1(34):30551-65. https://doi.org/10.1021/acsami.9b093 23.

89. Wang Z, Liu B, Sun Q, Dong S, Kuang Y, Dong Y, He F, Gai S, Yang P. Fusiform-like copper(ii)-based metal-organic framework through relief hypoxia and GSH-depletion co-enhanced starvation and chemodynamic synergetic cancer therapy. ACS Appl Mater Interfaces. 2020;12(15):17254-67. https://doi.org/10.1021/acsami.0c01539.

90. Mei X, Hu T, Wang H, Liang R, Bu W, Wei M. Highly dispersed nanoenzyme triggered intracellular catalytic reaction toward cancer specific therapy. Biomaterials. 2020;258: 120257. https://doi.org/10.1016/j. biomaterials.2020.120257.

91. Zhang L, Wan S-S, Li C-X, Xu L, Cheng H, Zhang X-Z. An adenosine triphosphate-responsive autocatalytic fenton nanoparticle for tumor ablation with self-supplied $\mathrm{H}_{2} \mathrm{O}_{2}$ and acceleration of $\mathrm{Fe}(\mathrm{III}) / \mathrm{Fe}$ (II) conversion. Nano Lett. 2018;18(12):7609-18. https://doi.org/10.1021/acs.nanol ett.8b03178.

92. Wan X, Song L, Pan W, Zhong H, Li N, Tang B. Tumor-targeted cascade nanoreactor based on metal-organic frameworks for synergistic ferroptosis-starvation anticancer therapy. ACS Nano. 2020;14(9):11017-28. https://doi.org/10.1021/acsnano.9b07789.

93. Li WP, Su CH, Chang YC, Lin YJ, Yeh CS. Ultrasound-induced reactive oxygen species mediated therapy and imaging using a fenton reaction activable polymersome. ACS Nano. 2016;10(2):2017-27. https://doi.org/ 10.1021/acsnano.5b06175.

94. Han $\mathrm{Y}$, Ouyang J, Li Y, Wang F, Jiang J-H. Engineering $\mathrm{H}_{2} \mathrm{O}_{2}$ self-supplying nanotheranostic platform for targeted and imaging-guided chemodynamic therapy. ACS Appl Mater Interfaces. 2020;12(1):288-97. https:// doi.org/10.1021/acsami.9b18676.

95. Fan J-X, Peng M-Y, Wang H, Zheng H-R, Liu Z-L, Li C-X, Wang X-N, Liu $X-H$, Cheng $S-X$, Zhang $X$ - Z. Engineered bacterial bioreactor for tumor therapy via fenton-like reaction with localized $\mathrm{H}_{2} \mathrm{O}_{2}$ generation. $\mathrm{Adv}$ Mater. 2019;31(16):1808278. https://doi.org/10.1002/adma.201808278.

96. Qian X, Han X, Yu L, Xu T, Chen Y. Manganese-based functional nanoplatforms: nanosynthetic construction, physiochemical property, and theranostic applicability. Adv Funct Mater. 2020;30(3):1907066. https:// doi.org/10.1002/adfm.201907066.

97. Singh N, Savanur MA, Srivastava S, D'Silva P, Mugesh G. A redox modulatory $\mathrm{Mn}_{3} \mathrm{O}_{4}$ nanozyme with multi-enzyme activity provides efficient cytoprotection to human cells in a parkinson's disease model. Angew Chem Int Ed. 2017;56(45):14267-71. https://doi.org/10.1002/anie.20170 8573.

98. Ding B, Zheng P, Ma PA, Lin J. Manganese oxide nanomaterials: synthesis, properties, and theranostic applications. Adv Mater. 2020;32(10):1905823. https://doi.org/10.1002/adma.201905823.

99. Zhang D, Zhao YX, Gao YJ, Gao FP, Fan YS, Li XJ, Duan ZY, Wang H. Antibacterial and in vivo tumor treatment by reactive oxygen species generated by magnetic nanoparticles. J Mater Chem B. 2013;1 (38):5100-7. https://doi.org/10.1039/c3tb20907e.

100. Feng L, Xie R, Wang C, Gai S, He F, Yang D, Yang P, Lin J. Magnetic targeting, tumor microenvironment-responsive intelligent nanocatalysts for enhanced tumor ablation. ACS Nano. 2018;12(11):11000-12. https:// doi.org/10.1021/acsnano.8b05042.

101. Cao S, Fan J, Sun W, Li F, Li K, Tai X, Peng X. A novel Mn-Cu bimetallic complex for enhanced chemodynamic therapy with simultaneous glutathione depletion. Chem Commun. 2019;55(86):12956-9. https:// doi.org/10.1039/c9cc06040e.

102. Gawande MB, Goswami A, Felpin FX, Asefa T, Huang X, Silva R, Zou X, Zboril R, Varma RS. Cu and Cu-based nanoparticles: synthesis and applications in catalysis. Chem Rev. 2016;116(6):3722-811. https://doi. org/10.1021/acs.chemrev.5b00482.

103. Su Z, Li J, Zhang D, Ye P, Li H, Yan Y. Novel flexible fenton-like catalyst: Unique $\mathrm{CuO}$ nanowires arrays on copper mesh with high efficiency across a wide ph range. Sci Total Environ. 2019;647:587-96. https://doi. org/10.1016/j.scitotenv.2018.08.022. 
104. Hu R, Fang Y, Huo M, Yao H, Wang C, Chen Y, Wu R. Ultrasmall Cu $\mathrm{Cu}_{2-x} \mathrm{~S}$ nanodots as photothermal-enhanced fenton nanocatalysts for synergistic tumor therapy at NIR-II biowindow. Biomaterials. 2019;206:10114. https://doi.org/10.1016/j.biomaterials.2019.03.014.

105. Tang W, Gao H, Ni D, Wang Q, Gu B, He X, Peng W. Bovine serum albumin-templated nanoplatform for magnetic resonance imaging-guided chemodynamic therapy. J Nanobiotechnol. 2019;17(1):68. https://doi. org/10.1186/s12951-019-0501-3.

106. Ma B, Wang S, Liu F, Zhang S, Duan J, Li Z, Kong Y, Sang Y, Liu H, Bu $W$, Li L. Self-assembled copper-amino acid nanoparticles for in situ glutathione "and" $\mathrm{H}_{2} \mathrm{O}_{2}$ sequentially triggered chemodynamic therapy. J Am Chem Soc. 2019;141(2):849-57. https://doi.org/10.1021/jacs.8b087 14.

107. Lu X, Gao S, Lin H, Yu L, Han Y, Zhu P, Bao W, Yao H, Chen Y, Shi J. Bioinspired copper single-atom catalysts for tumor parallel catalytic therapy. Adv Mater. 2020;32(36):2002246. https://doi.org/10.1002/adma.20200 2246

108. Dong $Z$, Yang $Z$, Hao Y, Feng L. Fabrication of $\mathrm{H}_{2} \mathrm{O}_{2}$-driven nanoreactors for innovative cancer treatments. Nanoscale. 2019;11(35):16164-86. https://doi.org/10.1039/c9nr04418c

109. Ju Y, Dong B, Yu J, Hou Y. Norganic nanomaterials for imaging-guided cancer therapy. Nano Today. 2019;26:108-22. https://doi.org/10.1016/j. nantod.2019.03.006

110. Zhao S, Li Y, Liu Q, Li S, Cheng Y, Cheng C, Sun Z, Du Y, Butch CJ, Wei H. An orally administered $\mathrm{CeO}_{2} @$ montmorillonite nanozyme targets inflammation for inflammatory bowel disease therapy. Adv Funct Mater. 2020;30(45):2004692. https://doi.org/10.1002/adfm.202004692.

111. Li Y, Jia R, Lin H, Sun X, Qu F. Synthesis of $\mathrm{MoSe}_{2} / \mathrm{CoSe}_{2}$ nanosheets for nir-enhanced chemodynamic therapy via synergistic in-situ $\mathrm{H}_{2} \mathrm{O}_{2}$ production and activation. Adv Funct Mater. 2021;31 (8):2008420. https:// doi.org/10.1002/adfm.202008420.

112. Xie Z, Liang S, Cai X, Ding B, Huang S, Hou Z, Ma P, Cheng Z, Lin J. O 2 -Cu/ZIF-8@Ce6/ZIF-8@F127 composite as a tumor microenvironment-responsive nanoplatform with enhanced photo-/chemodynamic antitumor efficacy. ACS Appl Mater Interfaces. 2019;11(35):31671-80. https://doi.org/10.1021/acsami.9b10685.

113. Wan X, Zhong H, Pan W, Li Y, Chen Y, Li N, Tang B. Programmed release of dihydroartemisinin for synergistic cancer therapy using a $\mathrm{CaCO}_{3}$ mineralized metal-organic framework. Angew Chem Int Ed. 2019;58(40):14134-9. https://doi.org/10.1002/anie.201907388.

114. Fang C, Deng Z, Cao G, Chu Q, Wu Y, Li X, Peng X, Han G. Co-ferrocene MOF/glucose oxidase as cascade nanozyme for effective tumor therapy. Adv Funct Mater. 2020;30(16):1910085. https://doi.org/10 1002/adfm.201910085.

115. Zhang J, Zuo T, Liang X, Xu Y, Yang Y, Fang T, Li J, Chen D, Shen Q. Fenton-reaction-stimulative nanoparticles decorated with a reactiveoxygen-species (ROS)-responsive molecular switch for ros amplification and triple negative breast cancer therapy. J Mater Chem B. 2019;7(45):7141-51. https://doi.org/10.1039/c9tb01702j.

116. Xiao Y, An F-F, Chen J, Xiong S, Zhang X-H. The impact of light irradiation timing on the efficacy of nanoformula-based photo/chemo combination therapy. J Mater Chem B. 2018;6(22):3692-702. https://doi. org/10.1039/C8TB00427G

117. Xiao Y-F, An F-F, Chen J-X, Yu J, Tao W-W, Yu Z, Ting R, Lee C-S, Zhang $X-H$. The nanoassembly of an intrinsically cytotoxic near-infrared dye for multifunctionally synergistic theranostics. Small. 2019;15(38):1903121. https://doi.org/10.1002/smll.201903121.

118. Tzogani K, Penttilä K, Lapveteläinen T, Hemmings R, Koenig J, Freire J, Márcia S, Cole S, Coppola P, Flores B, Barbachano Y, Roige S-D, Pignatti F. EMA review of daunorubicin and cytarabine encapsulated in liposomes (Vyxeos, CPX-351) for the treatment of adults with newly diagnosed, therapy-related acute myeloid leukemia or acute myeloid leukemia with myelodysplasia-related changes. Oncologist. 2020;25:e1414-20. https://doi.org/10.1634/theoncologist.2019-0785.

119. Bao Y-W, Hua X-W, Zeng J, Wu F-G. Bacterial template synthesis of multifunctional nanospindles for glutathione detection and enhanced cancer-specific chemo-chemodynamic therapy. Research. 2020. https://doi.org/10.34133/2020/9301215.

120. Fu J, Li T, Yang Y, Jiang L, Wang W, Fu L, Zhu Y, Hao Y. Activatable nanomedicine for overcoming hypoxia-induced resistance to chemotherapy and inhibiting tumor growth by inducing collaborative apoptosis and ferroptosis in solid tumors. Biomaterials. 2021;268:120537. https://doi. org/10.1016/j.biomaterials.2020.120537.

121. Cao R, Sun W, Zhang Z, Li X, Du J, Fan J, Peng X. Protein nanoparticles containing $\mathrm{Cu}(\mathrm{II})$ and DOX for efficient chemodynamic therapy via selfgeneration of $\mathrm{H}_{2} \mathrm{O}_{2}$. Chin Chem Lett. 2020;31(12):3127-30. https://doi. org/10.1016/j.cclet.2020.06.031.

122. Guo Y, Zhang X, Sun W, Jia H-R, Zhu Y-X, Zhang X, Zhou N, Wu F-G. Metal-phenolic network-based nanocomplexes that evoke ferroptosis by apoptosis: promoted nuclear drug influx and reversed drug resistance of cancer. Chem Mater. 2019;31(24):10071-84. https://doi.org/10. 1021/acs.chemmater.9b03042.

123. Mu M, Wang Y, Zhao S, Li X, Fan R, Mei L, Wu M, Zou B, Zhao N, Han B, Guo G. Engineering a pH/glutathione-responsive tea polyphenol nanodevice as an apoptosis/ferroptosis-inducing agent. ACS Appl Bio Mater. 2020;3(7):4128-38. https://doi.org/10.1021/acsabm.0c00225.

124. Fu LH, Hu YR, Qi C, He T, Jiang S, Jiang C, He J, Qu J, Lin J, Huang P. Biodegradable manganese-doped calcium phosphate nanotheranostics for traceable cascade reaction-enhanced anti-tumor therapy. ACS Nano. 2019;13(12):13985-94. https://doi.org/10.1021/acsnano.9b05836.

125. Wang $S$, Yu G, Wang Z, Jacobson O, Lin L-S, Yang W, Deng H, He Z, Liu Y, Chen Z-Y, Chen X. Enhanced antitumor efficacy by a cascade of reactive oxygen species generation and drug release. Angew Chem Int Ed. 2019;58(41):14758-63. https://doi.org/10.1002/anie.201908997.

126. Wang S, Li F, Qiao R, Hu X, Liao H, Chen L, Wu J, Wu H, Zhao M, Liu J, Chen R, Ma X, Kim D, Sun J, Davis TP, Chen C, Tian J, Hyeon T, Ling D. Arginine-rich manganese silicate nanobubbles as a ferroptosis-inducing agent for tumor-targeted theranostics. ACS Nano. 2018;12(12):12380-92. https://doi.org/10.1021/acsnano.8b06399.

127. Shen Z, Liu T, Li Y, Lau J, Yang Z, Fan W, Zhou Z, Shi C, Ke C, Bregadze VI, Mandal SK, Liu Y, Li Z, Xue T, Zhu G, Munasinghe J, Niu G, Wu A, Chen X. Fenton-reaction-acceleratable magnetic nanoparticles for ferroptosis therapy of orthotopic brain tumors. ACS Nano. 2018;12(11):11355-65. https://doi.org/10.1021/acsnano.8b06201.

128. Ma PA, Xiao H, Yu C, Liu J, Cheng Z, Song H, Zhang X, Li C, Wang J, Gu $Z$, Lin J. Enhanced cisplatin chemotherapy by iron oxide nanocarriermediated generation of highly toxic reactive oxygen species. Nano Lett. 2017;17(2):928-37. https://doi.org/10.1021/acs.nanolett.6b04269.

129. Ren Z, Sun S, Sun R, Cui G, Hong L, Rao B, Li A, Yu Z, Kan Q, Mao Z. A metal-polyphenol-coordinated nanomedicine for synergistic cascade cancer chemotherapy and chemodynamic therapy. Adv Mater. 2020;32(6): e1 1906024. https://doi.org/10.1002/adma.201906024.

130. Chen Y, Yao Y, Zhou X, Liao C, Dai X, Liu J, Yu Y, Zhang S. Cascade-reaction-based nanodrug for combined chemo/starvation/chemodynamic therapy against multidrug-resistant tumors. ACS Appl Mater Interfaces. 2019;11(49):46112-23. https://doi.org/10.1021/acsami.9b15848.

131. Ding B, Shao S, Jiang F, Dang P, Sun C, Huang S, Ma PA, Jin D, Kheraif $\mathrm{AAA}$, Lin J. $\mathrm{MnO}_{2}$-disguised upconversion hybrid nanocomposite: an ideal architecture for tumor microenvironment-triggered $\mathrm{ucl}$ / mr bioimaging and enhanced chemodynamic therapy. Chem Mater. 2019;31(7):2651-60. https://doi.org/10.1021/acs.chemmater.9b00893.

132. Wang S, Wang Z, Yu G, Zhou Z, Jacobson O, Liu Y, Ma Y, Zhang F, Chen $Z Y$, Chen $X$. Tumor-specific drug release and reactive oxygen species generation for cancer chemo/chemodynamic combination therapy. Adv Sci. 2019;6(5):1801986. https://doi.org/10.1002/advs.201801986.

133. Ding $Y, X u H, X u C$, Tong Z, Zhang $S$, Bai $Y$, Chen $Y, X u$ Q, Zhou L, Ding $H$, Sun Z, Yan S, Mao Z, Wang W. A nanomedicine fabricated from gold nanoparticles-decorated metal-organic framework for cascade chemo/ chemodynamic cancer therapy. Adv Sci. 2020;7(17):2001060. https:// doi.org/10.1002/advs.202001060.

134. Ke W, Li J, Mohammed F, Wang Y, Tou K, Liu X, Wen P, Kinoh H, Anraku $Y$, Chen H, Kataoka K, Ge Z. Therapeutic polymersome nanoreactors with tumor-specific activable cascade reactions for cooperative cancer therapy. ACS Nano. 2019;13(2):2357-69. https://doi.org/10.1021/acsna no.8b09082.

135. Guo Y, Jia H-R, Zhang X, Zhang X, Sun Q, Wang S-Z, Zhao J, Wu F-G. A glucose/oxygen-exhausting nanoreactor for starvation- and hypoxiaactivated sustainable and cascade chemo-chemodynamic therapy. Small. 2020;16(31):2000897. https://doi.org/10.1002/smll.202000897.

136. Cheng K, Ling C, Gu D, Gao Z, Li Y, An P, Zhang Y, You C, Zhang R, Sun B. Multimodal therapies: glucose oxidase-triggered tumor starvationinduced synergism with enhanced chemodynamic therapy and 
chemotherapy. New J Chem. 2020;44(4):1524-36. https://doi.org/10 1039/C9NJ05469C.

137. Dong Z, Feng L, Chao Y, Hao Y, Chen M, Gong F, Han X, Zhang R, Cheng L, Liu Z. Amplification of tumor oxidative stresses with liposomal fenton catalyst and glutathione inhibitor for enhanced cancer chemotherapy and radiotherapy. Nano Lett. 2019;19(2):805-15. https://doi.org/10. 1021/acs.nanolett.8b03905.

138. Liang R, Chen Y, Huo M, Zhang J, Li Y. Sequential catalytic nanomedicine augments synergistic chemodrug and chemodynamic cancer therapy. Nanoscale Horiz. 2019;4(4):890-901. https://doi.org/10.1039/C9NHO 0008A.

139. Gao W, Wei S, Li Z, Li L, Zhang X, Li C, Gao D. Nano magnetic liposomesencapsulated parthenolide and glucose oxidase for ultra-efficient synergistic antitumor therapy. Nanotechnology. 2020;31(35): 355104. https://doi.org/10.1088/1361-6528/ab92c8.

140. Yang B, Ding L, Yao H, Chen Y, Shi J. A metal-organic framework (MOF) fenton nanoagent-enabled nanocatalytic cancer therapy in synergy with autophagy inhibition. Adv Mater. 2020;32(12):1907152. https://doi. org/10.1002/adma.201907152.

141. Agostinis P, Berg K, Cengel KA, Foster TH, Girotti AW, Gollnick SO, Hahn SM, Hamblin MR, Juzeniene A, Kessel D, Korbelik M, Moan J, Mroz P, Nowis D, Piette J, Wilson BC, Golab J. Photodynamic therapy of cancer: an update. CA Cancer J Clin. 2011;61(4):250-81. https://doi.org/10 3322/caac.20114.

142. Zhou Z, Song J, Nie L, Chen X. Reactive oxygen species generating systems meeting challenges of photodynamic cancer therapy. Chem Soc Rev. 2016:45(23):6597-626. https://doi.org/10.1039/c6cs00271d.

143. Shi L, Hu F, Duan Y, Wu W, Dong J, Meng X, Zhu X, Liu B. Hybrid nanospheres to overcome hypoxia and intrinsic oxidative resistance for enhanced photodynamic therapy. ACS Nano. 2020;14(2):2183-90. https://doi.org/10.1021/acsnano.9b09032.

144. Wu S, Qiao Z, Li Y, Hu S, Ma Y, Wei S, Zhang L. Persistent luminescence nanoplatform with fenton-like catalytic activity for tumor multimodal imaging and photoenhanced combination therapy. ACS Appl Mater Interfaces. 2020;12(23):25572-80. https://doi.org/10.1021/acsami.0c044 38.

145. Choi Y, Chang JE, Jheon S, Han SJ, Kim JK. Enhanced production of reaCtive oxygen species in Hela cells under concurrent lowdose carboplatin and photofrin(r) photodynamic therapy. Oncol Rep. 2018;40(1):339-45. https://doi.org/10.3892/or.2018.6415.

146. Cioloboc D, Kennedy C, Boice EN, Clark ER, Kurtz DM Jr. Trojan horse for light-triggered bifurcated production of singlet oxygen and fentonreactive iron within cancer cells. Biomacromol. 2018;19(1):178-87. https://doi.org/10.1021/acs.biomac.7b01433.

147. Zhao Y, Wang J, Cai X, Ding P, Lv H, Pei R. Metal-organic frameworks with enhanced photodynamic therapy: synthesis, erythrocyte membrane camouflage, and aptamer-targeted aggregation. ACS Appl Mater Interfaces. 2020;12(21):23697-706. https://doi.org/10.1021/acsami. 0c04363.

148. Wang C, Zhao P, Jiang $D$, Yang G, Xue Y, Tang Z, Zhang M, Wang H, Jiang X, Wu Y, Liu Y, Zhang W, Bu W. In situ catalytic reaction for solving the aggregation of hydrophobic photosensitizers in tumor. ACS Appl Mater Interfaces. 2020;12(5):5624-32. https://doi.org/10.1021/acsami.9b215 89.

149. Hou H, Huang X, Wei G, Xu F, Wang Y, Zhou S. Fenton reaction-assisted photodynamic therapy for cancer with multifunctional magnetic nanoparticles. ACS Appl Mater Interfaces. 2019;1 1(33):29579-92. https://doi. org/10.1021/acsami.9b09671.

150. Kim J, Cho HR, Jeon H, Kim D, Song C, Lee N, Choi SH, Hyeon T. Continuous $\mathrm{O}_{2}$-evolving $\mathrm{MnFe}_{2} \mathrm{O}_{4}$ nanoparticle-anchored mesoporous silica nanoparticles for efficient photodynamic therapy in hypoxic cancer J Am Chem Soc. 2017;139(32):10992-5. https://doi.org/10.1021/jacs. 7 b05559.

151. Wang D, Wu H, Lim WQ, Phua SZF, Xu P, Chen Q, Guo Z, Zhao Y. A mesoporous nanoenzyme derived from metal-organic frameworks with endogenous oxygen generation to alleviate tumor hypoxia for significantly enhanced photodynamic therapy. Adv Mater. 2019;31 (27): e1901893. https://doi.org/10.1002/adma.201901893.

152. Wang T, Zhang H, Han Y, Liu H, Ren F, Zeng J, Sun Q, Li Z, Gao M. Light-enhanced $\mathrm{O}_{2}$-evolving nanoparticles boost photodynamic therapy to elicit antitumor immunity. ACS Appl Mater Interfaces. 2019;11(18):16367-79. https://doi.org/10.1021/acsami.9b03541.

153. Wang P, Liang C, Zhu J, Yang N, Jiao A, Wang W, Song X, Dong X. Manganese-based nanoplatform as metal ion-enhanced ros generator for combined chemodynamic/photodynamic therapy. ACS Appl Mater Interfaces. 2019;1 1(44):41140-7. https://doi.org/10.1021/acsami.9b166 17.

154. Xu T, Ma Y, Yuan Q, Hu H, Hu X, Qian Z, Rolle JK, Gu Y, Li S. Enhanced ferroptosis by oxygen-boosted phototherapy based on a 2-in-1 nanoplatform of ferrous hemoglobin for tumor synergistic therapy. ACS Nano. 2020;14(3):3414-25. https://doi.org/10.1021/acsnano.9b09426.

155. Li L, Yang Z, Fan W, He L, Cui C, Zou J, Tang W, Jacobson O, Wang Z, Niu G, Hu S, Chen X. In situ polymerized hollow mesoporous organosilica biocatalysis nanoreactor for enhancing ros-mediated anticancer therapy. Adv Funct Mater. 2020;30(4):1907716. https://doi.org/10.1002/ adfm.201907716.

156. Sun S, Chen Q, Tang Z, Liu C, Li Z, Wu A, Lin H. Tumor microenvironment stimuli-responsive fluorescence imaging and synergistic cancer therapy by carbon-dot-Cu ${ }^{2+}$ nanoassemblies. Angew Chem Int Ed. 2020;59(47):21041-8. https://doi.org/10.1002/anie.202007786.

157. Ai X, Hu M, Wang Z, Lyu L, Zhang W, Li J, Yang H, Lin J, Xing B. Enhanced cellular ablation by attenuating hypoxia status and reprogramming tumor-associated macrophages via nir light-responsive upconversion nanocrystals. Bioconjug Chem. 2018;29(4):928-38. https://doi.org/10. 1021/acs.bioconjchem.8b00068.

158. Huang $Y$, Jiang $Y$, Xiao Z, Shen $Y$, Huang $L$, Xu X, Wei G, Xu C, Zhao C. Three birds with one stone: a ferric pyrophosphate based nanoagent for synergetic NIR-triggered photo/chemodynamic therapy with glutathione depletion. Chem Eng J. 2020;380:122369. https://doi.org/ 10.1016/j.cej.2019.122369.

159. Liu Y, Bhattarai P, Dai Z, Chen X. Photothermal therapy and photoacoustic imaging via nanotheranostics in fighting cancer. Chem Soc Rev. 2019;48(7):2053-108. https://doi.org/10.1039/c8cs00618k.

160. Chen B, Zhang C, Wang W, Chu Z, Zha Z, He X, Zhou W, Liu T, Wang $\mathrm{H}$, Qian $\mathrm{H}$. Ultrastable AgBiS, hollow nanospheres with cancer cell-specific cytotoxicity for multimodal tumor therapy. ACS Nano. 2020;14(11):14919-28. https://doi.org/10.1021/acsnano.0c04370.

161. Chang M, Hou Z, Jin D, Zhou J, Wang M, Wang M, Shu M, Ding B, Li C, Lin J. Colorectal tumor microenvironment-activated bio-decomposable and metabolizable $\mathrm{Cu}_{2} \mathrm{O} @ \mathrm{CaCO}_{3}$ nanocomposites for synergistic oncotherapy. Adv Mater. 2020;32(43):2004647. https://doi.org/10.1002/ adma.202004647.

162. Zhang L, Wang D, Yang K, Sheng D, Tan B, Wang Z, Ran H, Yi H, Zhong Y, Lin $\mathrm{H}$, Chen Y. Mitochondria-targeted artificial "nano-RBCs" for amplified synergistic cancer phototherapy by a single NIR irradiation. Adv Sci. 2018:5(8):1800049. https://doi.org/10.1002/advs.201800049.

163. An F, Yang Z, Zheng M, Mei T, Deng G, Guo P, Li Y, Sheng R. Rationally assembled albumin/indocyanine green nanocomplex for enhanced tumor imaging to guide photothermal therapy. J Nanobiotechnol. 2020;18(1):49. https://doi.org/10.1186/s12951-020-00603-8.

164. Li S, Deng Q, Zhang Y, Li X, Wen G, Cui X, Wan Y, Huang Y, Chen J, Liu Z, Wang L, Lee C-S. Rational design of conjugated small molecules for superior photothermal theranostics in the NIR-II biowindow. Adv Mater. 2020;32(33):2001146. https://doi.org/10.1002/adma.202001146.

165. Meng X, Chen L, Lv R, Liu M, He N, Wang Z. A metal-phenolic networkbased multifunctional nanocomposite with $\mathrm{pH}$-responsive ROS generation and drug release for synergistic chemodynamic/photothermal/ chemo-therapy. J Mater Chem B. 2020;8(10):2177-88. https://doi.org/ 10.1039/DOTB00008F.

166. Liu F, Lin L, Zhang Y, Wang Y, Sheng S, Xu C, Tian H, Chen X. A tumormicroenvironment-activated nanozyme-mediated theranostic nanoreactor for imaging-guided combined tumor therapy. Adv mater. 2019;31 (40): e1902885. https://doi.org/10.1002/adma.201902885.

167. Fan L, Xu X, Zhu C, Han J, Gao L, Xi J, Guo R. Tumor catalytic-photothermal therapy with yolk-shell gold@carbon nanozymes. ACS Appl Mater Interfaces. 2018;10(5):4502-11. https://doi.org/10.1021/acsami.7b179 16.

168. Liu G, Zhu J, Guo H, Sun A, Chen P, Xi L, Huang W, Song X, Dong X. $\mathrm{Mo}_{2} \mathrm{C}$-derived polyoxometalate for NIR-Il photoacoustic imagingguided chemodynamic/photothermal synergistic therapy. Angew 
Chem Int Ed. 2019;58(51):18641-6. https://doi.org/10.1002/anie.20191 0815.

169. Guo Q, Wang D, Yang G. Photoacoustic imaging guided photothermal and chemodynamic combined therapy for cancer using "all in one" $W_{18} \mathrm{O}_{49}$ nanorod agent. J Biomed Nanotechnol. 2019;15(10):2090-9. https://doi.org/10.1166/jbn.2019.2832.

170. Chang M, Hou Z, Wang M, Wang M, Dang P, Liu J, Shu M, Ding B, Al Kheraif AA, Li C, Lin J. Cu $\mathrm{MoS}_{4} / \mathrm{Au}$ heterostructures with enhanced catalase-like activity and photoconversion efficiency for primary/metastatic tumors eradication by phototherapy-induced immunotherapy. Small. 2020:16(14):1907146. https://doi.org/10.1002/smll.201907146.

171. He L, Ni Q, Mu J, Fan W, Liu L, Wang Z, Li L, Tang W, Liu Y, Cheng Y, Tang L, Yang Z, Liu Y, Zou J, Yang W, Jacobson O, Zhang F, Huang P, Chen X. Solvent-assisted self-assembly of a metal-organic framework based biocatalyst for cascade reaction driven photodynamic therapy. J Am Chem Soc. 2020;142(14):6822-32. https://doi.org/10.1021/jacs.0c02497.

172. Wu C, Wang S, Zhao J, Liu Y, Zheng Y, Luo Y, Ye C, Huang M, Chen H. Biodegradable Fe(III)@WS,-PVP nanocapsules for redox reaction and tme-enhanced nanocatalytic, photothermal, and chemotherapy. Adv Funct Mater. 2019;29(26):1901722. https://doi.org/10.1002/adfm.20190 1722

173. Luo K, Zhao J, Jia C, Chen Y, Zhang Z, Zhang J, Huang M, Wang S. Integration of $\mathrm{Fe}_{3} \mathrm{O}_{4}$ with $\mathrm{Bi}_{2} \mathrm{~S}_{3}$ for multi-modality tumor theranostics. ACS Appl Mater Interfaces. 2020;12(20):22650-60. https://doi.org/10.1021/ acsami.0c05088.

174. Sun M, Yang D, Fanqi W, Wang Z, Ji H, Liu Z, Gai S, Zhang F, Yang P. SiO $@$ $\mathrm{Cu}_{7} \mathrm{~S}_{4}$ nanotubes for photo/chemodynamic and photo-thermal dualmode synergistic therapy under $808 \mathrm{~nm}$ laser irradiation. J Mater Chem B. 2020;8(26):5707-21. https://doi.org/10.1039/D0TB00696C.

175. She D, Peng S, Liu L, Huang H, Zheng Y, Lu Y, Geng D, Yin B. Biomimic $\mathrm{FeS}_{2}$ nanodrug with hypothermal photothermal effect by clinical approved NIR-II light for augmented chemodynamic therapy. Chem Eng J. 2020;400: 125933. https://doi.org/10.1016/j.cej.2020.125933.

176. Zhao Y, Ding B, Xiao X, Jiang F, Wang M, Hou Z, Xing B, Teng B, Cheng Z, $\mathrm{Ma}$ P, Lin J. Virus-like $\mathrm{Fe}_{3} \mathrm{O}_{4} @ \mathrm{Bi}_{2} \mathrm{~S}_{3}$ nanozymes with resistance-free apoptotic hyperthermia-augmented nanozymitic activity for enhanced synergetic cancer therapy. ACS Appl Mater Interfaces. 2020;12(10):11320-8. https://doi.org/10.1021/acsami.9b20661

177. Kang S, Gil Y-G, Min D-H, Jang H. Nonrecurring circuit nanozymatic enhancement of hypoxic pancreatic cancer phototherapy using speckled Ru-Te hollow nanorods. ACS Nano. 2020;14(4):4383-94. https://doi. org/10.1021/acsnano.9b09974.

178. Wang Y, Li Z, Hu Y, Liu J, Guo M, Wei H, Zheng S, Jiang T, Sun X, Ma Z, Sun Y, Besenbacher F, Chen C, Yu M. Photothermal conversion-coordinated fenton-like and photocatalytic reactions of $\mathrm{Cu}_{2-x} \mathrm{Se}-\mathrm{Au}$ Janus nanoparticles for tri-combination antitumor therapy. Biomaterials. 2020;255: 120167. https://doi.org/10.1016/j.biomaterials.2020.120167.

179. Chen Q, Luo Y, Du W, Liu Z, Zhang S, Yang J, Yao H, Liu T, Ma M, Chen H. Clearable theranostic platform with a $\mathrm{pH}$-independent chemodynamic therapy enhancement strategy for synergetic photothermal tumor therapy. ACS Appl Mater Interfaces. 2019;11(20):18133-44. https://doi. org/10.1021/acsami.9b02905.

180. Nie X, Xia L, Wang HL, Chen G, Wu B, Zeng TY, Hong CY, Wang LH, You $Y Z$. Photothermal therapy nanomaterials boosting transformation of fe(III) into fe(II) in tumor cells for highly improving chemodynamic therapy. ACS Appl Mater Interfaces. 2019;11(35):31735-42. https://doi. org/10.1021/acsami.9b11291.

181. Gu D, An P, He X, Wu H, Gao Z, Li Y, Chen F, Cheng K, Zhang Y, You C, Sun B. A novel versatile yolk-shell nanosystem based on nir-elevated drug release and GSH depletion-enhanced fenton-like reaction for synergistic cancer therapy. Colloids Surf B Biointerfaces. 2020;189: 110810. https://doi.org/10.1016/j.colsurfb.2020.110810.

182. Wang X, Zhong X, Zha Z, He G, Miao Z, Lei H, Luo Q, Zhang R, Liu Z, Cheng L. Biodegradable $\mathrm{CoS}_{2}$ nanoclusters for photothermal-enhanced chemodynamic therapy. Appl Mater Today. 2020;18:100464. https://doi. org/10.1016/j.apmt.2019.100464.

183. Liang R, Li Y, Huo M, Lin H, Chen Y. Triggering sequential catalytic fenton reaction on $2 \mathrm{~d}$ mxenes for hyperthermia-augmented synergistic nanocatalytic cancer therapy. ACS Appl Mater Interfaces. 2019;11(46):4291731. https://doi.org/10.1021/acsami.9b13598.
184. Wang S, Yang L, Cho HY, Chueng STD, Zhang H, Zhang Q, Lee KB. Programmed degradation of a hierarchical nanoparticle with redox and light responsivity for self-activated photo-chemical enhanced chemodynamic therapy. Biomaterials. 2019;224:119498. https://doi.org/ 10.1016/j.biomaterials.2019.119498.

185. Wu F, Zhang Q, Zhang M, Sun B, She Z, Ge M, Lu T, Chu X, Wang Y, Wang J, Zhou N, Li A. Hollow porous carbon coated FeS,-based nanocatalysts for multimodal imaging-guided photothermal, starvation, and triple-enhanced chemodynamic therapy of cancer. ACS Appl Mater Interfaces. 2020;12(9):10142-55. https://doi.org/10.1021/acsami.0c001 70.

186. Lei S, Chen J, Zeng K, Wang M, Ge X. Visual dual chemodynamic/photothermal therapeutic nanoplatform based on superoxide dismutase plus prussian blue. Nano Res. 2019;12(5):1071-82. https://doi.org/10.1007/ s12274-019-2348-1.

187. Chen Y, Li Z-H, Pan P, Hu J-J, Cheng S-X, Zhang X-Z. Tumor-microenvironment-triggered ion exchange of a metal-organic framework hybrid for multimodal imaging and synergistic therapy of tumors. Adv Mater. 2020;32(24):2001452. https://doi.org/10.1002/adma.202001452.

188. Zhang Q, Guo Q, Chen Q, Zhao X, Pennycook SJ, Chen H. Highly efficient 2d NIR-II photothermal agent with fenton catalytic activity for cancer synergistic photothermal-chemodynamic therapy. Adv Sci. 2020;7(7):1902576. https://doi.org/10.1002/advs.201902576.

189. Guan G, Wang X, Li B, Zhang W, Cui Z, Lu X, Zou R, Hu J." Transformed" $\mathrm{Fe}_{3} \mathrm{~S}_{4}$ tetragonal nanosheets: a high-efficiency and body-clearable agent for magnetic resonance imaging guided photothermal and chemodynamic synergistic therapy. Nanoscale. 2018;10(37):17902-11. https://doi.org/10.1039/c8nr06507a.

190. Li M, Lin H, Qu F. FeS @C-ICG-PEG nanostructure with intracellular $\mathrm{O}_{2}$ generation for enhanced photo-dynamic/thermal therapy and imaging. Chem Eng J. 2020;384:123374. https://doi.org/10.1016/j.cej.2019. 123374.

191. Pan C, Ou M, Cheng Q, Zhou Y, Yu Y, Li Z, Zhang F, Xia D, Mei L, Ji X. $Z$-scheme heterojunction functionalized pyrite nanosheets for modulating tumor microenvironment and strengthening photo/chemodynamic therapeutic effects. Adv Funct Mater. 2020;30(3):1906466. https://doi.org/10.1002/adfm.201906466.

192. Liu Y, Zhen W, Wang Y, Liu J, Jin L, Zhang T, Zhang S, Zhao Y, Song S, Li $\mathrm{C}$, Zhu J, Yang Y, Zhang H. One-dimensional $\mathrm{Fe}_{2} \mathrm{P}$ acts as a fenton agent in response to NIR-II light and ultrasound for deep tumor synergetic theranostics. Angew Chem Int Ed. 2019;58(8):2407-12. https://doi.org/ 10.1002/anie.201813702.

193. Zou Y, Chen X, Yang P, Liang G, Yang Y, Gu Z, Li Y. Regulating the absorption spectrum of polydopamine. Sci Adv. 2020;6(36):eabb4696. https:// doi.org/10.1126/sciadv.abb4696.

194. Yang P, Zhang S, Chen X, Liu X, Wang Z, Li Y. Recent developments in polydopamine fluorescent nanomaterials. Mater Horiz. 2020;7(3):74661. https://doi.org/10.1039/C9MH01197H.

195. Wang Y, Huang Q, He X, Chen H, Zou Y, Li Y, Lin K, Cai X, Xiao J, Zhang Q, Cheng Y. Multifunctional melanin-like nanoparticles for bone-targeted chemo-photothermal therapy of malignant bone tumors and osteolysis. Biomaterials. 2018;183:10-9. https://doi.org/10.1016/j.biomaterials. 2018.08.033.

196. An P, Fan F, Gu D, Gao Z, Hossain AMS, Sun B. Photothermal-reinforced and glutathione-triggered in situ cascaded nanocatalytic therapy. J Control Release. 2020;321:734-43. https://doi.org/10.1016/j.jconrel. 2020.03.007.

197. Zhu Y, Xin N, Qiao Z, Chen S, Zeng L, Zhang Y, Wei D, Sun J, Fan H. Novel tumor-microenvironment-based sequential catalytic therapy by Fe(II)engineered polydopamine nanoparticles. ACS Appl Mater Interfaces. 2019;11(46):43018-30. https://doi.org/10.1021/acsami.9b17951.

198. Xu K, Cheng Y, Yan J, Feng Y, Zheng R, Wu X, Wang Y, Song P, Zhang H. Polydopamine and ammonium bicarbonate coated and doxorubicin loaded hollow cerium oxide nanoparticles for synergistic tumor therapy. Nano Res. 2019;12(12):2947-53. https://doi.org/10.1007/ s12274-019-2532-3.

199. Liang S, Deng X, Ma PA, Cheng Z, Lin J. Recent advances in nanomaterial-assisted combinational sonodynamic cancer therapy. Adv Mater. 2020;32(47):2003214. https://doi.org/10.1002/adma.202003214.

200. Pan $X$, Wang H, Wang S, Sun X, Wang L, Wang W, Shen H, Liu H. Sonodynamic therapy (SDT): a novel strategy for cancer nanotheranostics. 
Sci China Life Sci. 2018;61(4):415-26. https://doi.org/10.1007/ s11427-017-9262-X.

201. Wu M, Ding Y, Li L. Recent progress in the augmentation of reactive species with nanoplatforms for cancer therapy. Nanoscale. 2019;11(42):19658-83. https://doi.org/10.1039/c9nr06651a.

202. Guan X, Yin HH, Xu XH, Xu G, Zhang Y, Zhou BG, Yue WW, Liu C, Sun LP, Xu HX, Zhang K. Tumor metabolism-engineered composite nanoplatforms potentiate sonodynamic therapy via reshaping tumor microenvironment and facilitating electron-hole pairs'separation. Adv Funct Mater. 2020;30(27):10. https://doi.org/10.1002/adfm.202000326.

203. Lin X, Song J, Chen X, Yang H. Ultrasound-activated sensitizers and applications. Angew Chem Int Ed. 2020;59(34):14212-33. https://doi. org/10.1002/anie.201906823.

204. Son S, Kim JH, Wang X, Zhang C, Yoon SA, Shin J, Sharma A, Lee MH, Cheng L, Wu J, Kim JS. Multifunctional sonosensitizers in sonodynamic cancer therapy. Chem Soc Rev. 2020;49(11):3244-61. https://doi.org/10. 1039/C9CS00648F.

205. Zhu J, Chu C, Li D, Pang X, Zheng H, Wang J, Shi Y, Zhang Y, Cheng Y, Ren E, Cheng J, Chen X, Liu G. Fe(III)-porphyrin sonotheranostics: a green triple-regulated ros generation nanoplatform for enhanced cancer imaging and therapy. Adv Funct Mater. 2019;29(36):1904056 https://doi.org/10.1002/adfm.201904056.

206. Lin X, Liu S, Zhang X, Zhu R, Chen S, Chen X, Song J, Yang H. An ultrasound activated vesicle of Janus Au-MnO nanoparticles for promoted tumor penetration and sono-chemodynamic therapy of orthotopic liver cancer. Angew Chem Int Ed. 2020;59(4):1682-8. https://doi.org/10. 1002/anie.201912768.

207. Zhong X, Wang X, Cheng L, Tang YA, Zhan G, Gong F, Zhang R, $\mathrm{Hu}$ J, Liu Z, Yang X. GSH-depleted PtCu 3 nanocages for chemodynamic- enhanced sonodynamic cancer therapy. Adv Funct Mater. 2020;30(4):1907954. https://doi.org/10.1002/adfm.201907954.

208. Bai S, Yang N, Wang X, Gong F, Dong Z, Gong Y, Liu Z, Cheng L. Ultrasmall iron-doped titanium oxide nanodots for enhanced sonodynamic and chemodynamic cancer therapy. ACS Nano. 2020;14(11):15119-30. https://doi.org/10.1021/acsnano.0c05235.

209. Chen Q, Chen M, Liu Z. Local biomaterials-assisted cancer immunotherapy to trigger systemic antitumor responses. Chem Soc Rev. 2019;48(22):5506-26. https://doi.org/10.1039/C9CS00271E.

210. Zhang C, Pu K. Molecular and nanoengineering approaches towards activatable cancer immunotherapy. Chem Soc Rev. 2020;49(13):423453. https://doi.org/10.1039/C9CS00773C.

211. Zhang W, Wang F, Hu C, Zhou Y, Gao H, Hu J. The progress and perspective of nanoparticle-enabled tumor metastasis treatment. Acta Pharm Sin B. 2020;10(11):2037-53. https://doi.org/10.1016/j.apsb.2020.07.013.

212. Jiang $Q$, Wang K, Zhang X, Ouyang B, Liu H, Pang Z, Yang W. Platelet membrane-camouflaged magnetic nanoparticles for ferroptosisenhanced cancer immunotherapy. Small. 2020;16(22):e2001704. https://doi.org/10.1002/smll.202001704.

213. Jiang F, Ding B, Liang S, Zhao Y, Cheng Z, Xing B, Ma PA, Lin J. Intelligent $\mathrm{MOS}_{2}-\mathrm{CUO}$ heterostructures with multiplexed imaging and remarkably enhanced antitumor efficacy via synergetic photothermal therapy/chemodynamic therapy/immunotherapy. Biomaterials. 2021;268:120545. https://doi.org/10.1016/j.biomaterials.2020.120545.

214. Ni K, Aung T, Li S, Fatuzzo N, Liang X, Lin W. Nanoscale metal-organic framework mediates radical therapy to enhance cancer immunotherapy. Chem. 2019;5(7):1892-913. https://doi.org/10.1016/j.chempr.2019. 05.013.

215. Hu C, Cai L, Liu S, Liu Y, Zhou Y, Pang M. Copper-doped nanoscale covalent organic polymer for augmented photo/chemodynamic synergistic therapy and immunotherapy. Bioconjug Chem. 2020;31 (6):1661-70. https://doi.org/10.1021/acs.bioconjchem.0c00209.

216. Xu B, Cui Y, Wang W, Li S, Lyu C, Wang S, Bao W, Wang H, Qin M, Liu Z, Wei W, Liu H. Immunomodulation-enhanced nanozyme-based tumor catalytic therapy. Adv Mater. 2020;32(33):2003563. https://doi.org/10. 1002/adma.202003563.

217. Tay ZW, Chandrasekharan P, Chiu-Lam A, Hensley DW, Dhavalikar R, Zhou XY, Yu EY, Goodwill PW, Zheng B, Rinaldi C, Conolly SM. Magnetic particle imaging-guided heating in vivo using gradient fields for arbitrary localization of magnetic hyperthermia therapy. ACS Nano. 2018;12(4):3699-713. https://doi.org/10.1021/acsnano.8b00893.
218. Shen J, Rees TW, Zhou Z, Yang S, Ji L, Chao H. A mitochondria-targeting magnetothermogenic nanozyme for magnet-induced synergistic cancer therapy. Biomaterials. 2020;251:120079. https://doi.org/10.1016/j. biomaterials.2020.120079.

219. Ying W, Zhang Y, Gao W, Cai X, Wang G, Wu X, Chen L, Meng Z, Zheng $Y$, Hu B, Lin X. Hollow magnetic nanocatalysts drive starvation-chemodynamic-hyperthermia synergistic therapy for tumor. ACS Nano. 2020;14(8):9662-74. https://doi.org/10.1021/acsnano.0c00910.

220. Liu X, Yan B, Li Y, Ma X, Jiao W, Shi K, Zhang T, Chen S, He Y, Liang $X-J$, Fan $\mathrm{H}$. Graphene oxide-grafted magnetic nanorings mediated magnetothermodynamic therapy favoring reactive oxygen speciesrelated immune response for enhanced antitumor efficacy. ACS Nano. 2020;14(2):1936-50. https://doi.org/10.1021/acsnano.9b08320.

221. Hauser AK, Mitov MI, Daley EF, McGarry RC, Anderson KW, Hilt JZ. Targeted iron oxide nanoparticles for the enhancement of radiation therapy. Biomaterials. 2016;105:127-35. https://doi.org/10.1016/j.bioma terials.2016.07.032.

222. Lv B, Zhang H, Zheng X, Wang H, Ge W, Ren Y, Tan Z, Zhang M, Tang Z, Liu Y, Zhang L, Wu Y, Jiang X, Bu W. Structure-oriented catalytic radiosensitization for cancer radiotherapy. Nano Today. 2020;35:100988. https://doi.org/10.1016/j.nantod.2020.100988.

223. Gong T, Li Y, Lv B, Wang H, Liu Y, Yang W, Wu Y, Jiang X, Gao H, Zheng $X$, Bu W. Full-process radiosensitization based on nanoscale metalorganic frameworks. ACS Nano. 2020;14(3):3032-40. https://doi.org/10. 1021/acsnano.9b07898.

224. Zhang $C$, Yan L, Wang X, Dong $X$, Zhou R, Gu Z, Zhao Y.Tumor microenvironment-responsive $\mathrm{Cu}_{2}(\mathrm{OH}) \mathrm{PO}_{4}$ nanocrystals for selective and controllable radiosentization via the $\mathrm{X}$-ray-triggered fenton-like reaction. Nano Lett. 2019;19(3):1749-57. https://doi.org/10.1021/acs. nanolett.8b04763.

225. Yu L, Hu P, Chen Y. Gas-generating nanoplatforms: Material chemistry, multifunctionality, and gas therapy. Adv Mater. 2018;30(49):1801964. https://doi.org/10.1002/adma.201801964.

226. Yang Z, Luo Y, Hu Y, Liang K, He G, Chen Q, Wang Q, Chen H. Photothermo-promoted nanocatalysis combined with $\mathrm{H}_{2} \mathrm{~S}$-mediated respiration inhibition for efficient cancer therapy. Adv Funct Mater. 2021;31(8):2007991. https://doi.org/10.1002/adfm.202007991.

227. Xie C, Cen D, Ren Z, Wang Y, Wu Y, Li X, Han G, Cai X. FeS@BSA nanoclusters to enable $\mathrm{H}_{2} \mathrm{~S}$-amplified ros-based therapy with MRI guidance. Adv Sci. 2020;7(7):1903512. https://doi.org/10.1002/advs.201903512.

228. Ma Z, Liu S, Ke Y, Wang H, Chen R, Xiang Z, Xie Z, Shi Q, Yin J. Biomimetic nano-nos mediated local no release for inhibiting cancer-associated platelet activation and disrupting tumor vascular barriers. Biomaterials. 2020;255: 120141. https://doi.org/10.1016/j.biomaterials.2020.120141.

229. Hu Y, Lv T, Ma Y, Xu J, Zhang Y, Hou Y, Huang Z, Ding Y. Nanoscale coordination polymers for synergistic no and chemodynamic therapy of liver cancer. Nano Lett. 2019;19(4):2731-8. https://doi.org/10.1021/acs. nanolett.9b01093.

230. Wang X-S, Zeng J-Y, Li M-J, Li Q-R, Gao F, Zhang X-Z. Highly stable iron carbonyl complex delivery nanosystem for improving cancer therapy. ACS Nano. 2020;14(8):9848-60. https://doi.org/10.1021/acsnano.0c025 16.

231. Liu S, Wang L, Lin M, Wang D, Song Z, Li S, Ge R, Zhang X, Liu Y, Li Z, Sun $\mathrm{H}$, Yang B, Zhang H. Cu(II)-doped polydopamine-coated gold nanorods for tumor theranostics. ACS Appl Mater Interfaces. 2017;9(51):44293306. https://doi.org/10.1021/acsami.7b13643.

232. An L, Cao M, Zhang X, Lin J, Tian Q, Yang S. Ph and glutathione synergistically triggered release and self-assembly of Au nanospheres for tumor theranostics. ACS Appl Mater Interfaces. 2020;12(7):8050-61. https:// doi.org/10.1021/acsami.0c00302.

233. Fang W, Zhu W, Chen H, Zhang H, Hong S, Wei W, Zhao T. MRI enhancement and tumor targeted drug delivery using $\mathrm{Zn}^{2+}$-doped $\mathrm{Fe}_{3} \mathrm{O}_{4}$ core/mesoporous silica shell nanocomposites. ACS Appl Bio Mater. 2020;3(3):1690-7. https://doi.org/10.1021/acsabm.9b01244.

234. Zhao Y, Ye F, Brismar TB, Li X, He R, Heuchel R, El-Sayed R, Feliu N, Zheng W, Oerther S, Dutta J, Parak WJ, Muhammed M, Hassan M. Multimodal imaging of pancreatic ductal adenocarcinoma using multifunctional nanoparticles as contrast agents. ACS Appl Mater Interfaces. 2020;12(48):53665-81. https://doi.org/10.1021/acsami.0c15430.

235. Suárez-García S, Arias-Ramos N, Frias C, Candiota AP, Arús C, Lorenzo J, Ruiz-Molina D, Novio F. Dual T1/T2 nanoscale coordination polymers as 
novel contrast agents for MRI: A preclinical study for brain tumor. ACS Appl Mater Interfaces. 2018;10(45):38819-32. https://doi.org/10.1021/ acsami.8b15594.

236. Dong L, Zhang P, Lei P, Song S, Xu X, Du K, Feng J, Zhang H. Pegylated $\mathrm{GdF}_{3}$ : Fe nanoparticles as multimodal $\mathrm{T} 1 / \mathrm{T} 2$-weighted mri and $\mathrm{X}$-ray $\mathrm{CT}$ imaging contrast agents. ACS Appl Mater Interfaces. 2017;9(24):2042634. https://doi.org/10.1021/acsami.7b04438.

237. Chen J, Wang X, Zhang Y, Zhang S, Liu H, Zhang J, Feng H, Li B, Wu X, Gao $Y$, Yang B. A redox-triggered $C$-centered free radicals nanogenerator for self-enhanced magnetic resonance imaging and chemodynamic therapy. Biomaterials. 2021;266:120457. https://doi.org/10.1016/j.bioma terials.2020.120457.

238. Tang Z, Zhang H, Liu Y, Ni D, Zhang H, Zhang J, Yao Z, He M, Shi J, Bu W. Antiferromagnetic pyrite as the tumor microenvironment-mediated nanoplatform for self-enhanced tumor imaging and therapy. Adv Mater. 2017. https://doi.org/10.1002/adma.201701683.

239. Yu J, Zhao F, Gao W, Yang X, Ju Y, Zhao L, Guo W, Xie J, Liang X-J, Tao X, Li J, Ying Y, Li W, Zheng J, Qiao L, Xiong S, Mou X, Che S, Hou Y. Magnetic reactive oxygen species nanoreactor for switchable magnetic resonance imaging guided cancer therapy based on ph-sensitive $\mathrm{Fe}_{5} \mathrm{C}_{2} @$ $\mathrm{Fe}_{3} \mathrm{O}_{4}$ nanoparticles. ACS Nano. 2019;13(9):10002-14. https://doi.org/ 10.1021/acsnano.9b01740.

240. Wang Z, Li Z, Sun Z, Wang S, Ali Z, Zhu S, Liu S, Ren Q, Sheng F, Wang B, Hou Y. Visualization nanozyme based on tumor microenvironment "unlocking" for intensive combination therapy of breast cancer. Sci Adv. 2020;6(48):eabc8733. https://doi.org/10.1126/sciadv.abc8733.

241. Ko J, Bhagwat N, Yee SS, Ortiz N, Sahmoud A, Black T, Aiello NM, McKenzie L, O'Hara M, Redlinger C, Romeo J, Carpenter EL, Stanger BZ, Issadore D. Combining machine learning and nanofluidic technology to diagnose pancreatic cancer using exosomes. ACS Nano. 2017:11(11):11182-93. https://doi.org/10.1021/acsnano.7b05503.

242. Tsvirkun D, Ben-Nun Y, Merquiol E, Zlotver I, Meir K, Weiss-Sadan T, Matok I, Popovtzer R, Blum G. CT imaging of enzymatic activity in cancer using covalent probes reveal a size-dependent pattern. J Am Chem Soc. 2018;140(38):12010-20. https://doi.org/10.1021/jacs.8b05817.

243. Cai P, Su D, Yang W, He Z, Zhang C, Liu H, Liu Z, Zhang X, Gao L, Liu Y, Jiang H, Gao F, Gao X. Inherently PET/CT dual modality imaging lipid nanocapsules for early detection of orthotopic lung tumors. ACS Appl Bio Mater. 2020;3(1):611-21. https://doi.org/10.1021/acsabm.9b00993.

244. Zhang J, Li C, Zhang X, Huo S, Jin S, An F-F, Wang X, Xue X, Okeke Cl, Duan G, Guo F, Zhang X, Hao J, Wang PC, Zhang J, Liang X-J. In vivo tumor-targeted dual-modal fluorescence/CT imaging using a nanoprobe co-loaded with an aggregation-induced emission dye and gold nanoparticles. Biomaterials. 2015;42:103-11. https://doi.org/10.1016/j. biomaterials.2014.11.053.

245. Hang L, Li H, Zhang T, Men D, Zhang C, Gao P, Zhang Q. Au@prussian blue hybrid nanomaterial synergy with a chemotherapeutic drug for tumor diagnosis and chemodynamic therapy. ACS Appl Mater Interfaces. 2019;11(43):39493-502. https://doi.org/10.1021/acsami.9b13470.

246. Feng J, Xu Z, Luo D, Liu X. Multiplexed imaging with coordination nanoparticles for cancer diagnosis and therapy. ACS Appl Bio Mater. 2020;3(1):713-20. https://doi.org/10.1021/acsabm.9b01038.

247. Liu C, Wang D, Zhan Y, Yan L, Lu Q, Chang MYZ, Luo J, Wang L, Du D, Lin Y, Xia J, Wu Y. Switchable photoacoustic imaging of glutathione using $\mathrm{MnO}_{2}$ nanotubes for cancer diagnosis. ACS Appl Mater Interfaces. 2018;10(51):44231-9. https://doi.org/10.1021/acsami.8b14944.

248. Ding H, Cai Y, Gao L, Liang M, Miao B, Wu H, Liu Y, Xie N, Tang A, Fan $\mathrm{K}$, Yan X, Nie G. Exosome-like nanozyme vesicles for $\mathrm{H}_{2} \mathrm{O}_{2}$-responsive catalytic photoacoustic imaging of xenograft nasopharyngeal carcinoma. Nano Lett. 2019;19(1):203-9. https://doi.org/10.1021/acs.nanol ett.8b03709.

249. Liu Y, Zhen W, Wang Y, Liu J, Jin L, Zhang T, Zhang S, Zhao Y, Song S, Li $\mathrm{C}$, Zhu J, Yang $\mathrm{Y}$, Zhang $\mathrm{H}$. One-dimensional $\mathrm{Fe}_{2} \mathrm{P}$ acts as a fenton agent in response to nir ii light and ultrasound for deep tumor synergetic theranostics. Angew Chem Int Ed. 2019;58(8):2407-12. https://doi.org/ 10.1002/anie.201813702.

250. Wang J, Liang D, Jin Q, Feng J, Tang X. Bioorthogonal sers nanotags as a precision theranostic platform for in vivo sers imaging and cancer photothermal therapy. Bioconjug Chem. 2020;31(2):182-93. https://doi. org/10.1021/acs.bioconjchem.0c00022.

251. Dong S, Wang Y, Liu Z, Zhang W, Yi K, Zhang X, Zhang X, Jiang C, Yang $S$, Wang $F$, Xiao $X$. Beehive-inspired macroporous sers probe for cancer detection through capturing and analyzing exosomes in plasma. ACS Appl Mater Interfaces. 2020;12(4):5136-46. https://doi.org/10.1021/ acsami.9b21333.

252. Cui K, Fan C, Chen G, Qiu Y, Li M, Lin M, Wan J-B, Cai C, Xiao Z. Paraaminothiophenol radical reaction-functionalized gold nanoprobe for one-to-all detection of five reactive oxygen species in vivo. Anal Chem. 2018;90(20):12137-44. https://doi.org/10.1021/acs.analchem.8b03116.

253. Burinaru TA, Avram M, Avram A, Mărculescu C, Tîncu B, Tucureanu V, Matei A, Militaru M. Detection of circulating tumor cells using microfluidics. ACS Comb Sci. 2018;20(3):107-26. https://doi.org/10.1021/acsco mbsci.7b00146.

254. Jian X, Xu J, Yang L, Zhao C, Xu J, Gao Z, Song Y-Y. Intracellular metalorganic frameworks: Integrating an all-in-one semiconductor electrode chip for therapy, capture, and quantification of circulating tumor cells. Anal Chem. 2020;92(19):13319-26. https://doi.org/10.1021/acs.analc hem.0c02618

255. Cai W, Fan G, Zhou H, Chen L, Ge J, Huang B, Zhou D, Zeng J, Miao Q, Hu C. Self-assembled hybrid nanocomposites for multimodal imagingguided photothermal therapy of lymph node metastasis. ACS Appl Mater Interfaces. 2020;12(44):49407-15. https://doi.org/10.1021/acsami. 0c14576.

256. Feng L, Gai S, He F, Yang P, Zhao Y. Multifunctional bismuth ferrite nanocatalysts with optical and magnetic functions for ultrasound-enhanced tumor theranostics. ACS Nano. 2020;14(6):7245-58. https://doi.org/10. 1021/acsnano.0c02458.

257. Zhao K, Sun J, Wang F, Song A, Liu K, Zhang H. Lanthanide-based photothermal materials: fabrication and biomedical applications. ACS Appl Bio Mater. 2020:3(7):3975-86. https://doi.org/10.1021/acsabm.0c00618.

258. Xu J, Shi R, Chen G, Dong S, Yang P, Zhang Z, Niu N, Gai S, He F, Fu Y, Lin J. All-in-one theranostic nanomedicine with ultrabright second nearinfrared emission for tumor-modulated bioimaging and chemodynamic/photodynamic therapy. ACS Nano. 2020;14(8):9613-25. https:// doi.org/10.1021/acsnano.0c00082.

259. Qi C, He J, Fu L-H, He T, Blum NT, Yao X, Lin J, Huang P. Tumor-specific activatable nanocarriers with gas-generation and signal amplification capabilities for tumor theranostics. ACS Nano. 2020;15(1):1627-39. https://doi.org/10.1021/acsnano.0c09223.

\section{Publisher's Note}

Springer Nature remains neutral with regard to jurisdictional claims in published maps and institutional affiliations. 